\title{
EPR Spectroscopy as a Tool in Homogeneous Catalysis Research
}

\author{
Monalisa Goswami $^{1,2} \cdot$ Andrei Chirila $^{2}$ Christophe Rebreyend ${ }^{1,2}$. \\ Bas de Bruin ${ }^{1,2}$
}

Published online: 4 August 2015

(C) The Author(s) 2015. This article is published with open access at Springerlink.com

\begin{abstract}
In the context of homogeneous catalysis, openshell systems are often quite challenging to characterize. Nuclear magnetic resonance (NMR) spectroscopy is the most frequently applied tool to characterize organometallic compounds, but NMR spectra are usually broad, difficult to interpret and often futile for the study of paramagnetic compounds. As such, electron paramagnetic resonance (EPR) has proven itself as a useful spectroscopic technique to characterize paramagnetic complexes and reactive intermediates. EPR spectroscopy is a particularly useful tool to investigate their electronic structures, which is fundamental to understand their reactivity. This paper describes some selected examples of studies where EPR spectroscopy has been useful for the characterization of open-shell organometallic complexes. The paper concentrates in particular on systems where EPR spectroscopy has proven useful to understand catalytic reaction mechanisms involving paramagnetic organometallic catalysts. The expediency of EPR spectroscopy in the study of organometallic chemistry and homogenous catalysis is contextualized in the introductory Sect. 1. Section 2 of the review focusses on examples of $\mathrm{C}-\mathrm{C}$ and $\mathrm{C}-\mathrm{N}$ bond formation reactions, with an emphasis on catalytic reactions
\end{abstract}

Bas de Bruin

B.deBruin@uva.nl

1 Department of Homogeneous Catalysis, Van 't Hoff Institute for Molecular Sciences, Faculty of Science, Universiteit Van Amsterdam, Postbus 94720, 1090 GS Amsterdam, The Netherlands

2 Homogeneous, Supramolecular and Bio-Inspired Catalysis Group, Van 't Hoff Institute for Molecular Sciences (HIMS), University of Amsterdam (UvA), Science Park 904, 1098 XH Amsterdam, The Netherlands where ligand/substrate non-innocence plays an important role. Both carbon and nitrogen centered radicals have been shown to play an important role in these reactions. A few selected examples of catalytic alcohol oxidation proceeding via related $\mathrm{N}$-centered ligand radicals are included in this section as well. Section 3 covers examples of the use of EPR spectroscopy to study important commercial ethylene oligomerization and polymerization processes. In Sect. 4 the use of EPR spectroscopy to understand the mechanisms of Atom Transfer Radical Polymerization is discussed. While this review focusses predominantly on the application of EPR spectroscopy in mechanistic studies of $\mathrm{C}-\mathrm{C}$ and $\mathrm{C}-\mathrm{N}$ bond formation reactions mediated by organometallic catalysts, a few selected examples describing the application of EPR spectroscopy in other catalytic reactions such as water splitting, photo-catalysis, photo-redox-catalysis and related reactions in which metal initiated (free) radical formation plays a role are included as well. EPR spectroscopic investigation in this area of research are dominated by EPR spectroscopic studies in isotropic solution, including spin trapping experiments. These reactions are highlighted in Sect. 5. EPR spectroscopic studies have proven useful to discern the correct oxidation states of the active catalysts and also to determine the effective concentrations of the active species. EPR is definitely a spectroscopic technique that is indispensable in understanding the reactivity of paramagnetic complexes and in conjunction with other advanced techniques such as X-ray absorption spectroscopy and pulsed laser polymerization it will continue to be a very practical tool.

Keywords EPR spectroscopy - Homogeneous catalysis · Metallo-radicals · Ligand-radicals · Substrate-radicals · Redox noninnocent 


\section{Introduction}

Organometallic chemistry and associated catalytic reactions have long been dominated by the study of diamagnetic complexes, using NMR as the main characterization technique. The field of open-shell organometallic chemistry is much less charted, but has received increasing attention over the past few years. Catalysis plays a crucial role in modern chemistry, and with the current trend to move away from expensive and toxic noble metals to more abundant and less toxic first-row transition metals, the study of open-shell (radical-type, paramagnetic) reactivity will likely become increasingly important. However, detailed mechanistic studies have traditionally focused on diamagnetic complexes, mainly because techniques such as NMR have conveniently facilitated identification of intermediates. Hence, the use of techniques to characterize the relevant paramagnetic complexes and intermediates, such as EPR spectroscopy, is expected to further grow over the next coming years. Paramagnetic complexes involved in homogeneous catalysis have received far less attention compared to diamagnetic complexes from the scientific community until 2000, particularly in the field of organometallic catalysis. However, over the past 15 years the organometallic community has witnessed a growing interest in open-shell reactivity in catalysis. This motivated several scientist to study organometallic reaction mechanism with techniques such as EPR and XAS spectroscopy, which are still rather unconventional tools in homogeneous catalysis research. In transition metal coordination chemistry EPR spectroscopy has been applied already for many years to identify paramagnetic metal complexes (metal-centered radicals) and to monitor their reactivity [1], which often involves the reduction or oxidation of the metal [2]. In organometallic chemistry and catalysis EPR spectroscopy has received far less attention, but also in this area of chemistry EPR spectroscopy is of course a highly practical technique to characterize the paramagnetic complexes and catalytic intermediates. Hence, with this review we hope to show that the technique is much more useful than currently appreciated in the organometallic chemistry community.

Over the past few years it has become clear that ligands bound to transition metals are not nearly always 'innocent', and many examples have been reported in which intramolecular electron transfer occurs from the metal to the ligand/substrate or vice versa. This influences the reactivity of the complex involved, in particular in the field of openshell organometallic chemistry. Most typically the reactivity of a metal complex is determined by its frontier orbitals, which largely determine its chemical properties. Hence, orbitals containing the unpaired electrons often determine the reactivity of a transition metal complex. In many cases the sites which bear the largest spin densities are also the most reactive ones. A word of warning is in place here, as for some hydrogen atom transfer reactions it has been shown that the site bearing most spin density is not always the most reactive [3, 4], especially if the unpaired electron is delocalized or easily moves and if steric factors are at play. Yet, it remains relevant to look at spin density distributions as one of the factors that can predict the (radical-type) reactivity of a paramagnetic complex, in particular for (ligand/substratebased) radical-radical coupling reactions. However, determining the exact location of an unpaired electron is not a trivial task, and often involves advanced computational and spectroscopic techniques. As such, EPR spectroscopy is a helpful spectroscopic tool to unravel spin density distributions and thus to characterize the singly occupied molecular orbitals (SOMOs) of paramagnetic compounds. This, in turn, helps to understand the (catalytic) reactivity of openshell organometallic compounds.

In particular for $S=1 / 2$ systems, containing only one unpaired electron, EPR spectra can be highly diagnostic to determine the spin density distribution in a complex. The g-tensor components of metal centered radicals often deviate significantly from the free electron value $g_{e}=2.0023$, while ligand radical complexes most frequently have a much smaller g-anisotropy. This is a result of spin-orbit coupling (SOC) being a relativistic effect, resulting in much larger SOC constants of (transition) metal atoms compared to the lighter atoms of a ligand. In practice, this means that for complexes with $g$ values below 1.95 or above 2.10 , the unpaired electron can be usually assigned as 'metal-centered', while for complexes with g values in between the aforementioned values the radical can often be attributed as 'ligand-centered'. Additionally, slower electron-spin relaxation often makes it possible to detect ligand-centered radicals at ambient temperatures in isotropic solution, which is convenient to extract isotropic g-values and (super)hyperfine interactions (HFIs). It should be mentioned at this point that even though the g-tensor is a useful guideline, a definite assignment of a complex being a 'metal-centered or ligandcentered radical' should never be made on the basis of g-tensor alone, as there is a sound theoretical basis for many exceptions. Hence, supporting DFT calculations are usually required to make any such assignments with confidence. Examples where the g-tensor can be misleading are some ligand-radical complexes of heavy transition metals such as iridium, for which SOC constants are large. In such cases even a small spin density at the metal can cause a substantial g-anisotropy, thus underlining the importance of combining EPR spectroscopy with DFT property calculations to determine spin density distributions $[5,6]$.

Electron-spin relaxation processes are generally much faster for metal-centered radicals, often causing severe line 
broadening and weak signals at ambient temperatures in isotropic solution. Hence, they are most conveniently detected at low temperatures $(<80 \mathrm{~K}$; either in the solid state or in a glass of a frozen solution), producing anisotropic g-tensors and HFI-tensors. These can be highly informative to characterize the electronic structure of such metal-centered radicals $[7,8]$. In most cases, conventional X-band EPR spectroscopy (microwave frequencies $\sim 9 \mathrm{GHz}$ ) in the continuous wave (CW) mode is enough to make useful assignments of $\mathrm{S}=1 / 2$ systems. Occasionally Q-band EPR spectroscopy (microwave frequencies $\sim 34 \mathrm{GHz}$ ) is needed to resolve g-anisotropy. For high spin transition metal complexes and other (odd-electron) complexes bearing more than one unpaired electron, the situation is different, and (large) zero field splitting parameters usually makes it rather difficult to correlate the measured g-tensors to the location of the unpaired electrons. High frequency (HF) EPR spectroscopy is often beneficial to record and interpret the spectra $[9,10]$, but it remains in general difficult to correlate the (apparent) g-tensors of $\mathrm{S}=\mathrm{n} / 2$ systems to the spin density distribution over the metal and the ligands. For oddelectron $S>1 / 2$ systems, the g-tensor components do however provide useful information about the spin states and zero-field splitting parameters. For integer spin systems ( $\mathrm{S}=1, \mathrm{~S}=2$, etc.) the situation is usually troublesome. With few exceptions these are usually EPR silent or the (forbidden) signals are multi-interpretable.

Apart from the g-tensors, additional information about the electronic structure of a complex can be obtained by looking at the HFIs of the unpaired electron with nuclear spins in the EPR spectra. These are directly correlated with the spin density at the respective atoms. Sometimes pulse-techniques such as electron nuclear double resonance (ENDOR), hyperfine sublevel correlation (HYSCORE) and electron spin echo envelope modulation (ESEEM) are needed to unveil HFIs hidden in broad signals. Inter-spin distances can be measured using double electron-electron resonance (DEER) and pulsed electron-electron double resonance (PELDOR) [11]. While such advanced hyperfine methodologies are useful and have been successfully applied in organometallic chemistry, they are more commonly encountered in the study of biological systems [12,13], with some notable examples including [Ni,Fe]hydrogenase [14], ribonucleotide reductase [15], the catalytic molybdenum-iron cofactor of the nitrogenase [16], and electron transfer processes occurring in green leaves of plants during photosynthesis [17]. For most metallo-enzymes, g-tensor and HFI information is (partially) lost due to g-strain and A-strain caused by a distribution of geometries with similar spectral features that overlap, leading to additional signal broadening. This amplifies the necessity of advance pulse-techniques compared to many organometallic complexes measured in frozen solution. For odd-electron systems with more than one unpaired electron, the HFIs are more generally unresolved. Hence advanced pulse techniques often becomes essential to obtain HFI information, also for organometallic complexes without g- or A-strain. An overview of advantages and limitations of the abovementioned techniques is listed in Table 1 .

Table 1 An overview of the advantages and disadvantages of several EPR spectroscopic tools

\begin{tabular}{lll}
\hline Technique & Advantage & Limitations \\
\hline X-band CW & $\begin{array}{c}\text { EPR tubes and sample sizes are larger, which can be convenient } \\
\text { to prepare samples under anaerobic conditions (Schlenk, } \\
\text { glovebox) }\end{array}$ & $\begin{array}{l}\text { g Values unresolved if they differ only slightly } \\
\text { Significant amount of sample needed } \\
\text { Similar sample sizes as for NMR, easier filling of the tubes }\end{array}$ \\
$\begin{array}{c}\text { 'Unresolved' HFIs common } \\
\text { In high spin complexes, the X-band microwave frequency } \\
\text { might be enough to induce } \Delta \mathrm{m}_{\mathrm{S}}=1 \text { transitions }\end{array}$
\end{tabular}

Q-Band/W-

Band and

higher $\mathrm{CW}$

Higher resolution of $\mathrm{g}$ values compared to X-band

Sample size can be much smaller, which can be advantageous if only a small total amount of sample is available or if low concentrations of intermediates are formed

ESEEM

Detection of 'unresolved' HFIs

Excellent for detection of small nuclear frequencies $(<20 \mathrm{MHz})$

ENDOR Detection of 'unresolved' HFIs

Excellent for detecting different hyperfine couplings

ELDOR Detection of 'unresolved' HFIs

Better detection at higher microwave frequencies for strongly coupled high-spin nuclei
Ligand hyperfine interaction often cannot be well-resolved due to fast line broadening $b$ interaction with a multitude of nuclear spins

Anaerobic handling of samples less convenient

'Unresolved' HFIs quite common

Strong anisotropic hyperfine couplings with large HFI constants can be difficult to detect for $\mathrm{N}$ and some metals

The detection of nuclear frequencies $<5 \mathrm{MHz}$ is difficult

Strong anisotropic hyperfine couplings with large HFI constants can be difficult to detect for $\mathrm{N}$ and some metals

Strong anisotropic hyperfine couplings with large HFI constants can be difficult to detect for $\mathrm{N}$ and some metals 
Hence, EPR spectroscopy is a broad term covering several techniques to characterize open-shell organometallic compounds and catalytic intermediates, and several useful diagnostic features can be used to distinguish metal- from ligand/substrate-centered radicals. Combined, this offers valuable mechanistic information. In this paper we give an overview of the use of EPR spectroscopy to study homogeneous catalytic processes, in particular for the identification of intermediates and to understand the electronic structure of key-intermediates in a catalytic cycle. The paper is not meant as a full critical review covering all literature examples, but rather as a tutorial overview showcasing the usefulness of EPR spectroscopy in homogeneous catalysis research involving organometallic complexes. The expediency of EPR spectroscopy in the study of organometallic chemistry and homogenous catalysis is contextualized in the introductory Sect. 1. Section 2 of the review focusses on examples of $\mathrm{C}-\mathrm{C}$ and $\mathrm{C}-\mathrm{N}$ bond formation reactions, with an emphasis on catalytic reactions where ligand/substrate noninnocence plays an important role in unique reaction pathways of catalysts operating via mechanisms involving substrate-radical intermediates. This includes the study of spin density distributions and discrimination of metal and ligand centered radicals. Both carbon and nitrogen centered radicals have been shown to play an important role in these reactions. A few selected examples of catalytic alcohol oxidation proceeding via related $\mathrm{N}$-centered ligand radicals are included in this section as well. Sections 3 and 4 demonstrate how EPR spectroscopy can be used to unravel the mechanisms of ethylene oligomerization and atom transfer radical polymerization reactions. These type of reactions are among the largest industrially applied homogeneously catalyzed reactions, and many questions arise regarding the oxidation states of the intermediates. While this review focusses predominantly on the use of EPR spectroscopy in mechanistic studies of $\mathrm{C}-\mathrm{C}$ and $\mathrm{C}-\mathrm{N}$ bond formation reactions mediated by organometallic catalysts, a few selected examples describing the application of EPR spectroscopy in other catalytic reactions are included as well. These examples mainly concern photocatalytic water splitting and a few related reactions in which metal initiated radical formation plays a role. EPR spectroscopic investigation in this area of research are dominated by EPR spectroscopic studies in isotropic solution, including spin trapping experiments. These reactions are highlighted in Sect. 5.

\section{C-C and C-N Bond Forming Reactions; Metal or Ligand Radical Involvement?}

The properties of a metal complex (catalyst) as a whole are determined by the interaction of the metal center with its surrounding ligands. Traditionally, the electronic and steric properties of the ligands influence the performance of the catalyst, in which case the ligands typically remain spectators while the reactivity takes place at the metal center. However, for some odd-electron organometallic complexes, often involving base metals, redox-active ligands can also play a more active role in catalytic cycles [18-20]. These types of ligands are sometimes called "redox noninnocent ligands", because assignment of their oxidation states can be a difficult task [21]. Both the ligand and the metal can be oxidized or reduced, and hence the assignment of formal oxidation states can be misleading. Instead of changes in the $d$-electron count of the metal, oxidation or reduction of the redox active ligand can occur, often leading to formation of ligand centered radicals in the coordination sphere of the metal. These are important to understand the reactivity of open-shell organometallic compounds [22, 23], and offer interesting opportunities to control radical-type reactions. Being able to control radical reactivity is a difficult challenge in synthetic organic and organometallic chemistry, but in the coordination sphere of (transition) metals reactions of radicals become more controlled. This makes it possible to steer radical reactivity in specific directions. Forming ligand/substrate centered radicals and making use of their redox activity helps in that perspective. This concept was initially applied in stoichiometric reactions, but over the past few years this concept slowly transitioned into the area of homogeneous catalysis to enhance the reactivity and steer the selectivity of various catalysts [7, 24, 25]. Active participation of a redox active ligand during a catalytic cycle following an open-shell radical-type pathway is represented schematically in Scheme 1. Roughly two different concepts have been explored in this field. In the first concept electrontransfer between the metal and a substrate-based ligand leads to formation of substrate-centered radicals which directly participate in radical coupling reactions. In the second concept spectator redox-active ligands are used as electron reservoirs, facilitating different oxidation state changes than normally expected (e.g. two-electron oxidative addition/reductive elimination steps for first-row transition metals or radical-type one-electron processes for diamagnetic complexes).

\subsection{Carbon-Centered Radicals in Catalysis}

EPR spectroscopy is an important tool in analyzing openshell complexes, and is even more valuable for detecting carbon-centered redox non-innocent ligands which are generally transient. In recent years, 'carbene radicals' have emerged as particularly interesting examples of substratebased ligand radicals that participate directly in catalytic reactions. These ligands can be regarded as one-electron reduced analogs of (Fischer-type) carbenes. Normally, 

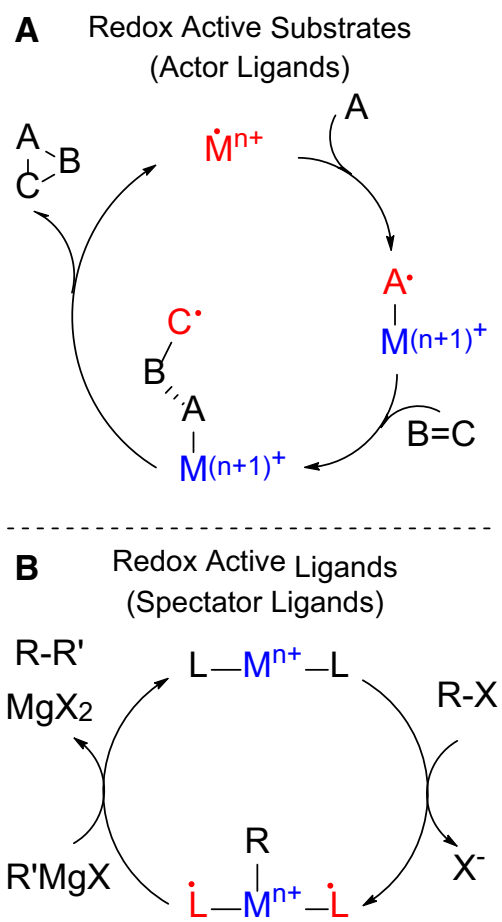

Scheme 1 Schematic representation of two main concepts explored in the use of redox active ligands in catalysis research

carbene radicals cannot be isolated, thus making many spectroscopic techniques such as X-ray diffraction impractical. Detection and characterization of these species with EPR therefore provided important information. In these studies, carbene radicals revealed a small $g$-anisotropy, with $g$-values close to that of the free electron $\left(g_{e}=2.0023\right)$ and clear hyperfine couplings with the metal to which they bind. These are diagnostic features of carbon-centered radicals, and indeed confirm the redox active nature of carbene ligands. Combining EPR measurements with in situ IR spectroscopy has provided important details about the nature of such intermediates formed during a catalytic cycle, showing the intermediacy of radical carbenes as active species in several catalytic reactions. Quantum mechanical computations, mainly using DFT methods [26], often support the EPR spectra and help understanding the spectral properties and spin density distributions of these open-shell complexes.

The oldest examples of redox active carbene ligands, experimentally detected with EPR spectroscopy, were reported in the 1970s by the group of Casey and coworkers, which were generated by one-electron reduction of Fischer-type carbenes of Group 6 transition metals using an external reducing agent [27, 28]. Complexes of Fischertype carbenes are known to be electrophilic, thus having their LUMO centered on the carbene carbon atom. Hence, reduction of the ligand instead of the metal can be expected
[29]. Reacting pentacarbonyl(alkoxyaryl)carbene complexes of group 6 transition metals $(\mathrm{Cr}, \mathrm{Mo}, \mathrm{W})$ with sodium/potassium alloy leads to persistent carbon-centered radical anions at $-50{ }^{\circ} \mathrm{C}$ as shown by EPR spectroscopic measurements (Fig. 1) [27]. After simulation of the spectrum, five distinct doublets corresponding to the phenyl protons and a quartet due to the methyl protons could be assigned. With a g value of 2.0032 , small ${ }^{53} \mathrm{Cr}$ splitting, and narrow line widths of $75 \mathrm{mG}$, the authors concluded that the radical is mainly located at the carbon atom. While interesting, in the 1970s these species were considered to be merely chemical curiosities rather than important intermediates in catalysis. More recently, the controlled radical-type reactivity of carbene radicals has been explored in catalytic reactions, using different metals than chromium. Yet, these group 6 transition metal complexes stand out as the first, classical examples of carbene-radical complexes. $\mathrm{C}-\mathrm{C}$ bonds could be formed in stoichiometric reactions by dimerization of tungsten aryl- or silyl-carbene complexes or react with electron-poor olefins such as ethyl acrylate, as shown by Fuchibe and Iwasawa [30].

The formation and reactivity of carbene radicals has been further explored and it was found that if carbenoids are formed at Group 9 transition metals in the oxidation state $+\mathrm{II}\left[\mathrm{Co}^{\mathrm{II}}, \mathrm{Rh}^{\mathrm{II}}, \mathrm{Ir}^{\mathrm{II}}\right]$, the metal effectively reduces the carbene by one electron, thus forming a carbene radical in an intramolecular redox process without the need of an external reducing agent [31]. As a result several examples of reactions in which $\mathrm{C}-\mathrm{C}$ and $\mathrm{C}-\mathrm{H}$ bonds are formed have been shown to involve carbene radicals [32-34]. The most representative examples are cyclopropanation reactions mediated by metallo-radical cobalt(II) porphyrin complexes. Experimental evidence for formation of cobalt coordinated carbene radicals in these reactions has been demonstrated by the groups of De Bruin and Zhang by reacting ethyl diazoacetate (EDA) with the cobalt
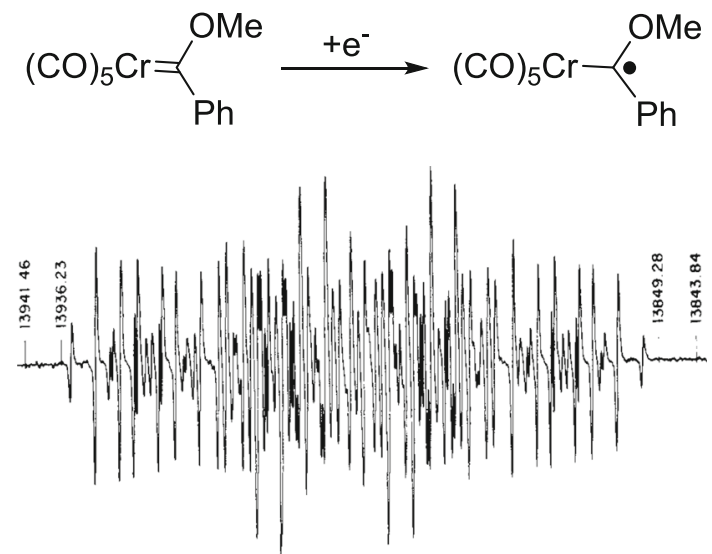

Fig. 1 First example of carbene radical complex reported by Casey et al. and its corresponding EPR spectrum (EPR spectrum reproduced with permission from Ref. [27]) 
porphyrin complexes and monitoring the reaction mixtures with EPR spectroscopy (Fig. 2) [31]. An important consideration is that most cobalt porphyrins rapidly become EPR silent upon reaction with EDA in absence of other reagents (likely due to fast formation of diamagnetic, deactivated cobalt(III)-alkyl species), but for the bulky Co(3,5-DitBu-ChenPhyrin) (Fig. 3) the EPR signals obtained when adding EDA are more persistent and reveal clear changes compared to the starting complex. Spectral simulation of the reaction mixture revealed the presence of three species, which were assigned to a simple EDA adduct (I), a bridging carbene species (II) and a terminal carbene (III) as shown in Fig. 3. While species I and II are both 'cobalt centered radicals', species III is a carbon centered radical having most of its spin density located at the carbene carbon $\mathrm{p}$-orbital. This readily explains the observed large differences in g- and A-anisotropy between the bridging carbene II and the terminal carbene III (see Table 2).

Further evidence for the formation of cobalt(III)-carbene radicals has been obtained using ethyl-styryldiazoacetate and CoTPP in the absence of an alkene substrate [35]. In this reaction a cobalt(III)-vinylcarbene radical is formed, which subsequently dimerizes to a diamagnetic, dinuclear cobalt(III) porphyrin complex via its $\gamma$-radical allylic resonance form (as evidenced by X-ray structural analysis; see Scheme 2). Furthermore, trapping the $\gamma$-radical allylic resonance form of the cobalt(III)-vinylcarbene radical with TEMPO proved possible, leading to formation of a mononuclear diamagnetic cobalt(III) complex via $\mathrm{C}-\mathrm{O}$ bond formation.

EPR measurements, combined with supporting DFT calculations, in situ IR and other techniques have indeed shown that carbene radicals are detectable species, with the cobalt-porphyrin system allowing control over the
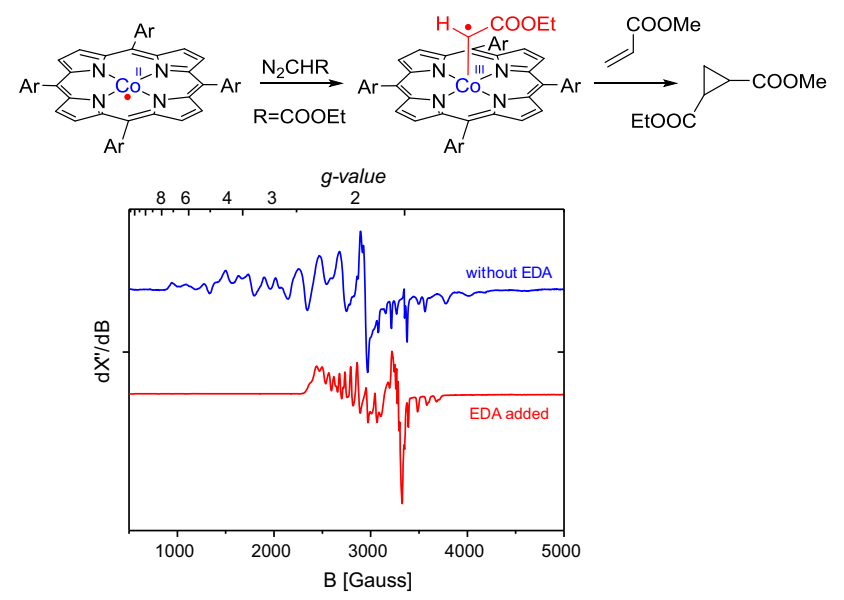

Fig. 2 In situ EPR detection of cobalt-carbene radical complexes, as intermediates in cyclopropanation (EPR spectrum reproduced with permission from Ref. [30])
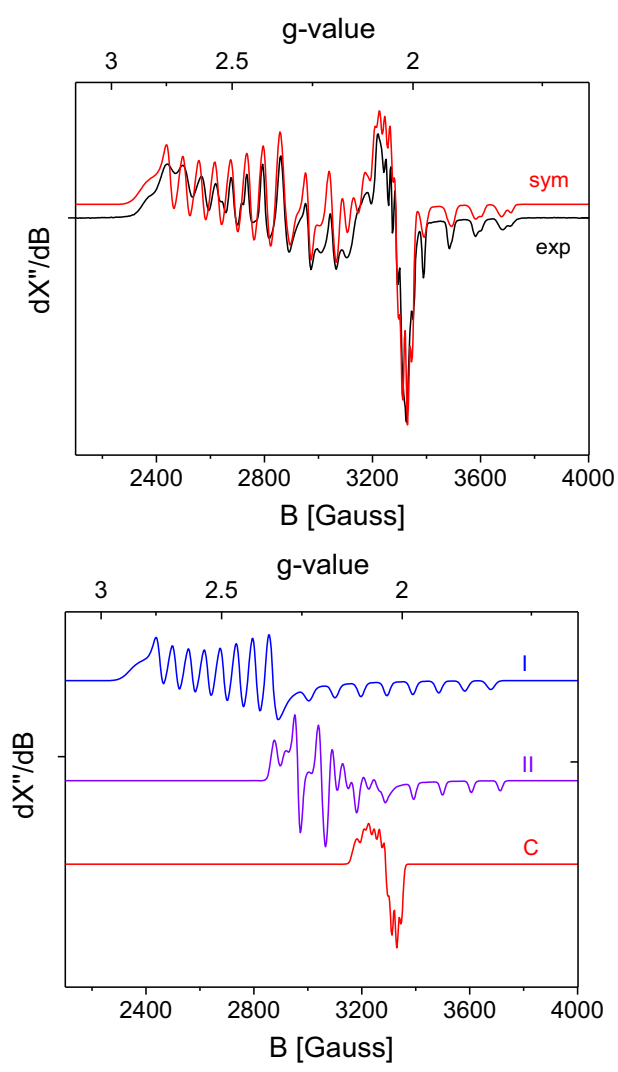

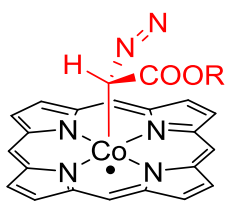

I

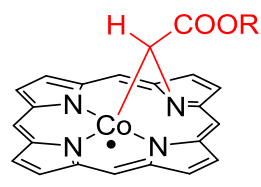

II
III

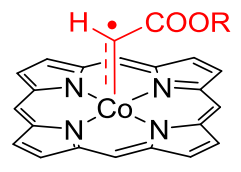

Fig. 3 Top spectral simulations revealing the presence of species I, II and III. Bottom simplified representation of the structure of species I, II and III. (EPR spectra reproduced with permission from Ref. [31])

Table 2 Spin Hamiltonian parameters of species I, II and III used in the spectral simulations of Fig. 3

\begin{tabular}{llllrrllll}
\hline & $\mathrm{g}_{\mathrm{x}}$ & $\mathrm{g}_{\mathrm{y}}$ & $\mathrm{g}_{\mathrm{z}}$ & $\mathrm{A}^{\mathrm{Co}_{\mathrm{x}}}$ & $\mathrm{A}^{\mathrm{Co}_{\mathrm{y}}}$ & $\mathrm{A}^{\mathrm{Co}_{\mathrm{z}}}$ & $\mathrm{A}^{\mathrm{H}_{\mathrm{x}}}$ & $\mathrm{A}^{\mathrm{H}_{\mathrm{y}}}$ & $\mathrm{A}^{\mathrm{H}_{z}}$ \\
\hline I & 2.558 & 2.520 & 2.004 & 255 & 208 & 270 & - & - & - \\
II & 2.228 & 2.120 & 2.005 & 110 & 115 & 300 & - & - & - \\
III & 2.060 & 2.048 & 2.030 & 40 & 56 & $\mathrm{nr}$ & 160 & 40 & $\mathrm{nr}$ \\
\hline
\end{tabular}

$n r$ not resolved

reactivity of these radicals. As such, enantioselective carbene transfer reactions are possible, despite the fact that these reactions proceed via radical-type mechanisms. Hence, substrate redox non-innocence is not just a chemical curiosity, and the cyclopropanation reactions mediated by cobalt porphyrins provided prime examples of catalytic reactions proceeding via carbene radicals behaving as 
Scheme 2 Dimerization of cobalt carbene radical complexes

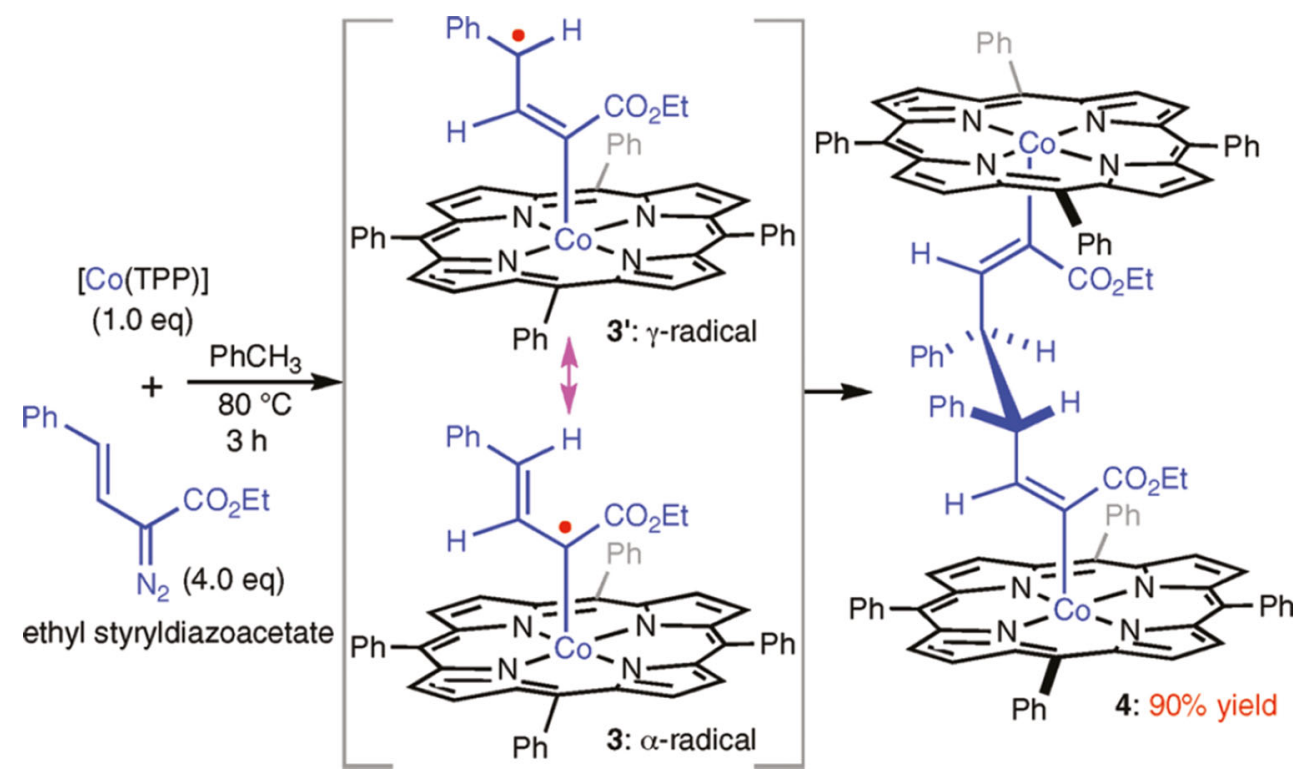

Fig. 4 Chiral $\mathrm{Co}^{\mathrm{II}}$ (porphyrins) used as catalysts

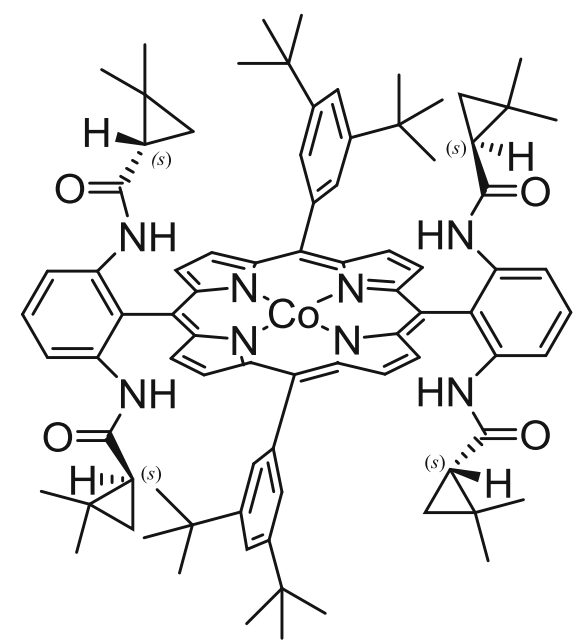

$\left[\mathrm{Co}^{\mathrm{II}}(\mathbf{P 1})\right]$

$\mathbf{P 1}=3,5-\mathrm{Di}{ }^{\dagger} \mathrm{Bu}-$ ChenPhyrin

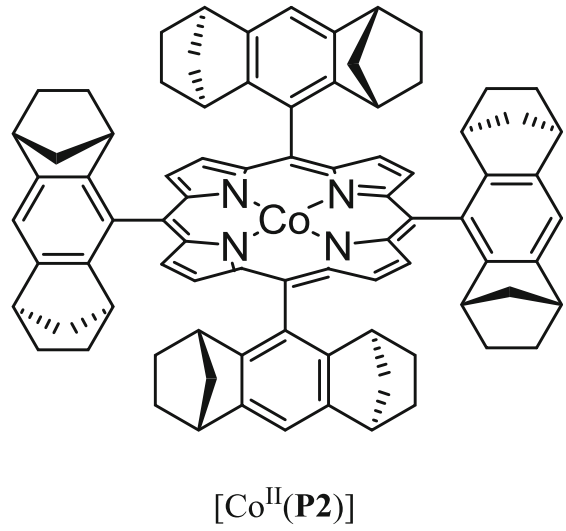

$\mathbf{P 2}=21 \mathrm{H}, 23 \mathrm{H}-$ Porphine, 5, 10,15,20tetrakis[(1R,4S,5S,8R)-

1,2,3,4,5,6,7,8-octahydro- $1,4: 5,8$ dimethanoanthracen-9-yl]- controlled radical species. Development of new chiral cobalt porphyrins (Fig. 4) [36-38] led to unprecedented reactivity and selectivity, which was explained by the increased nucleophilic character of the carbene radical compared to an unreduced Fischer-type carbene, allowing the pursuit of more challenging substrates such as electrondeficient olefins. The cooperation between the carbene radical and the metal is of crucial importance for catalysis and is actually similar to the way metallo-enzymes gain control over radicals in several enzymatic processes. The bulky chiral porphyrins ensure a protective environment for the carbene radicals, similar to the protective nature of the protein of real enzymes and comparable to other approaches in the field of artificial metallo-enzymes [39].

A key aspect in eliminating side reactions and obtaining enantioselectivity is having confined space around the metal. Thus, inspired by the protective nature of the protein surrounding the active sites of metallo-enzymes, De Bruin and coworkers have used artificial cages around the porphyrin in an attempt to better control radical carbenes (Fig. 5) [40, 41]. They described the synthesis and assembly of a new $\mathrm{M}_{8} \mathrm{~L}_{6}$ cage which selectively encapsulates tetra(4-pyridyl)metalloporphyrins ( $\mathrm{M}^{\mathrm{II}}$ (TPyP), $\mathrm{M}=$ $\mathrm{Zn}, \mathrm{Co})$ and its reactivity in radical-type transformations 

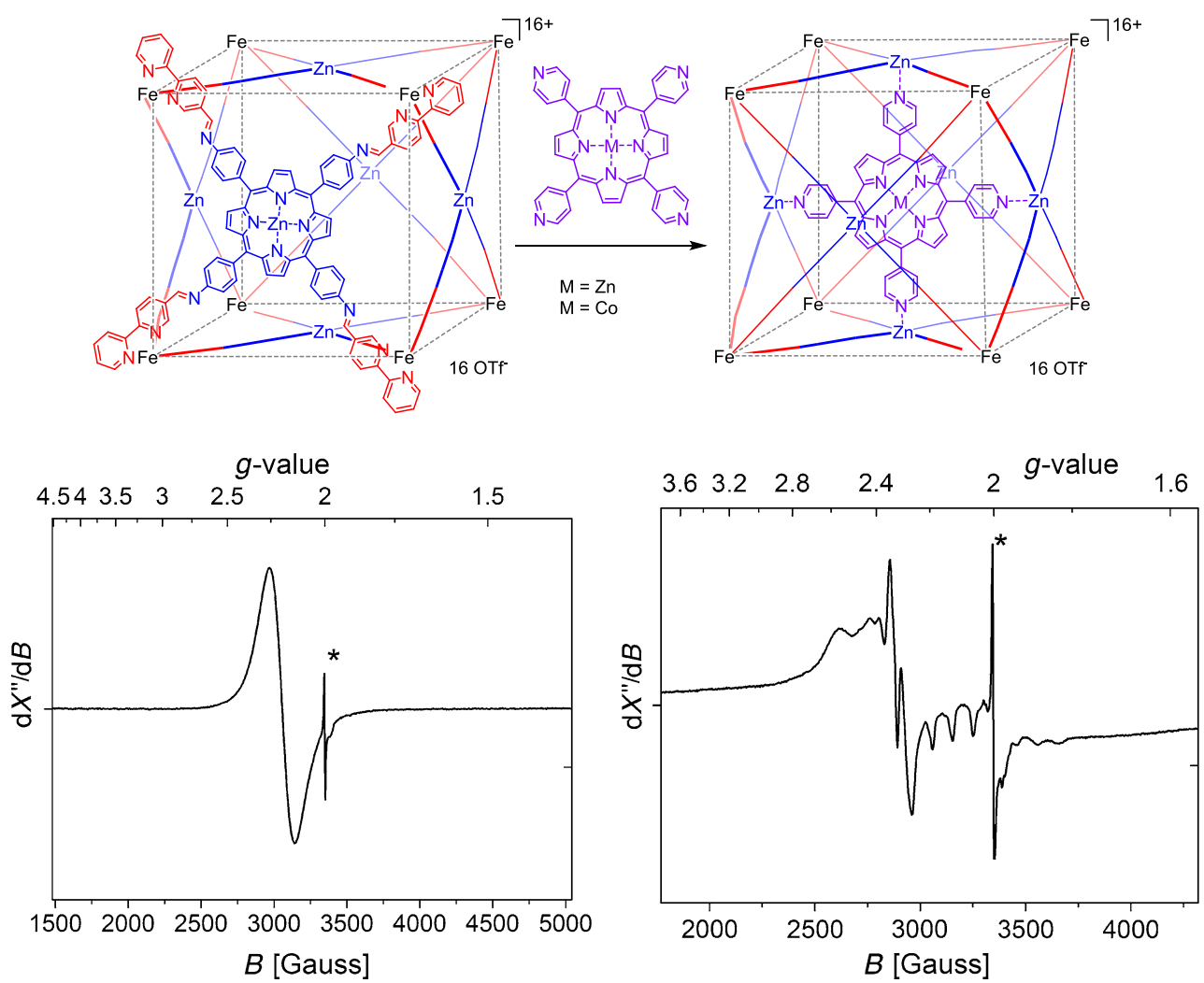

Fig. 5 Metalloporphyrins encapsulated in a cubic $\mathrm{M}_{8} \mathrm{~L}_{6}$ cage and EPR spectra of the corresponding species. (EPR spectra reproduced with permission from Ref. [40])

involving diazo compounds. The encapsulated cobalt porphyrin proved to have a significantly higher activity than the free $\mathrm{Co}^{\mathrm{II}}(\mathrm{TPyP})$ catalyst. EPR spectroscopy proved useful in the characterization of these compounds. The free $\mathrm{Co}^{\mathrm{II}}(\mathrm{TPyP})$ building block gives rise to a very broad, featureless EPR spectrum due to intermolecular aggregation involving pyridine coordination to cobalt(II). The same building block encapsulated in the supramolecular host behaves entirely differently, showing much sharper signals with resolved HFIs with cobalt characteristic of Co(por) species without strong binding axial ligands (Fig. 5).

Besides cyclopropanation, other catalytic reactions involving carbene radicals have also been reported recently $[33,34]$. One of them involves formation of ketene intermediates by carbonylation of metal carbene radicals, followed by trapping of the ketene with nucleophiles such as amines or imines, forming amides and $\beta$-lactams [42]. Cobalt(II) porphyrins act as catalysts in these transformations, by activating diazo compounds and forming metal coordinated carbene radicals. These are nucleophilic enough to react with carbon monoxide to generate ketenes (Scheme 3). In situ IR measurements have shown that the ketenes decoordinate from the catalyst after they are formed, and the subsequent reactions with nucleophiles are not catalyzed. Hence, no enantioselectivity was observed for these reactions. The mechanism has been investigated by DFT, and confirms the experiments in which several chiral cobalt porphyrins (Fig. 4) have no effect regarding the stereochemistry of the reaction. Nonetheless, by having a broad substrate scope, this reaction proved an interesting synthetic alternative to classical methods of ketene (and beta-lactam) formation.

A related example of carbene radical transformations is the cobalt-mediated catalytic one-pot synthesis of $2 \mathrm{H}$ chromenes [43]. This reaction involves activation of salicyl $N$-tosylhydrazones by cobalt(II) porphyrins forming cobalt(III)-carbene radicals that readily undergo radical addition to terminal alkynes such as phenylacetylene to form salicyl-vinyl radical intermediates. The latter ringclose to form the desired $2 \mathrm{H}$-chromenes after an intermediate hydrogen atom transfer step (Scheme 4). EPR measurements together with radical trapping experiments using TEMPO confirmed that the mechanism follows a radical pathway. DFT calculations surprisingly showed that after the hydrogen abstraction step by the vinyl radical, the ortho-quinone-methide intermediate dissociates from the metal and undergoes an endocyclic, sigmatropic ringclosing step. A further interesting feature of this reaction is the fact that exactly the same reaction with copper [44], which does not proceed via carbene radicals, led to the formation of benzofurans instead of $2 \mathrm{H}$-chromenes. 
Scheme 3 [Co ${ }^{\text {II }}($ Por $\left.)\right]$ catalyzed carbene carbonylation forming ketenes as intermediates in producing amides, esters and $\beta$-lactams (figure reproduced with permission from Ref. [42])

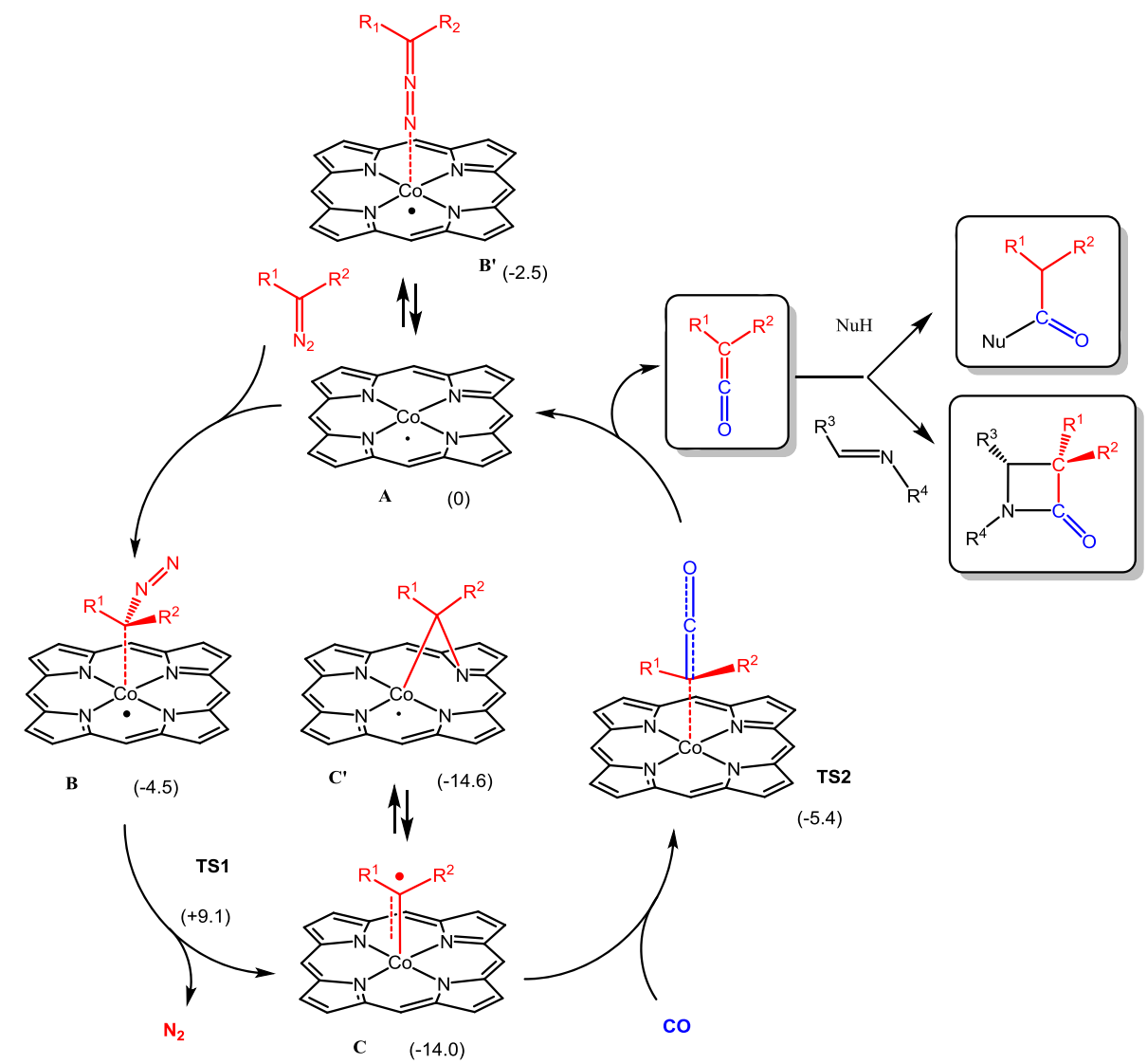

\subsection{Nitrogen-Centered Radicals in Catalysis}

Well-characterized examples of transition metal complexes containing $\mathrm{N}$-centered radicals are rare, and these inherently reactive species are quite challenging to isolate and characterize. However, they are interesting synthetic targets for catalytic applications involving functionalization of hydrocarbons, olefin aziridination, nitrene transfer as well as dinitrogen fixation [45]. Furthermore, their electronic structure is often complex and usually requires a combination of EPR and DFT studies to gain insight information about their spin density distribution.

A variety of different aminyl, imidyl and nitridyl complexes have been reported, many of which were simply proposed as reactive intermediates [46-48]. However, the number of reports of well-characterized $\mathrm{N}$-centered ligand radicals that are actually being employed in catalysis and shown to be reactive intermediates is limited. This section describes the characterization of these catalytic intermediates with EPR spectroscopy, often in conjunction with DFT calculations.

In 2005 the first stable and isolable aminyl radical transition-metal complex was reported by the group of Grütmacher [49]. The initially isolated aminyl-radical complex of rhodium, bearing a $5 H$-dibenzo[a,d]cyclohepten-5-yl (trop) moiety (Fig. 6), gave rise to the development of related examples bound to rhodium and iridium. Most of these complexes are able to abstract hydrogen atoms from a variety of substrates, such as $\mathrm{Bu}_{3} \mathrm{SnH}, \mathrm{PhSH}, \mathrm{PhOH}, \mathrm{Ph}_{3} \mathrm{SiH}$ and $\mathrm{R}_{3} \mathrm{CH}$.

Aminyl radical complexes have been successfully employed in two instances as organometallic models of the enzyme GOase, which convert alcohols to aldehydes or ketones [50]. Tanaka and coworkers reported a proposed aminyl radical complex as an intermediate in the catalytic cycle, but thorough spectroscopic investigations of the intermediate are lacking [51].

Grützmacher's iridium complex $\mathbf{C}$ (Scheme 5) is the second reported example. It is proposed to be a key intermediate in the catalytic oxidation of alcohols to aldehyde, with potassium tert-butoxide as a base [52]. Complex $\mathbf{C}$ can be generated from the corresponding amine by deprotonation with $\mathrm{KOtBu}$ and subsequent oxidation with para-benzoquinone. This complex can now coordinate alcohols, after which the aminyl moiety abstracts a hydrogen atom from the coordinated alcoholate. The complex is subsequently oxidized by semiquinone, after which the aldehyde dissociates and the catalytic cycle is closed (Scheme 5). The catalyst is very active $\left(60,000-150,000 \mathrm{TOF} \mathrm{h}^{-1}\right)$ and works with low catalysts loadings $(0.01 \%)$.

The electronic structure of the aminyl radical complex was examined in situ with pulsed EPR experiments 
Scheme $4 \mathrm{COo}^{\mathrm{II}}$ (Por) $]$

catalyzed metalloradical coupling-cyclization using alkynes and salicyl tosylhydrazones to produce $2 \mathrm{H}$ Chromenes (figure reproduced with permission from Ref. [43])
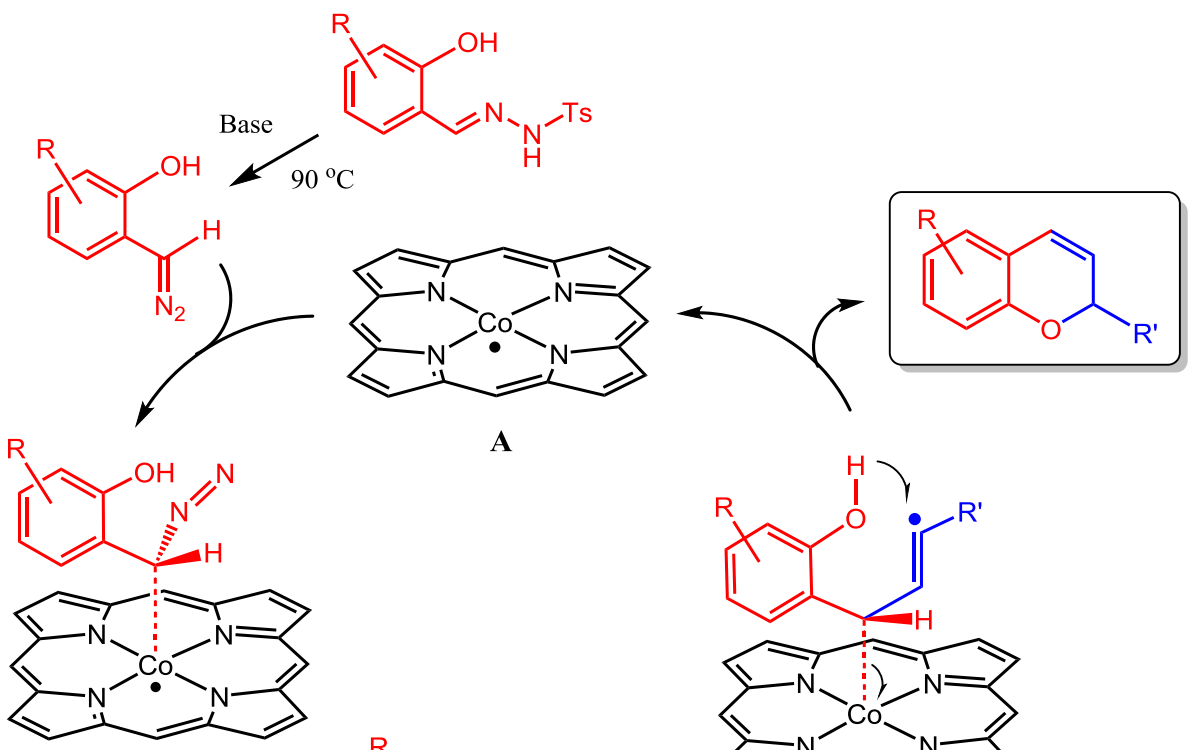

B

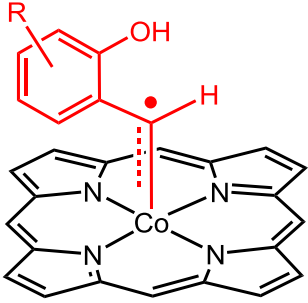

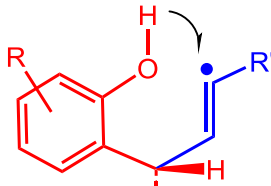

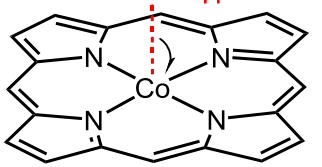

D

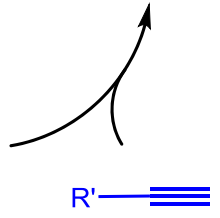

C

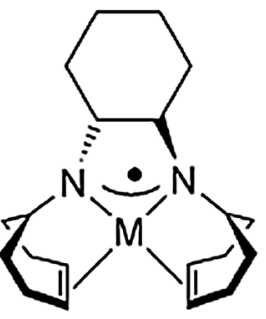

and was estimated to be 0.7 and $27 \%$ in the $2 \mathrm{~s}$ and $2 \mathrm{p}$ orbitals respectively for each nitrogen atom. Further, there is barely any spin density on the metal, in agreement with the g-values being close to $\mathrm{g}_{\mathrm{e}}$.

One example of catalytic functionalization of a $\mathrm{C}-\mathrm{H}$ bond with an aminyl radical complex was reported by Cundari et al. [53]. The aminyl complex is prepared by reaction of a dinuclear copper complex with lithium 1-adamantylamide. The complex is able to abstract hydrogen atoms from ethyl benzene and indane, generating $\mathrm{R}^{\bullet}$ radicals. A second equivalent of the aminyl radical then traps the organic radical, generating an amine that can be readily dissociated from the copper center. Another route to the aminyl radical complex is reaction of a copper tertbutoxide complex with 1-adamantylamine, with tert-butanol as a side product. The tert-butoxide complex can be generated from the benzene-bridged dinuclear copper species with tert-butylperoxide. This reactivity now allows for catalytic $\mathrm{C}-\mathrm{H}$ bond amination, applying tert-butylperoxide as a sacrificial reagent. The catalytic cycle is depicted in Scheme 6.

To gain a better understanding of the hydrogen abstraction properties of the aminyl radical complex, its electron structure was studied by a combination of EPR and DFT computations. X-band EPR spectroscopy 
Scheme 5 Oxidation of alcohols to aldehydes by an iridium aminyl radical complex

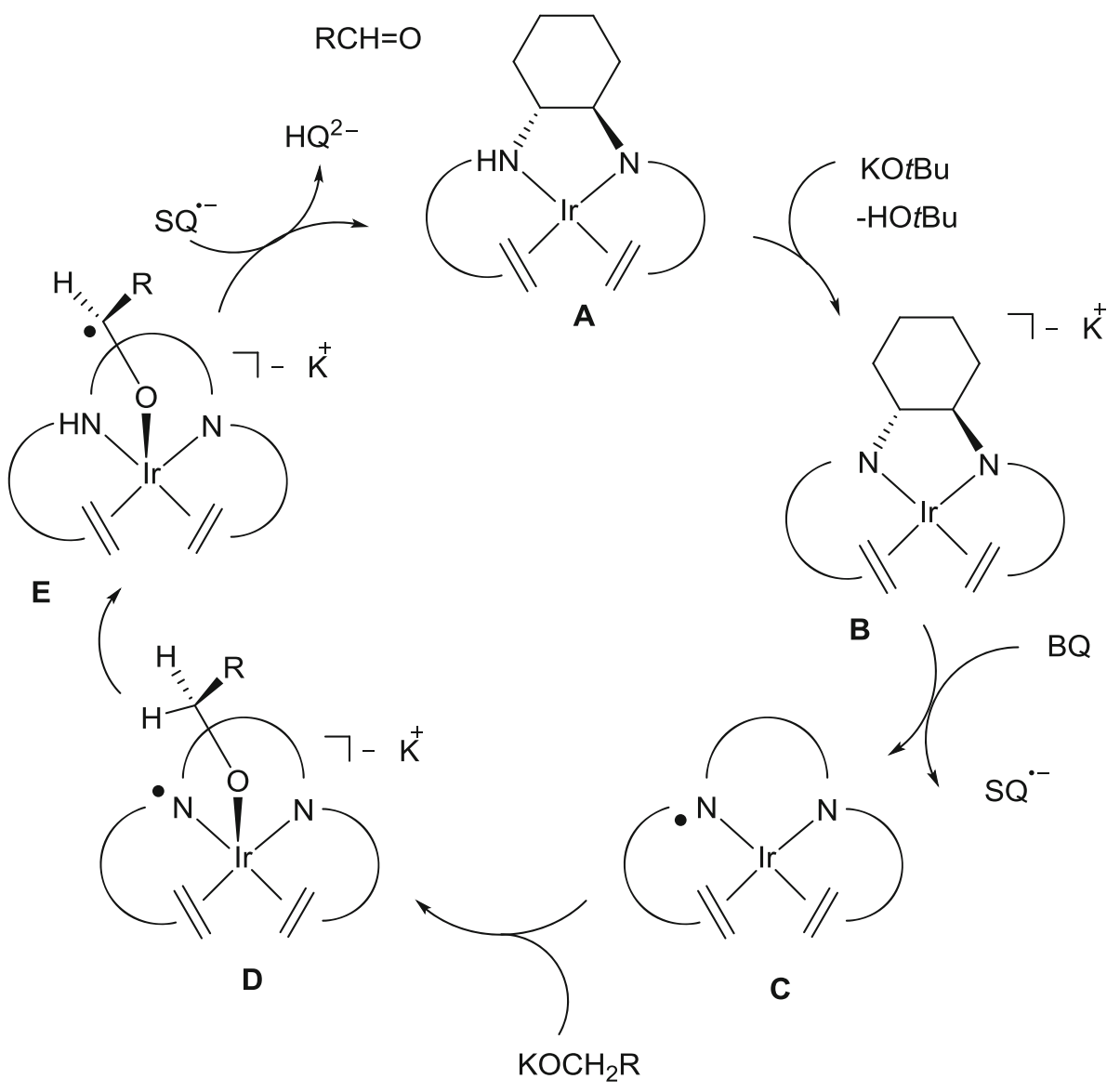

(Fig. 8) disclosed an anisotropic spectrum $\left(\mathrm{g}_{1}=2.133\right.$, $\left.\mathrm{g}_{2}=2.036, \mathrm{~g}_{3}=2.031\right)$. A large anisotropic $\mathrm{Cu}$ hyperfine (365 MHz) and a $\mathrm{N}_{\text {aminyl }}$ hyperfine splitting $(65 \mathrm{MHz})$ are clear. DFT calculations revealed that the unpaired electron resides in a $\pi^{*}-\mathrm{Cu}-\mathrm{N}$ orbital, with $49 \%$ spin density on the $\mathrm{N}$ and $30 \%$ on the copper, confirming the aminyl radical nature of the complex. The spin density in the $\mathrm{Cu}-\mathrm{N}$ orbital most likely explains the facile formation of $\mathrm{N}-\mathrm{H}$ and $\mathrm{N}-\mathrm{C}$ bonds, which is crucial for the catalysis.

Characterized imidyl complexes are even scarcer than their aminyl counterparts, in part due to the lower steric protection. A number of imidyl complexes have been reported [45] and are employed in stoichiometric reactions. However, reports wherein imidyl complexes are unambiguously detected intermediates in catalytic reactions are extremely scarce. The first example of such a detected intermediate was reported by de Bruin in close collaboration with the group of Zhang, featuring the catalytic amination of benzylic $\mathrm{C}-\mathrm{H}$ bonds with organic azides (Scheme 7) [54].

Earlier computational studies revealed that the imido intermediate in this reaction has most of its spin density on the nitrogen atom, and the complex is best described as a nitrene radical complex [55]. The DFT calculations suggested that formation of the nitrene radical complex upon reaction with the organic azide and the cobalt porphyrin is exothermic, which should allow detection of the intermediate in the absence of other substrates. Therefore, $\mathrm{X}$-band EPR studies at room temperature were conducted on cobalt porphyrin catalysts in the presence of an excess of the applied organic azide. Indeed, clear EPR spectra were obtained which are characteristic of nitrene radical complexes (Fig. 9). The EPR parameters are characteristic for a ligand-centered radical. The isotropic g-value and HFI with nitrogen $(6-10 \mathrm{MHz})$ points to an $\mathrm{S}=1 / 2$ system located at the light atoms of an organic (ligand) fragment, while the detected hyperfine couplings with cobalt (25-27 MHz) show that this fragment is bound to the metal. As such, EPR spectroscopy provided unique new insights into the mechanism of catalytic nitrene transfer reactions mediated by cobalt porphyrin complexes.

More thorough spectroscopic investigations were recently reported of these systems, showing among others that the mono-nitrene species I and II are actually 6-coordinate complexes bearing an additional ligand trans to the nitrene moiety. Furthermore, the more powerful nitrene transfer reagent produces bis-nitrene species with an unusual "triple-radical" electronic structure [56]. 

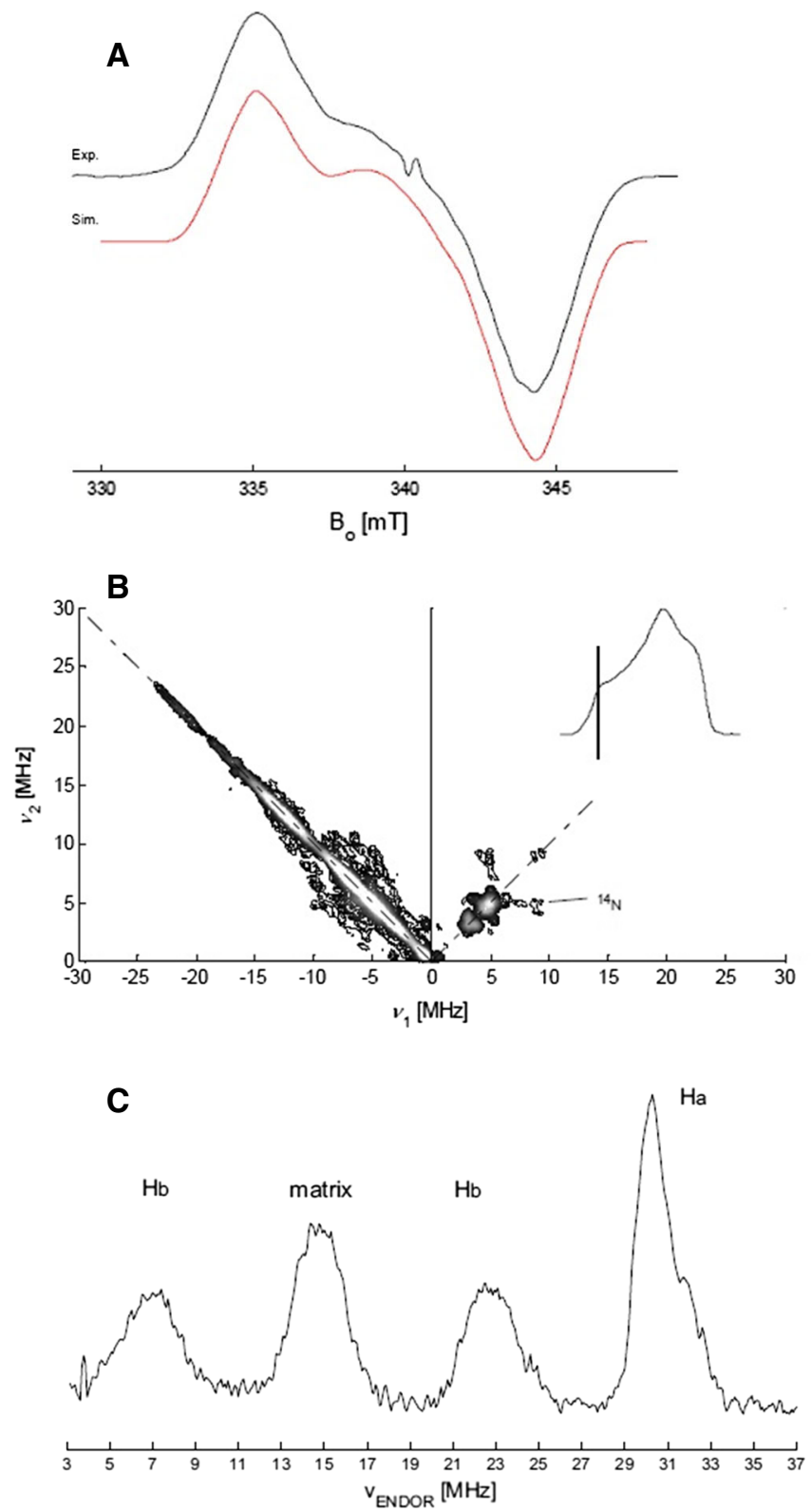

Fig. 7 a X-band (CW, first derivative) and Q-Band (pulse, absorption mode) EPR spectrum of the aminyl complex measured at $20 \mathrm{~K}$ (black) and simulation (red), with $g_{1}=1.974, \quad g_{2}=1.993$, $g_{3}=2.028$; b Q-band HYSCORE spectrum of the aminyl complex

\subsection{Application of EPR for Redox Active Ligands}

As depicted in Scheme 1, redox active ligands are also used to facilitate two-electron processes (such as oxidative addition and reductive elimination) at first row transition metals which normally react via one-electron redox processes. An example includes $\mathrm{C}-\mathrm{H}$ activation/arylation, by the group of Fensterbank, applying iron complexes bearing a bisiminopyridine ligand [57]. Several other examples have been described using this concept [23], but in most cases these were not investigated with EPR spectroscopy.
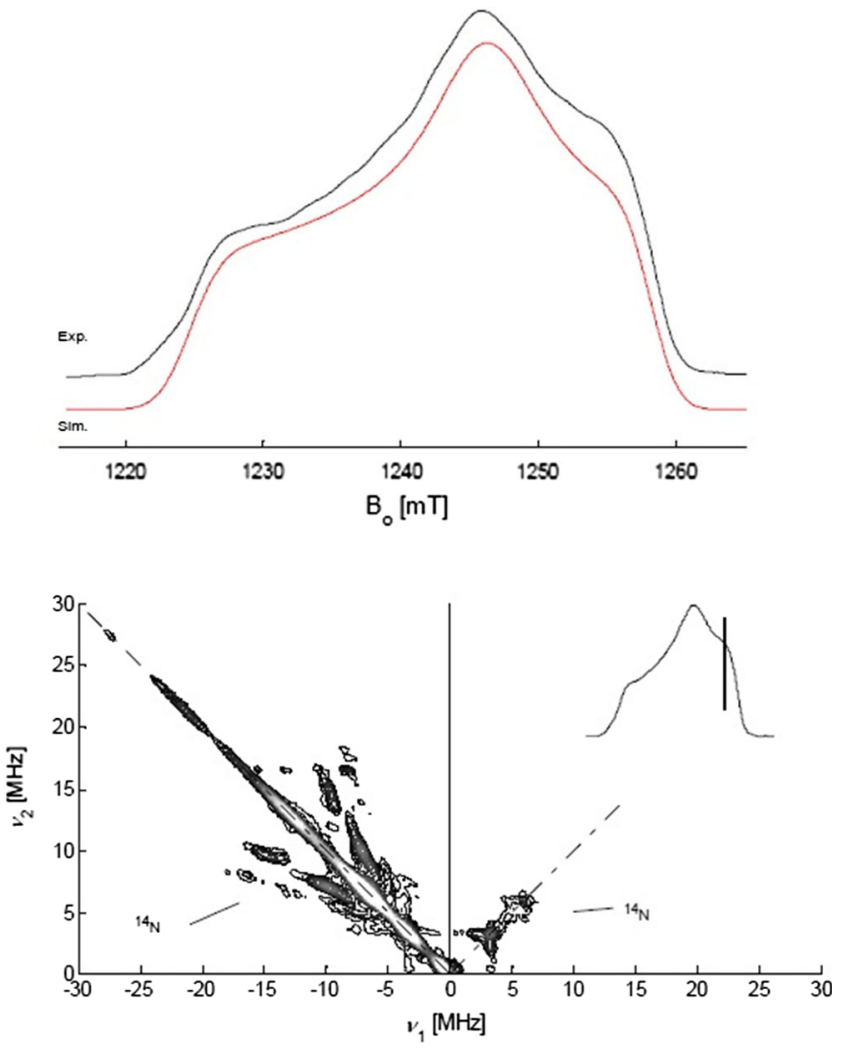

D

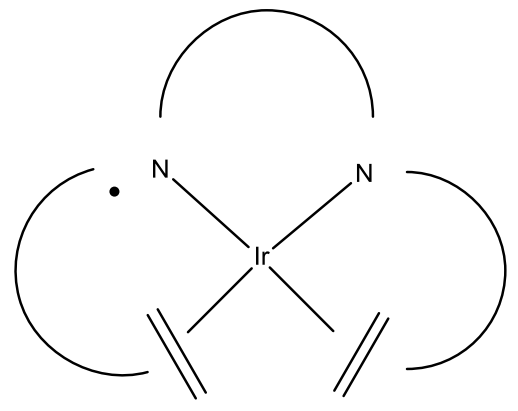

at observer points $1246 \mathrm{mT}$ and $1274 \mathrm{mT}$; c X-band Davies ENDOR spectrum at the observer point of the $\mathrm{g}_{2}$ position. The matrix line belongs to all the protons in vicinity of the unpaired electron. (Figure adapted from Ref. [52])

Recently, Van der Vlugt and coworkers (in collaboration with De Bruin) showed that diamagnetic second-row transition metals can also be tuned to undergo one-electron radical-type transformations making use of redox active ligands (Fig. 10) [58]. Coordinating a redox-active tridentate NNO ligand to $\mathrm{Pd}(\mathrm{II})$ leads to the formation of a paramagnetic complex, which proved to contain a ligand centered radical, evidenced by EPR measurements. Reducing it by one-electron yields a diamagnetic amidophenolato complex capable of activating aliphatic azides. Intramolecular ligand-to-substrate single-electron 

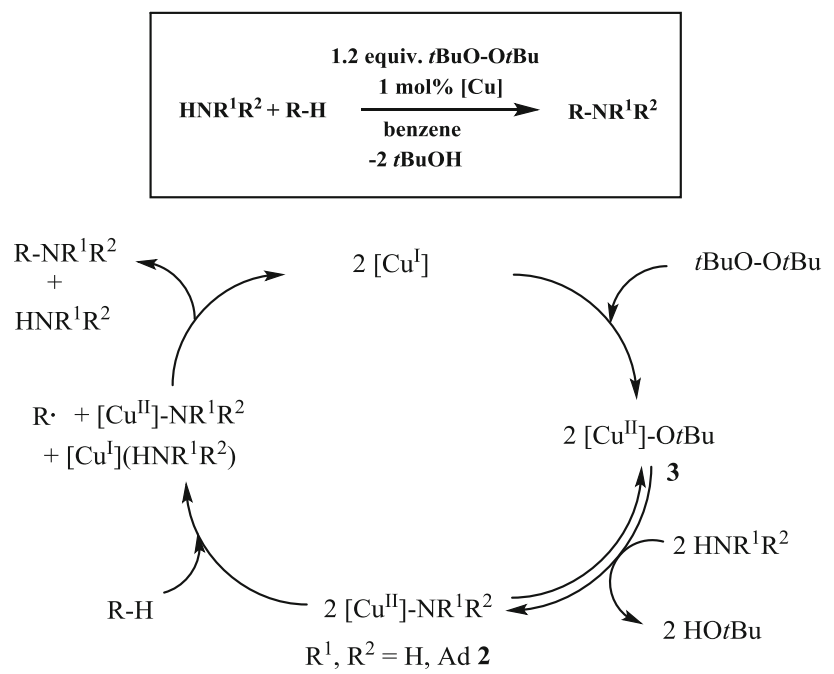

Scheme 6 Mechanism of catalytic C-H amination with an aminyl radical complex

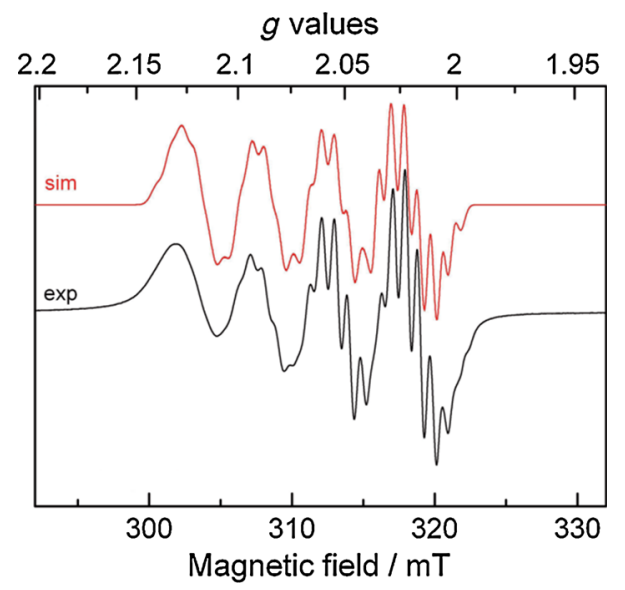

Fig. 8 X-band EPR spectrum of the copper aminyl complex (figure reproduced with permission from Ref. [53])

transfer was proposed to occur, yielding a complex with an open-shell singlet electronic structure containing both a substrate nitrogen-based radical and a ligand carbon-based radical. This last complex enabled radical-type $\mathrm{C}-\mathrm{H}$ amination with palladium. Another example from the same group involves a related $\mathrm{Pd}(\mathrm{II})$ ligand centered radical complex, which has been used to split the bond of diphenyldisulfide. Investigations revealed an unprecedented intramolecular homolytic S-S bond cleavage facilitated by ligand-to-disulfide single-electron transfer with the release of a thiyl radical [59].

\subsection{Olefin Metathesis in Ionic Liquids}

Olefin metathesis is an important chemical reaction applied by chemists for decades. Recently, considerable attention has been given to metathesis reactions in ionic liquids, as safer and greener alternatives to traditional organic solvents. In principle, mechanisms involving ionic liquids do not differ from the traditional metathesis mechanism [60]. However, one example involving paramagnetic $\mathrm{W}(\mathrm{V})$ and $\mathrm{Mo}(\mathrm{V})$ species is important here [61]. The catalysts were prepared by dissolving the W/Mo chlorides in the ionic liquids (molar ratio between $1 / 10$ and 1/100) and applied for hex-1-ene metathesis at r.t. For this purpose $\mathrm{WCl}_{6}$ and $\mathrm{MoCl}_{5}$ were dissolved in different ionic liquids (tetrafluoroborates of 1-ethyl-3-methylimidazolium, 1-hexyl-3-methylimidazolium, $N$-hexylpyridinium and 1-butyl-3-methylimidazolium, trihexyl(tetradecyl)phosphonium and 1-ethyl-3methyl-imidazoolium). In the catalytic reactions oct-4-ene was formed as the main product, which means that fast isomerization of hex-1-ene to hex-2-ene takes place. EPR spectroscopy revealed that the metathesis reaction causes formation of a large number of W(V) species (Fig. 11). In contrast, bulk $\mathrm{WCl}_{6}$ only gives rise to a very weak low-field EPR signal, attributed to a small admixture of paramagnetic $\mathrm{W}(\mathrm{V})$ ions in the bulk $\mathrm{WCl}_{6}$. This signal was applied to test for bulk $\mathrm{WCl}_{6}$ present in the reaction mixture.

In this study the authors attempt to quantify the number of $\mathrm{W}(\mathrm{V})$ ions present in the ionic layers by comparing the double integral of the spectrum with an appropriate standard. However, no proper W(V) EPR standard was available. Therefore, $\mathrm{Mo}(\mathrm{V})$, being a close analogue, was applied to quantify the number of $\mathrm{W}(\mathrm{V})$ species in an approximate manner. All ionic liquids, except the phosphonium based one, gave considerable amounts of $\mathrm{W}(\mathrm{V})$ after the reaction (5-20\% after $2.5 \mathrm{~h}$ reaction at r.t.). Further, $\mathrm{Mo}(\mathrm{V})$ could also function as a catalyst. Similar to the abovementioned experiments, $\mathrm{MoCl}_{5}$ was dissolved in the same ionic liquids and applied for the metathesis of hex-1-ene. Again, oct-4-ene was formed as the main product. To evaluate the amount of EPR visible $\mathrm{Mo}(\mathrm{V})$ ions in the ionic liquid, the results were compared with those obtained from a diluted $\mathrm{MoCl}_{5}$ solution. A $10 \%$ $\mathrm{MoCl}_{5}$ in 1-hexyl-3-methylimidazolium tetrafluoroborate revealed the presence of about $25 \%$ of $\operatorname{Mo}(\mathrm{V})$. When this ionic liquid solution was applied in catalytic olefin metathesis, and followed in time, it could be seen that the intensity of the $\mathrm{Mo}(\mathrm{V})$ signal increases drastically (Fig. 12). After $60 \mathrm{~min}$ of reaction, the amount of EPR active $\mathrm{Mo}(\mathrm{V})$ was about $90 \%$. Although this study does not elaborate on the reaction mechanism, the involvement of paramagnetic $\mathrm{W}(\mathrm{V})$ and $\mathrm{Mo}(\mathrm{V})$ species is evident.

\section{Ethylene Oligomerization}

There is a steadily growing demand for $\alpha$-olefins such as 1-butene, 1-hexene and 1-octene which act as co-monomers for the industrial production of different types of 
Scheme 7 Catalytic C-H amination with cobalt porphyrins (figure reproduced

with permission from Ref. [54])

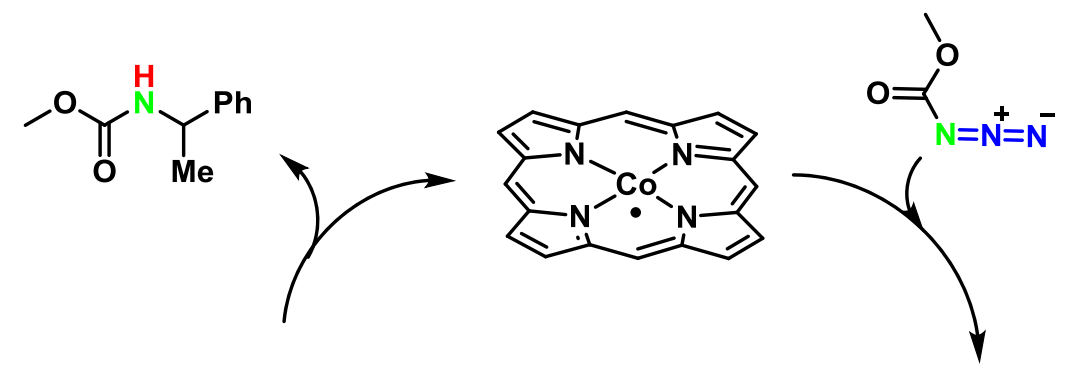

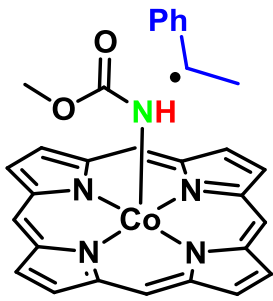

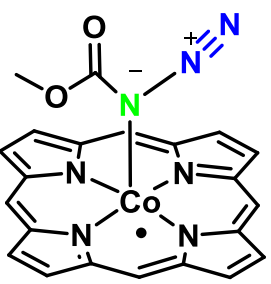<smiles>CCCC</smiles><smiles>CCCc1ccccc1</smiles>

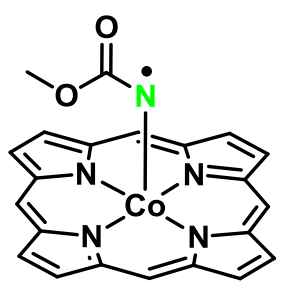<smiles>CCC1C(C)C1CN</smiles>
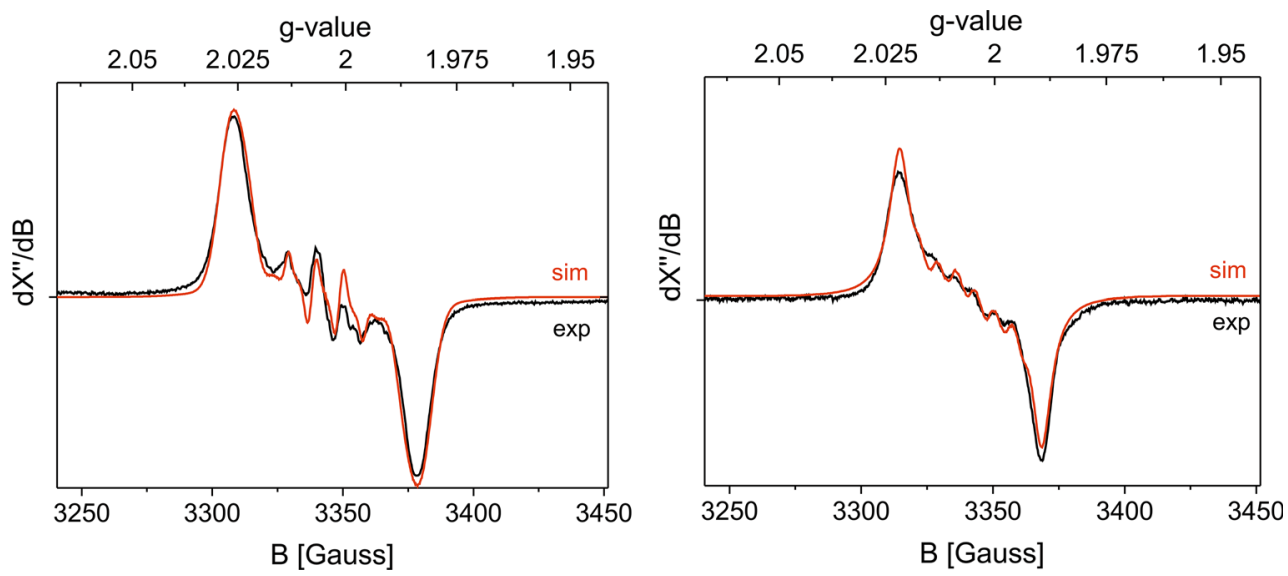

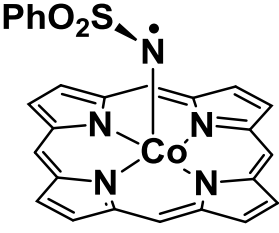

I

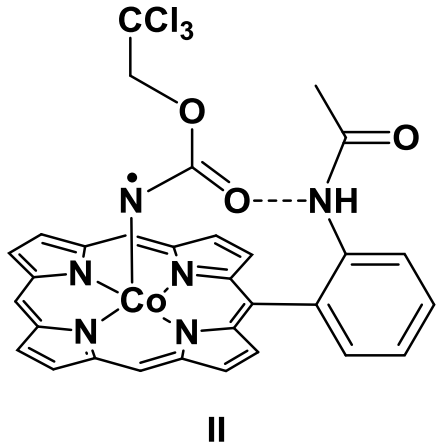

Fig. 9 X-band EPR spectra of Co(por) imidyl radicals and a schematic representation of their (electronic) structure (figure reproduced with permission from Ref. [54]) 
Fig. 10 Redox states of $\mathrm{Pd}^{\mathrm{II}}$ coordinated NNO ligand and synthesis of a "nitrene-substrate radical, ligand radical" on $\operatorname{Pd}(\mathrm{II})$ (figure reproduced with permission from Ref. [58])
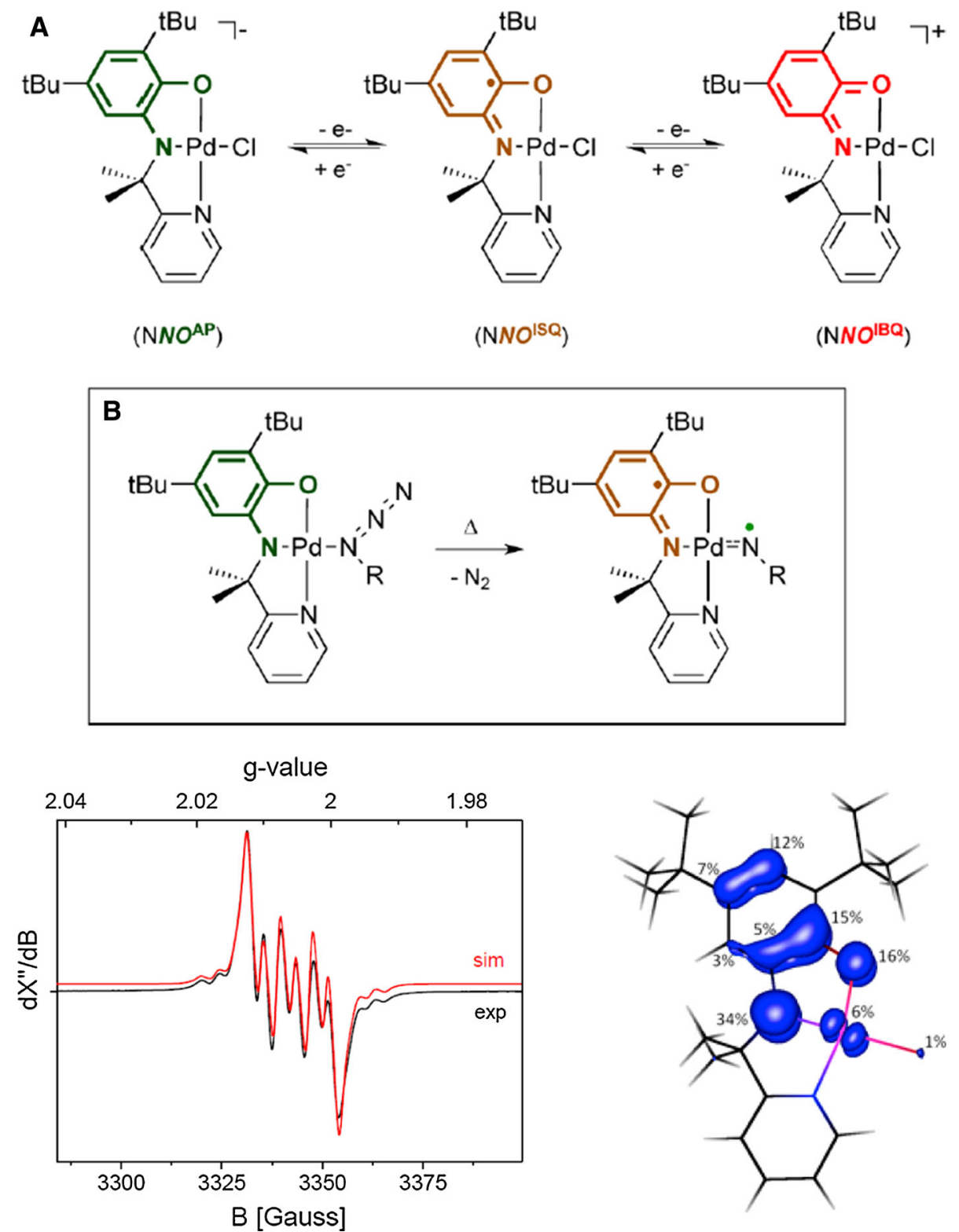

linear low-density polyethylene (LLDPE) copolymers $[62,63]$. Hence, selective catalysts that do not yield a Schulz-Flory or Poisson distribution of various oligomers but only products that match specific market needs are highly desirable. A whole range of olefin oligomerization catalytic systems were reviewed a few years ago by McGuiness [64]. Another extensive review by Morgan and coworkers in 2004 covered the ethylene trimerization topic in particular [65]. Of all the transition metals active in olefin oligomerization, the most widely studied and applied ones are the $\mathrm{Cr}$ based systems [64, 65]. These were also the first examples of catalysts that are selective for ethylene trimerization [65]. Additionally, a few years ago the $\mathrm{Cr}$ based systems have also been shown to be active in ethylene tetramerization reactions where selectivities of up to $70 \%$ were achieved [66]. Obviously, the development of any catalytic system is rooted in the understanding of the mechanism, characterization of intermediates and knowledge of the kinetics of the process. However, the detailed study of these reaction mechanisms and reactive intermediates in particular has faced difficulties, such as the paramagnetic nature of the various chromium oxidation states $\left(\mathrm{Cr}^{\mathrm{I}}\right.$ and $\left.\mathrm{Cr}^{\mathrm{III}}\right)$ involved in the cycle making the use of NMR spectroscopy almost redundant. Additionally the existence of a variety of different spin states for the paramagnetic species also means that theoretical studies are not straightforward. 

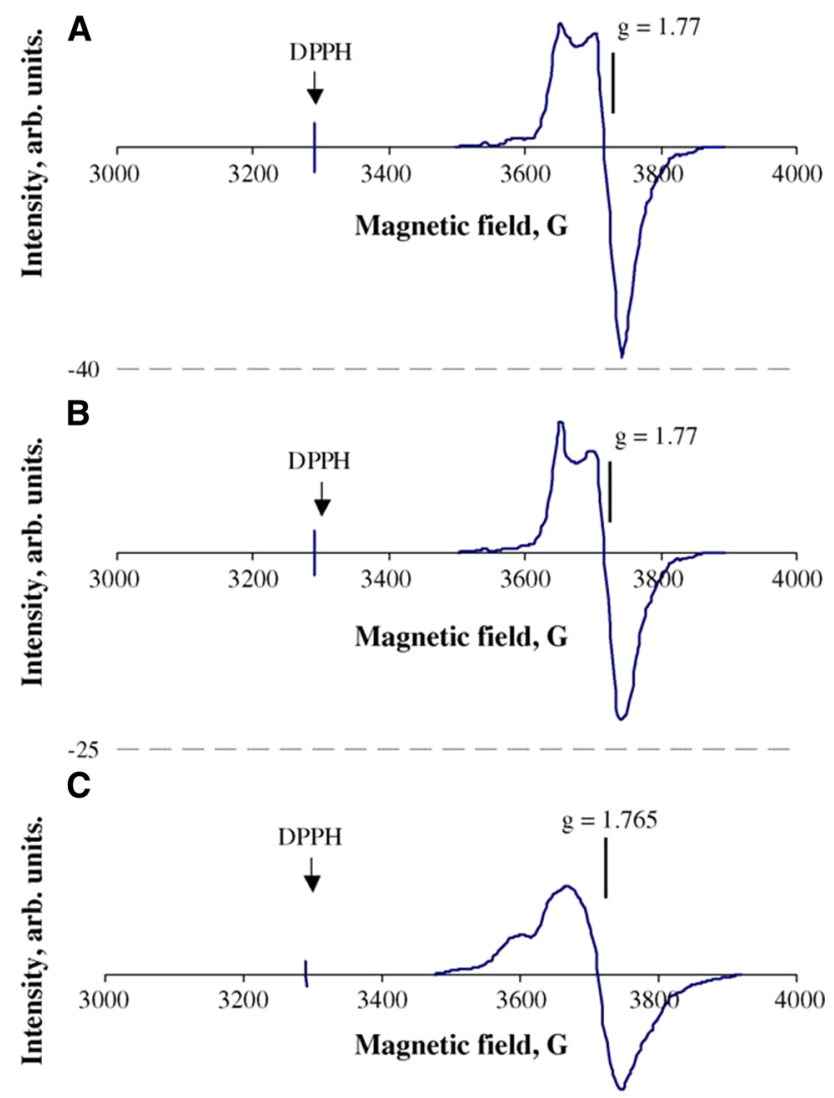

Fig. $11 \mathrm{X}$-Band EPR spectra (recorded at $-196{ }^{\circ} \mathrm{C}$ ) of the ionic liquid layers after $2 \mathrm{~h}$ of hex-1-ene metathesis at r.t. a $10 \% \mathrm{WCl}_{6}$ in 1-hexyl-3-methylimidazolium tetrafluoroborate; b $10 \% \mathrm{WCl}_{6}$ in 1-hexyl-3-methylimidazolium tetrafluoroborate; c $5 \% \mathrm{WCl}_{6}$ in 1-ethyl-3-methylimidazolium tetrafluoroborate (figure reproduced with permission from Ref. [61])

The mechanistic studies performed so far on these systems have been recently reviewed by Talsi and coworkers, who also touched upon the Phillips trimerization catalyst, chromium catalysts based on diphosphinoamine ligands and the Sasol heteroatomic chromium catalysts [67]. However, the focus was more general and not especially on the use of EPR spectroscopy to understand these systems. The various EPR experiments performed, techniques used and the implications of these studies are summarized in this section.

The generally accepted mechanism of trimerization by the Phillips catalyst was proposed by Briggs [68], and is depicted in Scheme 8. The mechanism is based on the shuttling of the $\mathrm{Cr}$ species between $\mathrm{Cr}^{\mathrm{n}}$ and $\mathrm{Cr}^{\mathrm{n}+2}$ oxidation states. The metallacyclic intermediates have been supported by the well-characterized $\eta^{5}$-cyclopentadienylstabilized chromacyclopentane and chromacycloheptane complexes in 1997 [69]. However, a logical mechanistic speculation concerning the oxidation states of chromium in

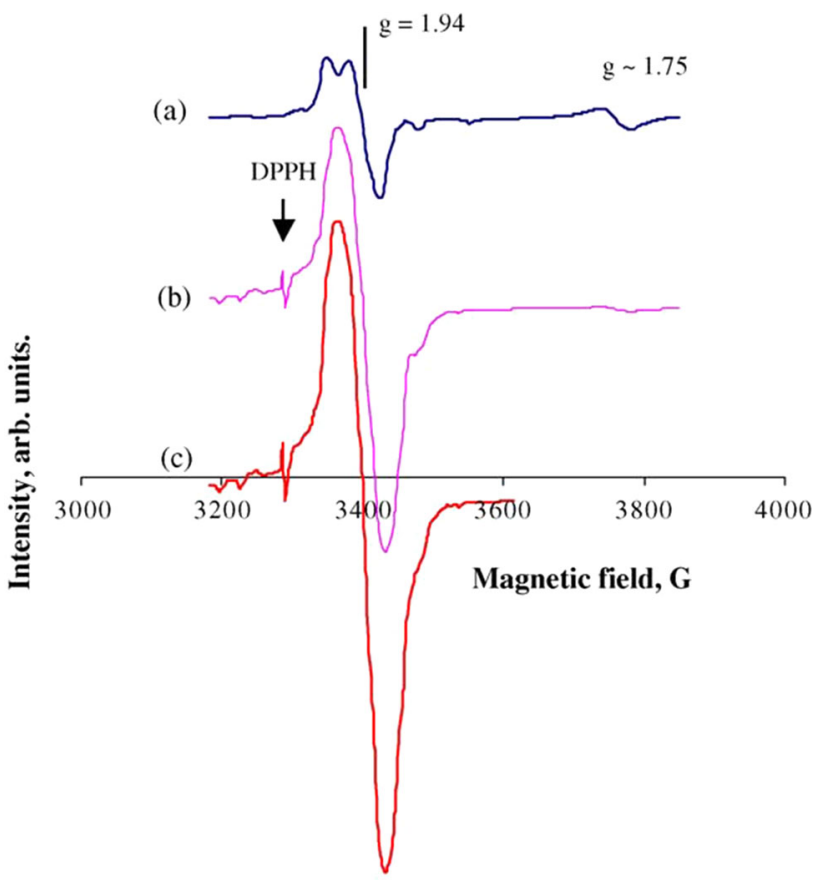

$-180$

Fig. 12 EPR spectra taken at $-196{ }^{\circ} \mathrm{C}$ of the $\mathrm{MoCl}_{5}+1$-hexyl-3methylimidazolium tetrafluoroborate layer in the metathesis of hex-1ene. $a$ Before the reaction; $b$ after $10 \mathrm{~min}$ of reaction and $(c)$ after $60 \mathrm{~min}$ of reaction (figure reproduced with permission from Ref. [61])

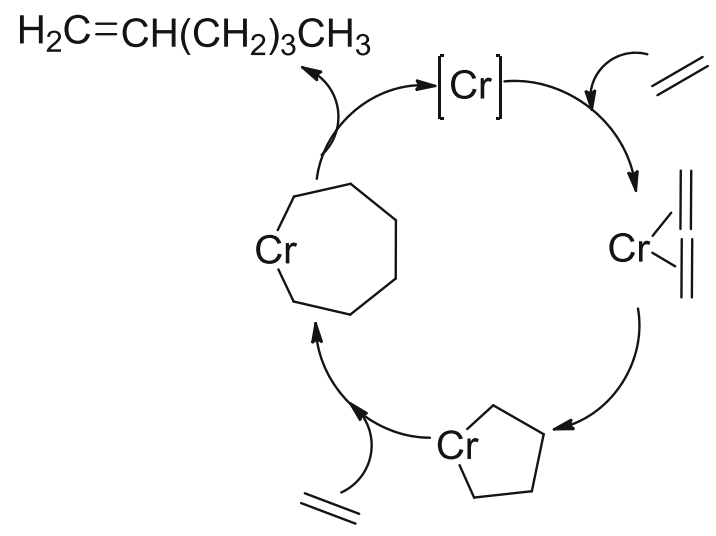

Scheme 8 Brigg's metallacycle mechanism of trimerization by Philips catalyst

the Phillips trimerization catalytic system came 11 years later in 2008, when Gambarotta and coworkers isolated a single component trimerization and polymerization chromium catalyst. The catalyst shown in Scheme 9 was prepared by combining a chromium precursor, 2,3,4,5tetrahydro- $1 \mathrm{H}$ - carbazole and $\mathrm{AlEt}_{3}$ and $\mathrm{AlEt}_{2} \mathrm{Cl}[70,71]$. The Gambarotta group found that the use of only $\mathrm{Cr}^{\mathrm{III}}$ led to non-selective oligomerization, while using only $\mathrm{Cr}^{\mathrm{II}}$ polymerization was observed. The authors showed that $\mathrm{Cr}^{\mathrm{I}}$ is responsible for selective trimerization of ethylene. The results of this study gave a reasonably realistic picture of 
Scheme 9 Synthesis of the isolated single-component oligomerization and polymerization catalyst

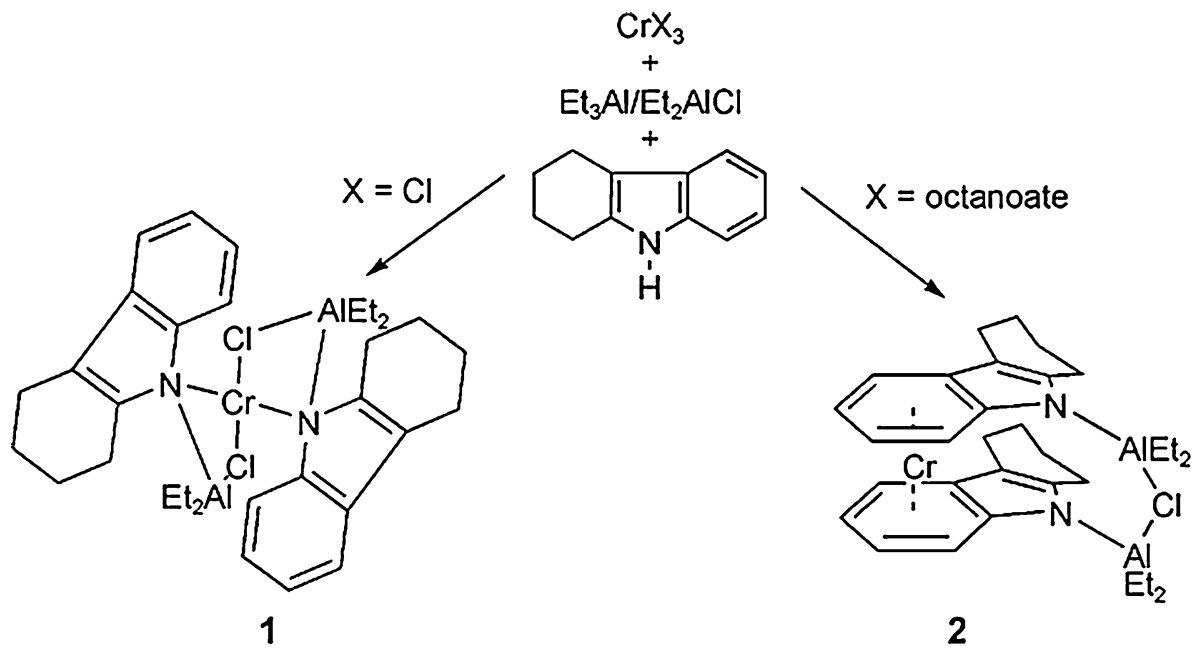

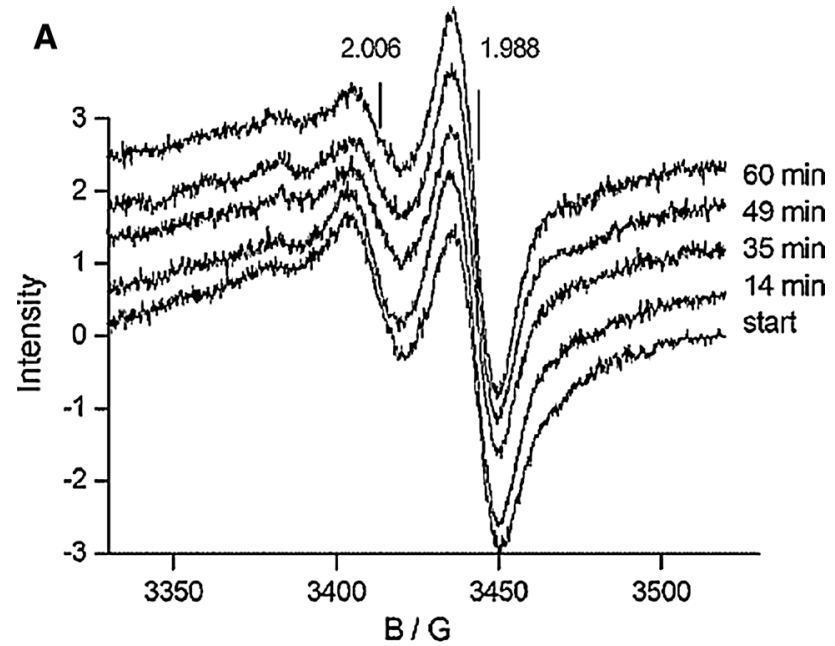

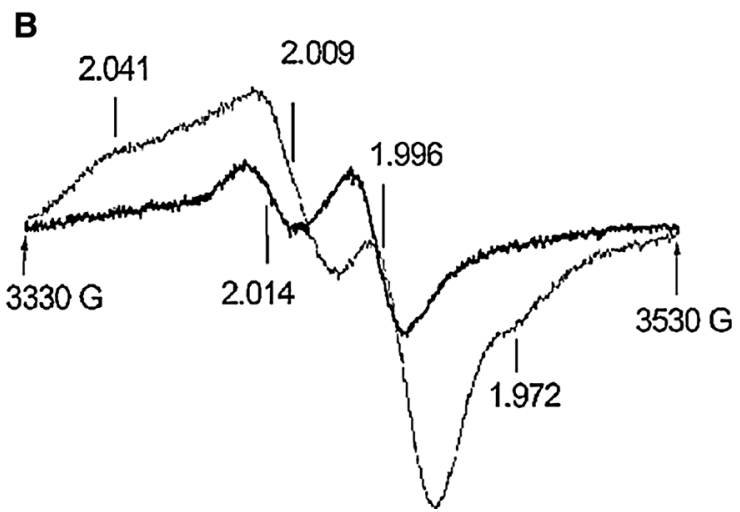

Fig. 13 a In situ X-band EPR spectra of Cr-ac/PNP/MMAO during isothermal treatment at $333 \mathrm{~K}$ with 10 bar of ethylene. b EPR spectra recorded after the reaction measured at room temperature (thick line) and at $77 \mathrm{~K}$ (thin line) (EPR spectra reproduced with permission from Ref. [73])

the complex nature of this catalytic system, but the mechanism is unlikely to be general for all $\mathrm{Cr}$ systems. In addition to studies on trimerization of ethylene, the
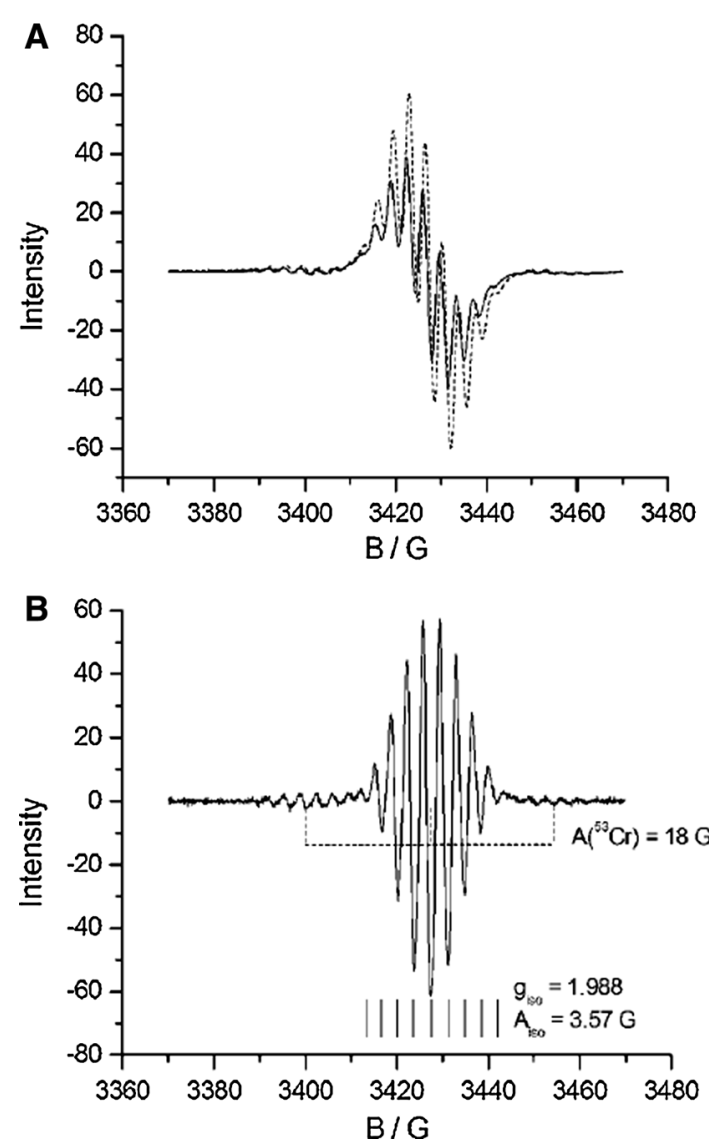

Fig. 14 a EPR spectra of $\left[(\mathrm{PNP}) \mathrm{CrCl}_{2}(\mu-\mathrm{Cl})\right]_{2}$ in toluene measured at $293 \mathrm{~K}$ after $5 \mathrm{~min}$ (solid line) and $15 \mathrm{~min}$ (dashed line) contact with MMAO. b Second derivative of the spectrum after 15 min (EPR spectra reproduced with permission from Ref. [73])

chromium catalyzed tetramerization mechanism was also proven to be an extended metallacyclic mechanism [72]. These studies were so far based on pre-catalysts which require activation by alkyl aluminium compounds before 
they can actually take part in catalysis. Therefore, for real time monitoring of these catalytic systems, active species and resting states, EPR spectroscopy proved a useful tool as some oxidation states for $\mathrm{Cr}$ in the catalytic cycle are EPR active while others are EPR silent.

The first in situ EPR spectroscopy on the ethylene oligomerization systems was reported on the evolution of the $\mathrm{Cr}(\mathrm{acac})_{3} /$ bidentate diphosphinoamine ligand (PNP)/modified methyl aluminoxane (MMAO) catalytic system in cyclohexane and toluene [73]. Two types of systems were used, one consisting of a mixture of $\mathrm{Cr}(\mathrm{acac})_{3}$ and a $\mathrm{PNP}$ ligand $\left(\mathrm{PNP}=\mathrm{PPh}_{2} \mathrm{PN}(\mathrm{i}-\mathrm{Pr}) \mathrm{PPh}_{2}\right)$ and the isolated $\left[(\mathrm{PNP}) \mathrm{CrCl}_{2}(\mu-\mathrm{Cl})\right]_{2}$ complex for comparison. The precursors leading to the active catalyst and its interaction with ethylene were studied at high temperatures and pressures using in situ EPR spectroscopy, which provided direct information about the various $\mathrm{Cr}$ oxidation states under realistic reaction conditions. It was found that in the presence of MMAO the $\mathrm{Cr}^{3+}$ in the initial $\mathrm{Cr}$ ac/cyclohexane, $\mathrm{Cr}$-acac/PNP/cyclohexane, and [PNP- $i$-Pr$\left.\mathrm{CrCl}_{2}(\mu-\mathrm{Cl})\right]_{2} /$ toluene solutions is reduced to low-spin $\mathrm{Cr}^{+}$. The corresponding EPR spectra for the $\mathrm{Cr}$-ac/PNP/MMAO system are shown in Fig. 13.

For $\mathrm{Cr}(\mathrm{acac})_{3} / \mathrm{PNP}\left(\mathrm{PPh}_{2} \mathrm{PN}(\mathrm{i}-\mathrm{Pr}) \mathrm{PPh}_{2}\right), \mathrm{Cr}^{3+}$ reduction was found to be faster than low-spin $\mathrm{Cr}^{+}$formation, suggesting that the major active species is EPR-silent. This EPR silent species could possibly be an antiferromagnetically coupled $\mathrm{Cr}^{+}$dimer or $\mathrm{Cr}^{2+}$. In toluene solutions, fast decomposition of $\left[(\mathrm{PNP}) \mathrm{CrCl}_{2}\right.$ $(\mu-\mathrm{Cl})]_{2}$ to $\left[\mathrm{Cr}\left(\eta^{6}-\mathrm{CH}_{3} \mathrm{C}_{6} \mathrm{H}_{5}\right)_{2}\right]^{+}$was postulated to be a probable reason for low activity. This was because on measuring isotropic EPR spectra of the $\left[(\mathrm{PNP}) \mathrm{CrCl}_{2}(\mu-\right.$ $\mathrm{Cl})]_{2} / \mathrm{MMAO}$ in toluene at room temperature, a sharp EPR signal was detected showing a multiline (super)hyperfine pattern (Fig. 14). This could arise from the coupling of the electron spin on $\mathrm{Cr}^{+}(S=1 / 2)$ with the nuclear spins of 10 protons $(I=1 / 2)$ of the two aromatic toluene rings. The isotropic values $g_{\text {iso }}=1.988$ and $A_{\text {iso }}=3.57 \mathrm{G}$ as well as the hyperfine coupling constant of the electron spin $(S=1 / 2)$ with the nuclear spin of the ${ }^{53} \mathrm{Cr}$ isotope $(I=3 /$ 2, natural abundance $\left.9.5 \% ; A\left({ }^{53} \mathrm{Cr}\right)=18 \mathrm{G}\right)$ were found to be in excellent agreement with values found for the $\left[\mathrm{Cr}\left(\eta^{6}-\mathrm{CH}_{3} \mathrm{C}_{6} \mathrm{H}_{5}\right)_{2}\right]^{+}$cation in $\mathrm{CH}_{3} \mathrm{CN}$ solution. Hence, this multiplet was assigned to $\left[\mathrm{Cr}\left(\eta^{6}-\mathrm{CH}_{3} \mathrm{C}_{6} \mathrm{H}_{5}\right)_{2}\right]^{+}$. Detection of this signal was a clear indication that the transformation of the pre-catalyst occurs alongside undesired release of PNP ligand. This observation also correlates with the fact that this catalyst in toluene solution showed slower reaction rates. Toluene therefore doesn't seem to be a solvent of choice for these systems.

Following this report, the Phillips ethylene trimerization catalyst was studied using model systems and to understand the effect of the various components in these catalysts on the $\mathrm{Cr}(\mathrm{III})$ and $\mathrm{Cr}(\mathrm{I})$, EPR was once again used [74]. The catalyst systems were prepared by combining $\mathrm{Cr}(\mathrm{acac})_{3-}$ or $\mathrm{Cr}(\mathrm{EH})_{3}(\mathrm{EH}=$ ethyl hexanoate) with pyrrole (HPyr), $\mathrm{AlEt}_{3}$, and $\mathrm{AlEt}_{2} \mathrm{Cl}$ in cyclohexane. The overall goal was to establish the correlation between the concentrations of the particular chromium species and the trimerization activity. The conclusion of this study was that the catalyst system $\mathrm{Cr}(\mathrm{acac})_{3}: \mathrm{HPyr}_{\mathrm{AlEt}}{ }_{3}=1: 3: 30$ was more active in ethylene trimerization than the catalyst system $\mathrm{Cr}(\mathrm{acac})_{3}$ : $\mathrm{AlEt}_{3}=1: 30$. Hence, the addition of pyrrole promotes the trimerization of ethylene. The comparison of the EPR spectra of the systems $\mathrm{Cr}(\mathrm{acac})_{3} / \mathrm{AlEt}_{3}$ and $\mathrm{Cr}(\mathrm{acac})_{3} / \mathrm{HPyr} /$ $\mathrm{AlEt}_{3}$ indicated that the more active system displayed a larger concentration of the mononuclear $\mathrm{Cr}(\mathrm{I})$ species (Figs. 15, 16). Thus the trimerization activity correlates with the presence of mononuclear $\mathrm{Cr}(\mathrm{I})$ species in the reaction mixture. Similar data were also obtained for $\mathrm{Cr}(\mathrm{EH})_{3}: \mathrm{HPyr}_{\mathrm{AlEt}} \mathrm{Al}_{3}=1: 3: 30$ and $\mathrm{Cr}(\mathrm{EH})_{3}: \mathrm{AlEt}_{3}=1: 30$, $\mathrm{Cr}(\mathrm{acac})_{3}: \mathrm{AlEt}_{2} \mathrm{Cl}=1: 20$. All data, therefore pointed to participation of $\mathrm{Cr}(\mathrm{I})$ species in catalytic ethylene trimerization, and thus the $\mathrm{Cr}(\mathrm{I})-\mathrm{Cr}(\mathrm{III})$ mechanism was concluded to be the most plausible candidate operational in this reaction mediated by the Phillips catalyst. The supporters of the $\mathrm{Cr}(\mathrm{II})-\mathrm{Cr}(\mathrm{IV})$ cycle argue the presence of an EPR silent species that is most active and this of course cannot be excluded. However, the important finding of this study was that systems containing $\mathrm{Cr}(\mathrm{I})$ species exhibit noticeable trimerization activity, which is in support of the $\mathrm{Cr}(\mathrm{I}) / \mathrm{Cr}(\mathrm{III})$ mechanism.

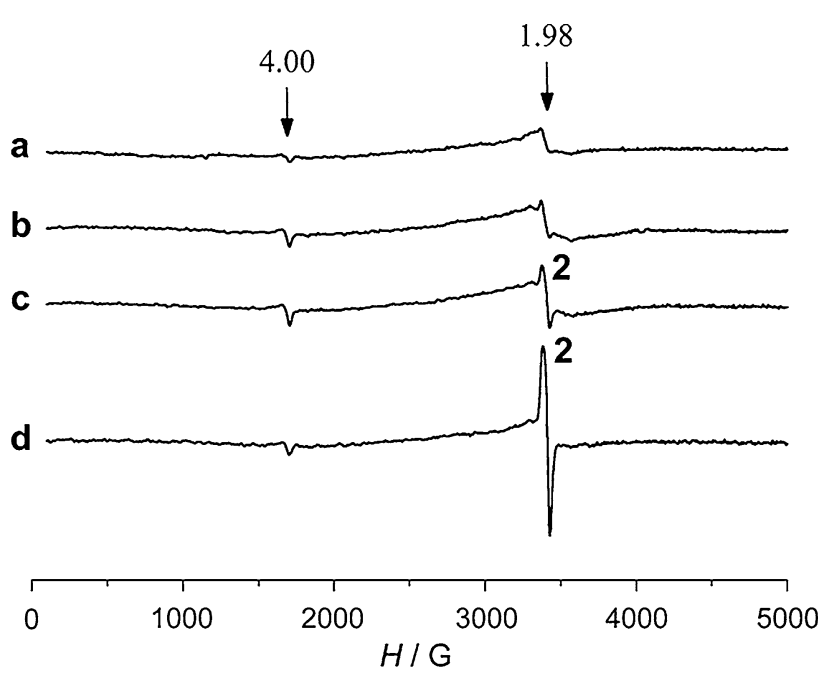

Fig. 15 EPR spectra $\left(-196{ }^{\circ} \mathrm{C}\right)$ of the sample $\mathrm{Cr}(\mathrm{acac})_{3} / \mathrm{AlEt}_{3}$ $\left(\left[\mathrm{AlEt}_{3}\right]:\left[\mathrm{Cr}(\mathrm{acac})_{3}\right]=20,\left[\mathrm{Cr}(\mathrm{acac})_{3}\right]=10^{-2} \mathrm{M}, \mathrm{C}_{6} \mathrm{H}_{12}\right)$ after various treatments: $1(a), 6(b)$, and $15 \mathrm{~min}(c)$ storing at $20{ }^{\circ} \mathrm{C} ; 1 \mathrm{~min}$ after storing sample " $c$ " at $65^{\circ} \mathrm{C}(d)$. The signal at $\mathrm{g}=4.0$ arises from to unreacted $\mathrm{Cr}$ (III) (EPR spectra reproduced with permission from Ref. [74]) 
Another attempt to correlate trends in EPR-derived parameters with real catalysis data was made by Smith et al. [75]. A series of $\left[\mathrm{Cr}(\mathrm{CO})_{4} \mathrm{~L}\right]^{+}\left(\mathrm{L}=\mathrm{Ph}_{2} \mathrm{PN}(\mathrm{R}) \mathrm{PPh}_{2}\right.$, $\mathrm{Ph}_{2} \mathrm{P}(\mathrm{R}) \mathrm{PPh}_{2}$ ) complexes which are used as pre-catalysts for selective oligomerization of ethylene were prepared and characterized. The electronic properties and structural features of these complexes in frozen solution were established via continuous wave X-band EPR (CW-EPR) and continuous wave ${ }^{1} \mathrm{H},{ }^{14} \mathrm{~N}$ and ${ }^{31} \mathrm{P}$ electron nuclear double resonance (CW-ENDOR) spectroscopy. The ligands $\mathrm{L}$ used for the synthesis of $\left[\mathrm{Cr}(\mathrm{CO})_{4} \mathrm{~L}\right]^{+}$are shown in Scheme 10. The CW-EPR spectra of complex $\left[\mathrm{Cr}(\mathrm{CO})_{4} \mathrm{~b}\right]^{+}$is shown in Fig. 17. Because the ligand in $\mathrm{b}$ is $\mathrm{P}-\mathrm{C}-\mathrm{P}$ based a 1:2:1 triplet pattern is clearly seen arising from the superhyperfine interactions from the ${ }^{31} \mathrm{P}$ nuclei $(\mathrm{I}=1 / 2)$. Due to the low abundance of ${ }^{53} \mathrm{Cr}(\mathrm{I}=3 / 2)$ $(\sim 9.5 \%)$ in combination with some signal broadening, no anisotropic hyperfine interaction associated with ${ }^{53} \mathrm{Cr}$ was detected in the frozen solutions. In general, from the spin Hamiltonian parameters ( $\mathrm{g}$ and A) some hints on the coordination environment and the symmetry of the metal center can be derived. Although the clear tetragonal distortion in the complexes $\left[\mathrm{Cr}(\mathrm{CO})_{4} \mathrm{~L}\right]^{+}$was reflected in the $\Delta \mathrm{g}$ shift no obvious correlations could be made between the observed spectral shifts and the type of ligand, that is, $\mathrm{P}-\mathrm{N}-\mathrm{P}$ or $\mathrm{P}-\mathrm{C}-\mathrm{P}$. Apart from that, the SOMO of the complex (in its ground state) of all complexes investigated was found to be dominated by the chromium $\mathrm{d}_{x y}$ orbital.

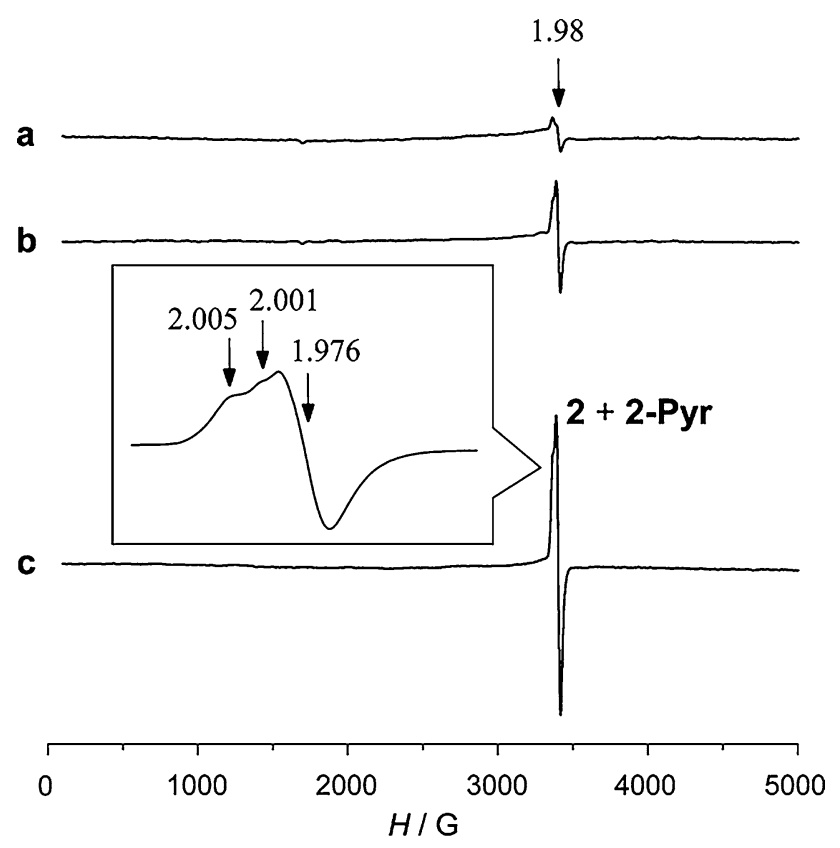

Fig. 16 EPR spectra $\left(-196{ }^{\circ} \mathrm{C}\right)$ of the sample $\mathrm{Cr}(\mathrm{acac})_{3}: \mathrm{HPyr}$ : $\mathrm{AlEt}_{3}=1: 3: 20\left(\left[\mathrm{Cr}(\mathrm{acac})_{3}\right]=10^{-2} \mathrm{M}, \mathrm{C}_{6} \mathrm{H}_{12}\right)$ after various treatments: $1(a), 5(b)$, and $28 \mathrm{~min}(c)$ storing at $20{ }^{\circ} \mathrm{C}$ (EPR spectra reproduced with permission from Ref. [74])
Structural differences in the $\left[\mathrm{Cr}(\mathrm{CO})_{4} \mathrm{~L}\right]^{+}$complexes were also detected using ${ }^{1} \mathrm{H}$ ENDOR spectroscopy. The observed spectral changes were attributed to variations in the phenyl ring conformations as a function of the ligand type. The isotropic Fermi contact term was found to be largest for complexes containing ligands $\mathrm{d}, \mathrm{f}$, e and $\mathrm{g}$, suggesting that the ${ }^{31} \mathrm{P} 3 \mathrm{~s}$ character in the SOMO is higher for the P-N-P type ligands than for the P-C-P types.

The CW-EPR and ENDOR studies performed in this study reflect on the power of these spectroscopic techniques in resolving structural and electronic properties of paramagnetic complexes and also to reveal subtle electronic and structural differences which are imparted by different ligands. However, in context of these particular ethylene oligomerization catalysis reactions, the EPRderived parameters ( $g$ values, ${ }^{31} \mathrm{P}$ spin density and Fermi contact terms) and relevant catalytic data did not quite correlate. This could be partly because of the fact that on addition of an excess of trialkylaluminium to these precatalysts for activation, the coordination environment gets heavily perturbed. Additionally the effect of the applied ethylene pressure on the activated catalyst is also of great importance. Thus, similar EPR spectroscopic studies on species that are closer to the catalytically active species might shed more light on the oxidation states of the active species in $\mathrm{Cr}$ catalyzed ethylene oligomerization.

The effect of different ligand structures on the activity and selectivity of $\mathrm{Cr}$ (III) complexes relevant in ethylene oligomerization and polymerization reactions was studied using EPR spectroscopy in combination with EXAFS and XANES and other techniques by Tromp et al. [76]. The

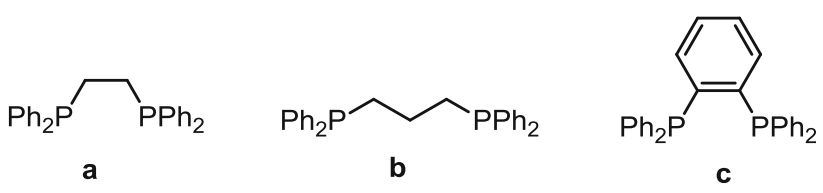

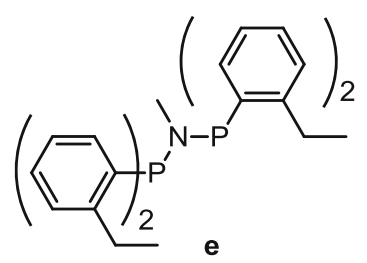
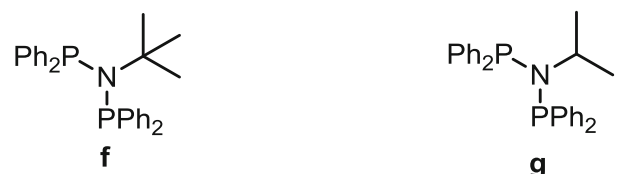

Scheme 10 Different ligands used for the synthesis of $\left[\mathrm{Cr}(\mathrm{CO})_{4} \mathrm{~L}\right]^{+}$ complexes used in CW-EPR and ENDOR studies 
Fig. 17 Experimental and simulated CW-EPR spectra $(140 \mathrm{~K})$ of $\left[\mathrm{Cr}(\mathrm{CO})_{4}(\mathrm{~b})\right]^{+}$ recorded in dichloromethanetoluene at a microwave frequency of $9.371 \mathrm{GHz}$. The angular dependency curves calculated for the $\operatorname{Cr}(\mathrm{I}) g$ matrix and the ${ }^{31} \mathrm{P} A$ matrix are shown in the lower trace (EPR spectra reproduced with permission from Ref. [75])

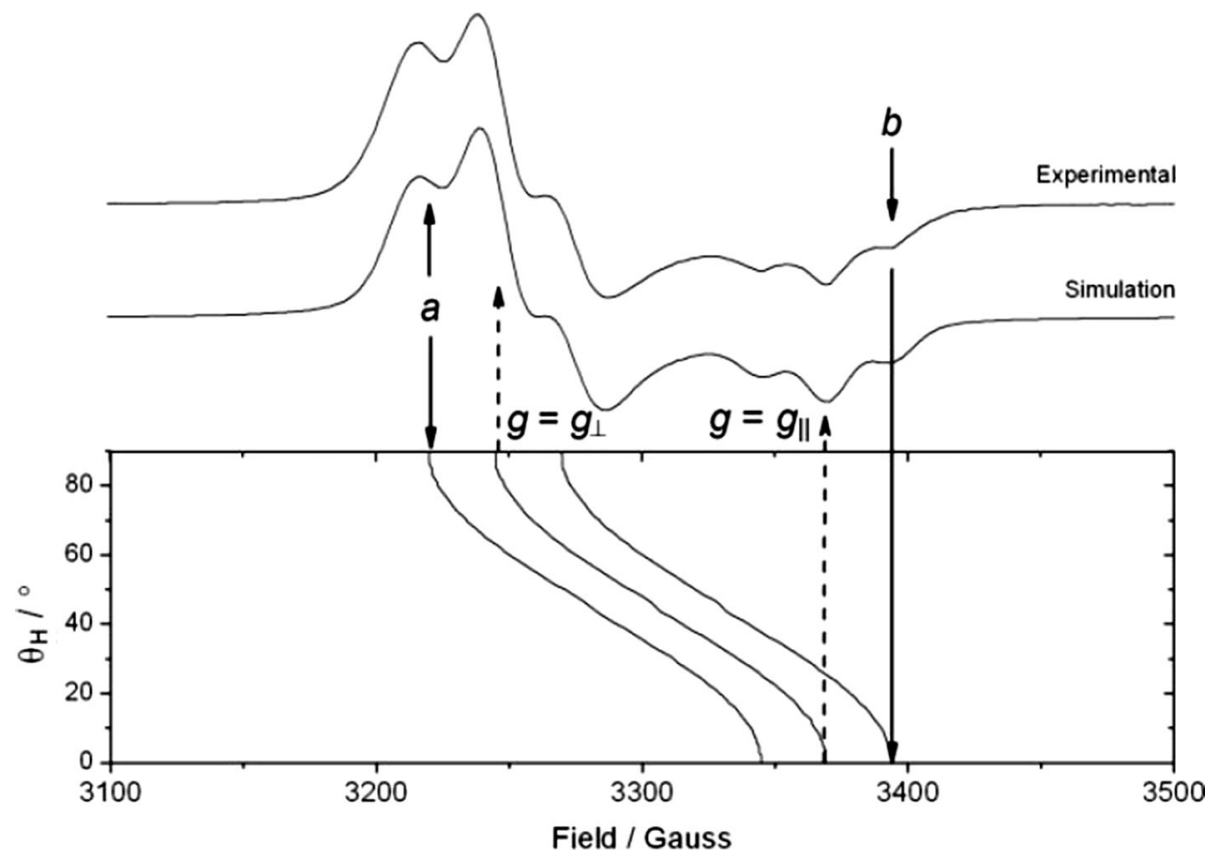

$$
\mathrm{S}\left(\mathrm{CH}_{2} \mathrm{CH}_{2} \mathrm{SC}_{10} \mathrm{H}_{21}\right)_{2}\left(\mathrm{~L}^{1}\right)
$$

$\operatorname{MeC}\left(\mathrm{CH}_{2} \mathrm{SnC}_{4} \mathrm{H}_{9}\right)_{3}\left(\mathrm{~L}^{3}\right)$<smiles>CCN1CCNCCNCC1</smiles>

1-Decyl-1,4,7-triazacyclononane $\left(L^{5}\right)$

\section{$\mathrm{O}\left(\mathrm{CH}_{2} \mathrm{CH}_{2} \mathrm{SC}_{10} \mathrm{H}_{21}\right)_{2}\left(\mathrm{~L}^{2}\right)$}

$\operatorname{MeC}\left(\mathrm{CH}_{2} \mathrm{SC}_{10} \mathrm{H}_{21}\right)_{3}\left(\mathrm{~L}^{4}\right)$

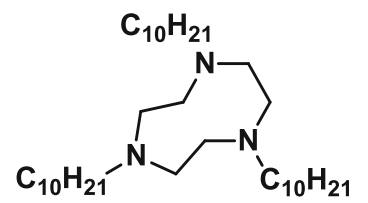

1,4,7-Tris(decyl)-1,4,7-triazacyclononane $\left(\mathrm{L}^{6}\right)$ ligand backbones in this study were tridentate S-, S/O- or $\mathrm{N}$-donor comprising of three distinct architectures (Scheme 11). The properties of the parent $\left[\mathrm{CrCl}_{3}(\mathrm{~L})\right]$ complexes were studied using cyclic voltammetry (CV), UV-Vis, EPR, EXAFS and XANES measurements. In catalysis, on activation by MMAO co-catalyst the complex with ligand $\mathrm{L}^{1}$ was selective towards ethylene trimerization, $\mathrm{L}^{3}$ and $\mathrm{L}^{4}$ produced polymers while $\mathrm{L}^{5}$ gave a SchulzFlory distribution of oligomers. For all these cases the species obtained on activation by $\mathrm{Me}_{3} \mathrm{Al}$ once again led to formation of mostly EPR silent species (Fig. 18), which points directly towards a change in oxidation state to either $\mathrm{Cr}$ (II) or $\mathrm{Cr}(\mathrm{IV})$ and substantial dissociation of the $\mathrm{S}$ and S/O-donor ligands. In this study, in addition to the EPR studies, the partial structure of the active species was resolved using EXAFS spectroscopy. However, the nature of the structural changes responsible for the difference in catalytic activity of $\mathrm{L}^{1}$ and $\mathrm{L}^{2}-\mathrm{L}^{4}$ remained somewhat unclear.

As mentioned before, a major loophole in the studies discussed so far is the fact that they were not performed under 'real' conditions of catalysis, that is, higher temperatures and high pressures of ethylene. For the first time in 2012, an operando EPR measurement of the $\mathrm{Cr}(\mathrm{I}) \mathrm{in} \mathrm{Cr} /$ PNP/MMAO solutions at $40{ }^{\circ} \mathrm{C}$ using ethylene pressures of up to 14 bar was reported for the tetramerizaton of ethylene [77]. The obtained EPR spectra are shown in Fig. 19.

In addition to the effect of total pressure, the effect of different solvents, such as cyclohexane, toluene, chlorobenzene and fluorobenzene was also analyzed and the results were correlated to catalytic activity. Once again, in addition to EPR, the presence of EPR silent $\mathrm{Cr}$ (II) species was verified through XANES/EXAFS measurements. In contrast to the studies performed before, in this case the 

of $\left[\mathrm{CrCl}_{3}\left(\mathrm{~L}_{6}\right)\right]$ in toluene$\mathrm{CH}_{2} \mathrm{Cl}_{2}$ before (blue) and after (red) treatment with three molar equivalents of $\mathrm{Me}_{3} \mathrm{Al}(115 \mathrm{~K})$, $\mathrm{g}=1.98$ (EPR spectra reproduced with permission from Ref. [76])
Fig. 18 EPR spectra (Q-band)
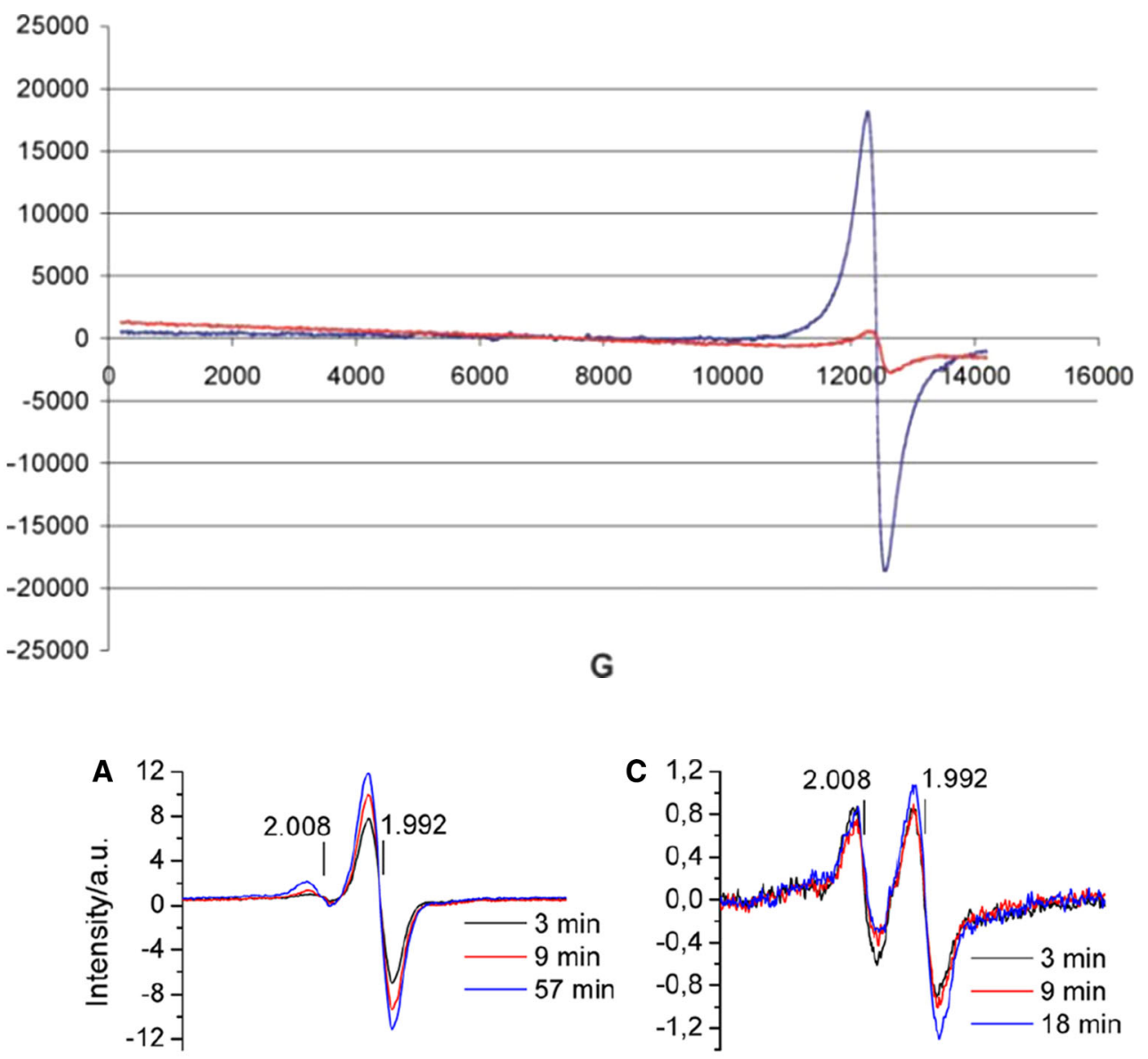
$\mathrm{PNP} / \mathrm{MMAO}$ in cyclohexane at $40{ }^{\circ} \mathrm{C}$ recorded at different reaction times (a) without pressurizing the reactor with $\mathrm{C}_{2} \mathrm{H}_{4}$ (blind experiment) and applying ethylene at different pressures: $\mathrm{p}\left(\mathrm{C}_{2} \mathrm{H}_{4}\right)=($ b) 5 (c) 10 , and (d) 14 bar (EPR spectra reproduced with permission from Ref. [77])

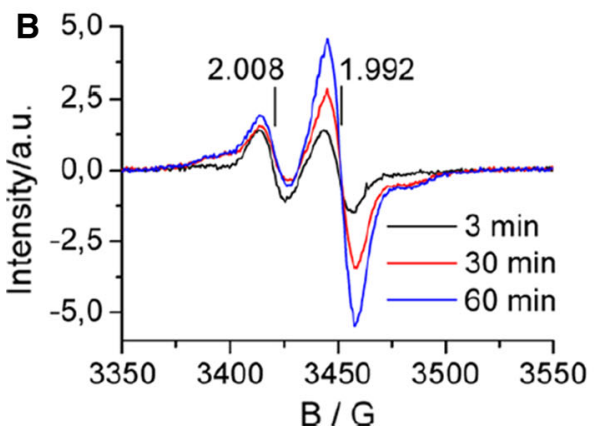

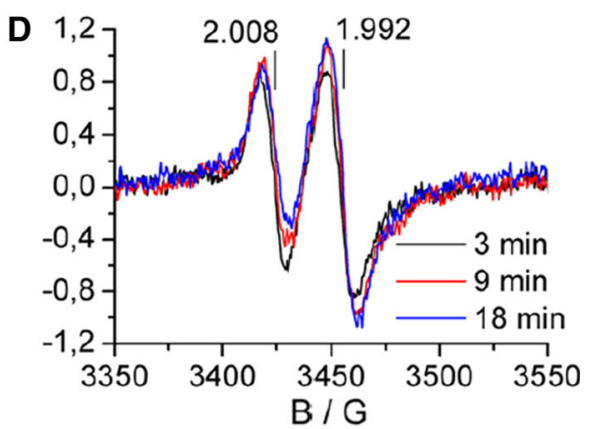

EPR data combined with the XAS data suggest that the tentative species formed in situ upon adding MMAO is actually an EPR silent (PNP) $\mathrm{Cr}(\mathrm{II})\left(\mathrm{CH}_{3}\right)_{2}$ complex. The authors suggest that depending on the mode of coordination of ethylene, the reactions could pass through a $\mathrm{Cr}(\mathrm{II}) /$ $\mathrm{Cr}(\mathrm{IV})$ or a $\mathrm{Cr}(\mathrm{II}) / \mathrm{Cr}(\mathrm{III})$ redox cycle (Scheme 12). Deeper reduction to $\mathrm{Cr}(\mathrm{I})$ was suggested to be a deactivation pathway rather than a productive route.

As reported earlier, in toluene solutions, $\mathrm{Cr}(\mathrm{acac})_{3}$ is completely transformed into a PNP-free $\mathrm{Cr}(\mathrm{I})$ complex in the absence of ethylene [73], and the same is observed at 14 bar $\mathrm{C}_{2} \mathrm{H}_{4}$. The obtained spectra are shown in Fig. 20 . The effect of the solvents on the catalytic system can be rationalized from the proposed scheme. In toluene, solvent coordination is so effective that even at 14 bar ethylene the deactivation route to the $\mathrm{Cr}(\mathrm{I})$ sandwich complex $\left.\left[\mathrm{Cr}(\text { toluene })_{2}\right)\right]^{+}$dominates almost completely over the active cycle, and the metalla-cyclic intermediate might have a negligible lifetime (this was also suggested by additional kinetic measurements). This hypothesis is in accordance with previously reported studies on similar complexes. In weaker coordinating aromatic solvents like chloro- and fluorobenzene, the active cycle is favored over the deactivation route. Although EPR and XAS measurements seem to be complimentary techniques to study the ethylene oligomerization catalysts, it should be borne in 
Scheme 12 Proposed reaction pathways based on operando EPR and X-ray absorption studies

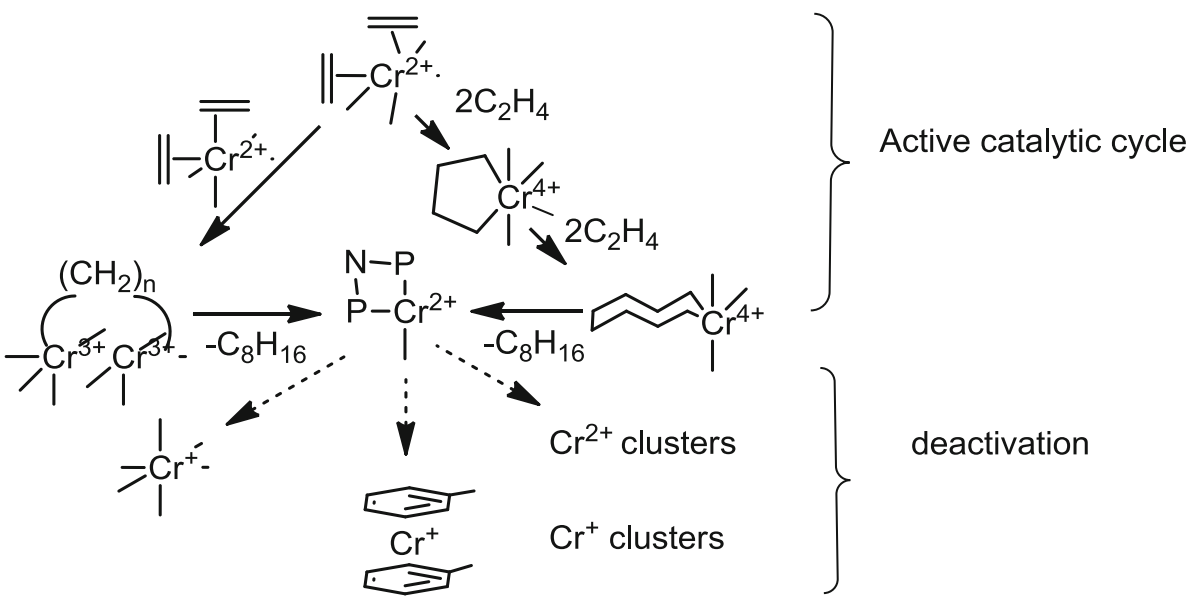

points to a $\mathrm{Cr}(\mathrm{I})-\mathrm{Cr}(\mathrm{III})$ cycle for the trimerization reactions.

\section{Atom Transfer Radical Polymerization}

Radical polymerization is employed to produce annually around 100 million tons of polymers of different compositions and properties. A controlled way of conducting these radical polymerization techniques has led to the development of advanced materials with tunable molecular architectures and consequently very specific physical properties. The term commonly used for such controlled radical polymerization is reversible-deactivation radical polymerization (RDRP). The challenging aspect of controlling these processes is that two radicals always terminate at a very fast, diffusion-controlled rate, but can be reversibly regenerated. Thus, it is important to achieve dynamic equilibria between activation and deactivation pathways. One way to do this is by making sure that the propagating radicals are deactivated in a dormant state from which they can be intermittently reactivated in a catalytic manner. When this is the case, the process is called atom transfer radical polymerization (ATRP). The equilibrium in the ATRP process is depicted in Scheme 13.

ATRP is such a catalytic process and is in most cases mediated by a redox event of $\mathrm{Cu}$ complexes with $\mathrm{Cu}^{\mathrm{I}} / \mathrm{L}$ and $\mathrm{X}-\mathrm{Cu}^{\mathrm{II}} / \mathrm{L}$ (for example, $\mathrm{L}=2,2^{\prime}$-bipyidine) species. The $\mathrm{Cu}^{\mathrm{II}}$ species act as deactivators that moderate the reaction rates and are responsible for maintaining low polydispersities in the polymer. The halogenated initiator reacts with the diamagnetic $\mathrm{Cu}(\mathrm{I})$ complex to form an initiating radical and a paramagnetic copper(II) species. EPR studies on these systems were conducted in the late 1990s and some insight on the role of copper as a catalyst was gained. Estimated concentrations of $\mathrm{Cu}$ (II) species in ATRP systems initiated by 1-phenylethyl bromide and benzyl 
Scheme 13 Proposed mechanism of $\mathrm{Cu}$ - mediated ATRP

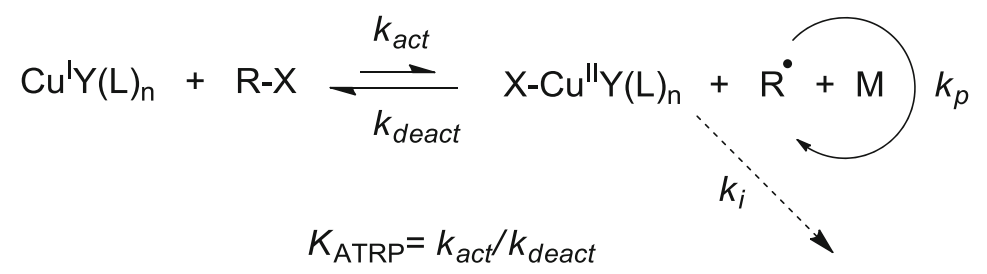

$\mathrm{R}-\mathrm{R} ; \mathrm{RH} \& \mathrm{R}^{=}$

$(\mathrm{L})_{n}$, ligand; R-X initiator, $\mathrm{M}$ monomer; $k_{p}$, propagation rate coefficient; $k t$, termination rate coefficient; R-R, radical-radical combination product; $\mathrm{R}^{\mathrm{H}}$ and $\mathrm{R}^{=}$, saturated and unsaturated product, respectively, of radical-radical disproportionation.

bromide were found to be about 4-6\% relative to $\mathrm{Cu}(\mathrm{I})$ source added, and this information was obtained using EPR spectroscopy, by following the growing concentration of paramagnetic $\mathrm{Cu}(\mathrm{II})$ species over time (Fig. 21) [79]. This also implies that only 5-6\% of the chains terminated and $95 \%$ of the chains were in the dormant state and capable of further growth. By combining the EPR experiments with simultaneous kinetic studies it was concluded that a critical concentration of $\mathrm{Cu}(\mathrm{II})$ species is required to control the ATRP systems [80]. The same was also studied for the ATRP of (meth)acrylates [81] and once again correlation with kinetics [82] led to the same conclusion about the critical concentration of $\mathrm{Cu}(\mathrm{II}) \mathrm{Br}$ that controls the reaction. EPR studies on the ATRP of poly(ethylene glycol) dimethacrylate have also been performed, and the presence of radical intermediates was confirmed [83]. Interestingly, at around $40 \%$ conversion the ATRP was found to proceed in a living manner as expected. However, further on in the reaction, the increased diffusion resistance was found to restrict the mobility of the catalyst/ligand complexes and interrupt the equilibrium between the growing radicals and the dormant species leading the polymerization to proceed via a conventional free radical pathway. First attempts to actually characterize the $\mathrm{Cu}(\mathrm{II}) \mathrm{L}$ ( $\mathrm{L}=$ bipyridine-type ligand) complex involved was reported in 2003, and once again EPR studies were used for this [84]. With 1 or 2 equivalents of either dNbpy or d $n$ Nbpy ligands (Scheme 14) $\mathrm{Cu}(\mathrm{II}) \mathrm{Br}_{2}$ forms predominantly the neutral complexes $\mathrm{Cu}$ (II) (dNbpy) $\mathrm{Br}_{2}$ and $\mathrm{Cu}(\mathrm{II})(\mathrm{d} n \mathrm{Nbpy}) \mathrm{Br}_{2}$, respectively. Bromine atom transfer between $\left[\mathrm{Cu}(\mathrm{I})(\mathrm{d} n \mathrm{Nbpy})_{2}\right]^{+}\left[\mathrm{Cu}(\mathrm{I}) \mathrm{Br}_{2}\right]^{-}$and ethyl 2-bromoisobutyrate (EBriB) in methyl isobutyrate (MIB) does not yield $\mathrm{Cu}(\mathrm{II})(\mathrm{d} n \mathrm{Nbpy}) \mathrm{Br}_{2}$. Instead, it leads to the complex $\left[\mathrm{Cu}(\mathrm{II})(\mathrm{d} n \mathrm{Nbpy})_{2} \mathrm{Br}\right]^{+}\left[\mathrm{Cu}(\mathrm{I}) \mathrm{Br}_{2}\right]^{-}$as depicted in Scheme 15.

The latter species is also formed in an equilibration reaction of $\mathrm{Cu}(\mathrm{II})(\mathrm{d} n \mathrm{Nbpy}) \mathrm{Br}_{2}$ with $\left[\mathrm{Cu}(\mathrm{I})(\mathrm{d} n \mathrm{Nbpy})_{2}\right]^{+}$ $\left[\mathrm{Cu}(\mathrm{I}) \mathrm{Br}_{2}\right]^{-}\left(K \geq 100 \mathrm{M}^{-1 / 2}, 23^{\circ} \mathrm{C}, \mathrm{MIB}\right)$. Therefore, the concentration of the $\mathrm{Cu}(\mathrm{I}) \mathrm{Br}_{2}$-anion, which is a counterion to both the $\mathrm{Cu}(\mathrm{I})(\mathrm{bpy})^{2+}$ and $\mathrm{Cu}(\mathrm{III})(\mathrm{bpy})_{2} \mathrm{Br}^{+}$cations, should
$0 \mathrm{~min}$

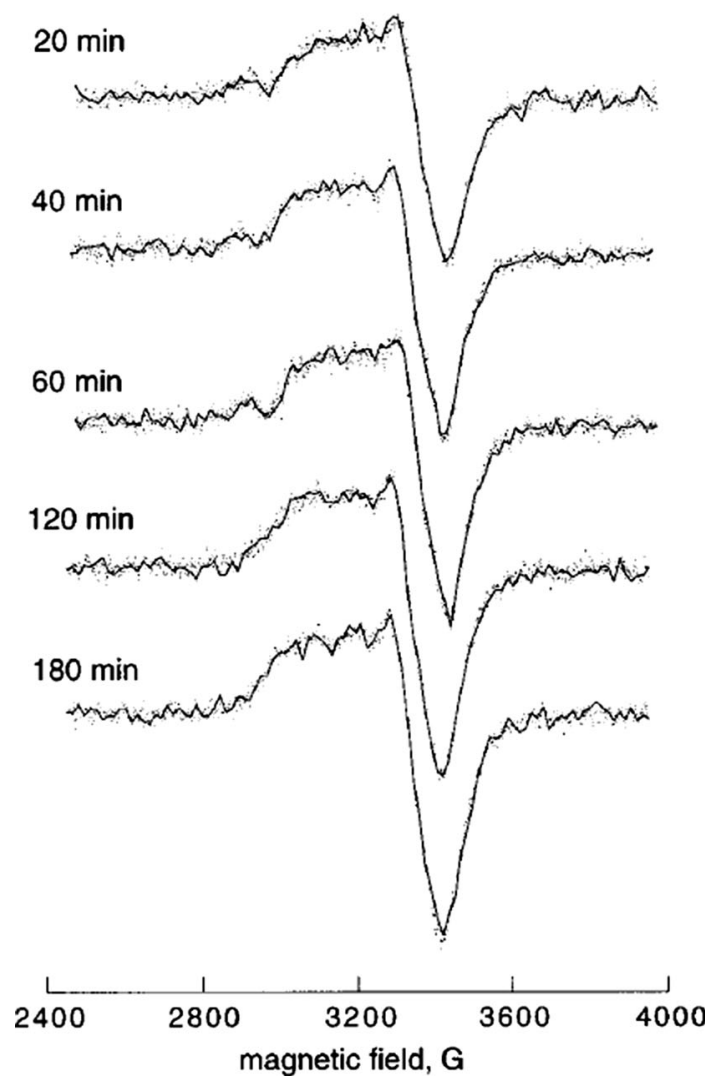

Fig. 21 EPR spectra of the polymerization mixture measured at $25^{\circ} \mathrm{C}$ after $0,20,40,60,120$, and $180 \mathrm{~min}$ at $110{ }^{\circ} \mathrm{C}$. Styrene/ 1-phenylethyl bromide/CuBr/dNbipy $(=100 / 1 / 1 / 2)$ in toluene (50 vol\%).(EPR spectra reproduced with permission from Ref. [79])

be subtracted from the concentration of the initially added $\mathrm{Cu}(\mathrm{I})$ precursor in interpretation of kinetic data $\left.\left(\left[\mathrm{Cu}(\mathrm{I})(\mathrm{bpy})_{2}^{+}\right]=[\mathrm{Cu}(\mathrm{I}) \mathrm{Br}]_{0}-\left[\mathrm{Cu}(\mathrm{II}) \mathrm{Br}_{2}\right]_{0}\right) / 2\right)$. This study therefore pointed out that the earlier reports on the value of $\mathrm{k}_{\mathrm{act}}$ required correction, as the concentration of the $\mathrm{Cu}(\mathrm{I})(\mathrm{bipy})_{2}$ species should lower than originally anticipated. 
Apart from studying the initiating $\mathrm{Cu}$ halides with EPR, the propagating species in ATRP were also studied with EPR spectroscopy [85, 86]. Model radicals were generated through the reaction of organotin compounds with radical precursors prepared by atom transfer radical addition (ATRA) or atom transfer radical polymerization (ATRP). Dimers of various (meth)acrylate units, MA, tert-butyl acrylate (tBA) and MMA, MA-MA-Br, MA-tBA-Br, tBAtBA-Br, MMA-tBa-Br and MA-MMA-Br were prepared by ATRA. These dimers provided radicals mimicking the active species in a radical copolymerization of MA, MMA and tBA. From the EPR spectra the electronic and steric effects of the penultimate unit on the propagating radical could be determined. The dimeric model radicals are described below as an example to demonstrate the use of EPR spectroscopy to study these effects. Dimeric radicals with an acrylate terminal group were generated in the reaction of the corresponding alkyl bromides for example, tBA-tBA-Br and so on with an organotin compound under irradiation. The resulting hydrogenated dimeric radicals were studied through EPR and are shown in Fig. 22.

On comparing the EPR spectra of MMA-tBA with that of H-MA-tBA the effect of the methacrylate penultimate unit can be seen. The presence of MMA unit shows only

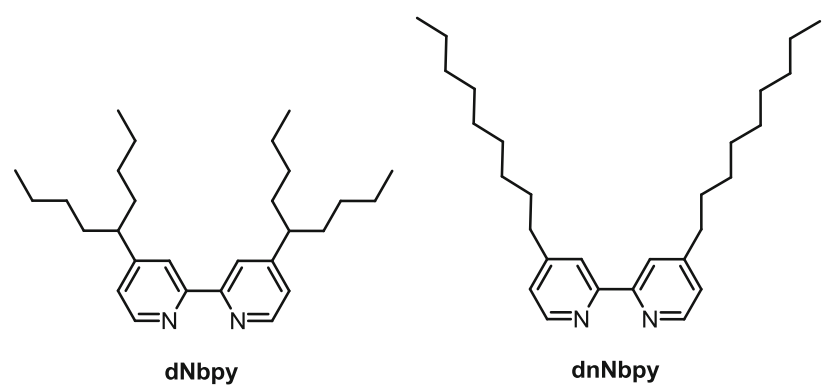

Scheme 14 The ligands 4,4'-Di(5-nonyl)-2,2'-bipyridine (dNbpy) and $4,4^{\prime}$-Di- $n$-nonyl-2,2'-bipyridine (d $n \mathrm{Nbpy}$ ) applied in copperbased ATRP small variations in the couplings of the $\alpha$ proton. Obviously, the spin density at the $\alpha$ carbon atom does not change appreciably by $\beta$ substitution. On the other hand, the couplings of $\beta$-methylene protons vary considerably with the presence of an MMA penultimate unit. The value of hfc at $\beta$-methylene protons for H-MMA-tBA (2.210 $\mathrm{mT})$ is smaller than that of H-MA-tBA $(2.270 \mathrm{mT})$ or of H-tBA-tBA (2.270 mT). The electronic effect of a penultimate MMA unit is larger than those of substituents. These findings show an electron-withdrawing effect of the MMA unit. Steric effects caused by the presence of the $\gamma$ methyl group may be the cause of a broader line width than in the case of H-MA- $t \mathrm{BA}$. In comparison with the EPR spectrum of H-MA- $t \mathrm{BA}$, the steric effect of $\mathrm{H}-t \mathrm{BA}-t \mathrm{BA}$ appeared in the line width of the spectrum, although the electronic effect of replacement of a methyl group by a tert-butyl group is very small. Sterically, the small ester methyl group of MA caused less hindrance to the rotation of the $\mathrm{C}_{\beta}-\mathrm{C}_{\alpha}$ bond. As a result, a clear separation of spectroscopic lines, due to narrower line width, was observed. This difference in the EPR spectra between $\mathrm{H}-\mathrm{MMA}-t \mathrm{BA}$ and $\mathrm{H}-t \mathrm{BA}-t \mathrm{BA}$ suggests that the reactivity of the terminal $t \mathrm{BA}$ radical may depend on the penultimate unit in copolymerizations of MMA and $t \mathrm{BA}$.

The state of the art method of measuring the rate coefficients of radical polymerization today is the pulsed laser polymerization (PLP) technique. During PLP a high concentration of radicals is achieved almost instantaneously via photoionization using an excimer laser pulse. PLP can also be carried out in conjunction with highly time-resolved near-infrared spectroscopy allowing time-resolved measurements following the evolution of the monomer concentration in time after firing a single laser pulse (SP). Combining EPR spectroscopy with PLP and SP to study radical polymerization techniques is an extremely valuable tool, in which the decay of radical concentrations subsequent to applying a laser pulse is monitored. In addition, SP-PLPEPR also allows for measuring the kinetics of different types

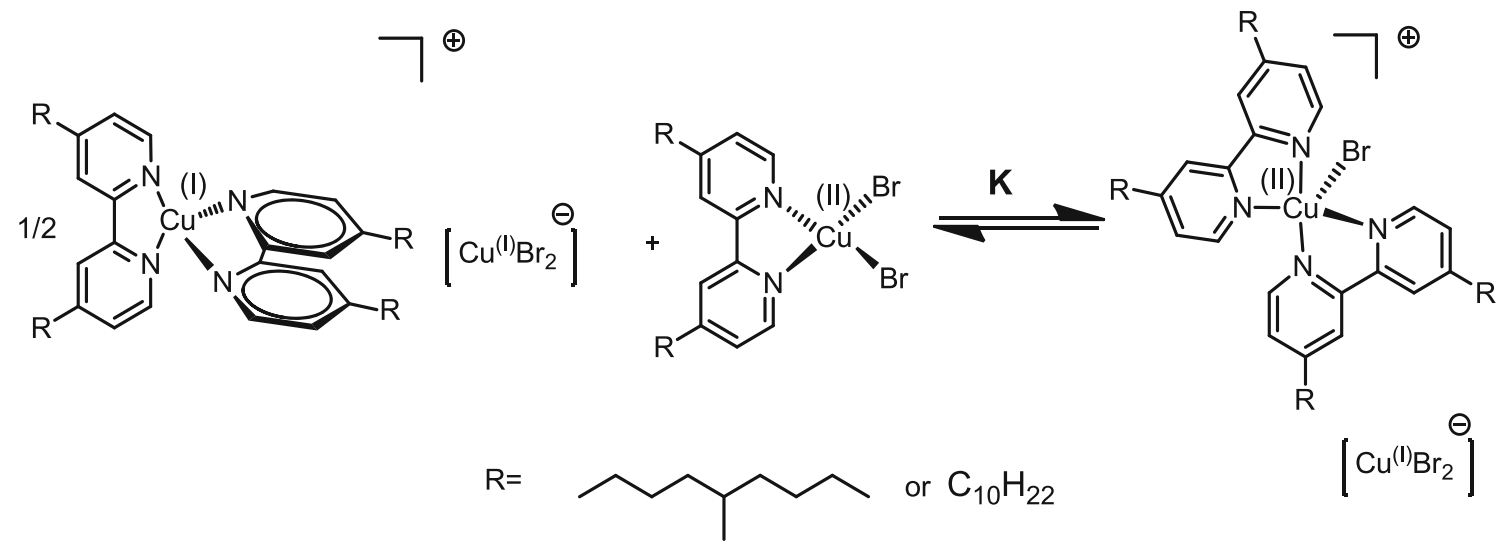

Scheme 15 Proposed equilibrium for the reaction of $\left[\mathrm{Cu}^{\mathrm{I}}(\mathrm{d}(n) \mathrm{Nbpy})_{2}\right]^{+}\left[\mathrm{Cu}^{\mathrm{I}} \mathrm{Br}_{2}\right]^{-}$with $\mathrm{Cu}^{\mathrm{II}}(\mathrm{d}(n) \mathrm{Nbpy}) \mathrm{Br}_{2}$ 
Fig. 22 EPR spectra of dimeric model radicals generated from corresponding alkyl bromides observed at $30{ }^{\circ} \mathrm{C}$ : a $\mathrm{H}-$ tBAtBA; b H-MA-tBA; $\mathbf{c}$ HMMA-tBA; and d H-MA-MA: Spectroscopic lines appearing at the center of the spectra (indicated by dashed line) are due to radicals of tin compounds (EPR spectra reproduced with permission from Ref. [85, 86])
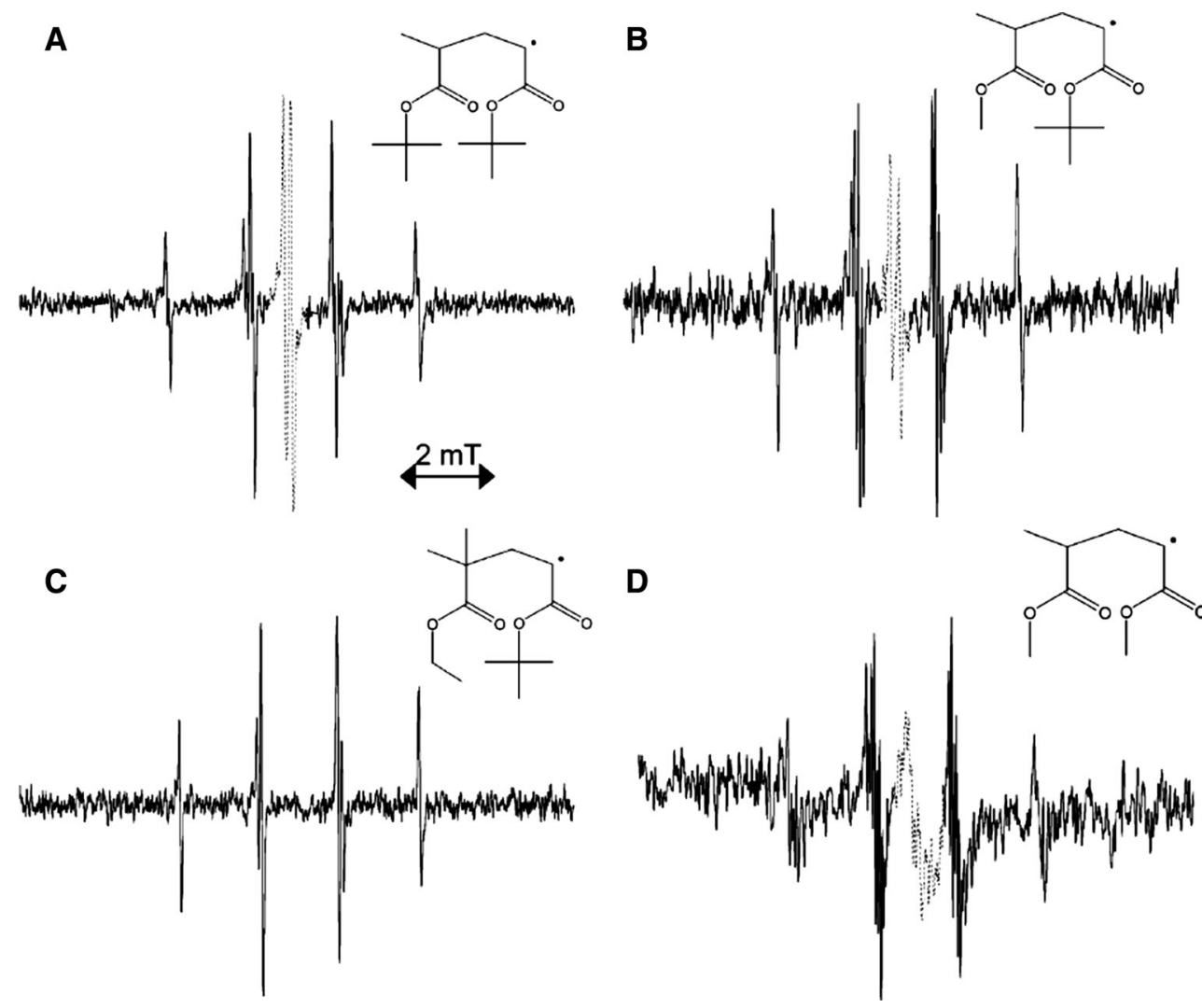

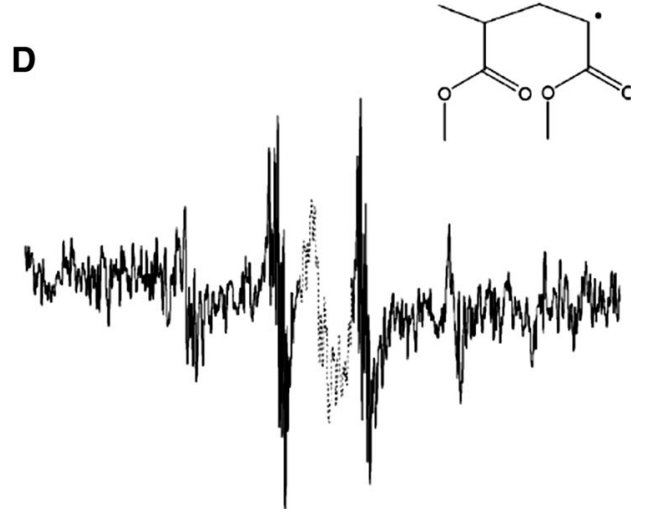

of radical species that may evolve after laser-induced production of primary radical fragments. Figure 23 shows the EPR spectra of $\mathrm{Cu}^{\mathrm{II}}$ species and $n$-dodecyl methacrylate (DMA) macroradicals formed during laser-initiated polymerization at $0{ }^{\circ} \mathrm{C}$ with $351 \mathrm{~nm}$ laser pulses with a repetition rate of $20 \mathrm{~Hz}$. The EPR concentrations of the $\mathrm{Cu}^{\mathrm{II}}$ species obtained from the EPR measurements were converted to absolute radical concentration by calibration against TEMPO [87]. The details of the kinetic treatment of the data obtained from all these three techniques combined together is beyond the scope of this review, but it is definitely worth pointing out that EPR in conjunction with other techniques like PLP and SP is of interest, allowing rapid radical production and subsequent monitoring of terminating and deactivating paramagnetic species.

\section{Photocatalytic Water Splitting and Spin Trapping Experiments}

The above Sects. 2, 3 and 4 of this review are focused on the use of EPR spectroscopy in mechanistic studies of C-C and $\mathrm{C}-\mathrm{N}$ bond formation reactions mediated by organometallic catalysts. In this section, a few selected examples are highlighted involving the application of EPR

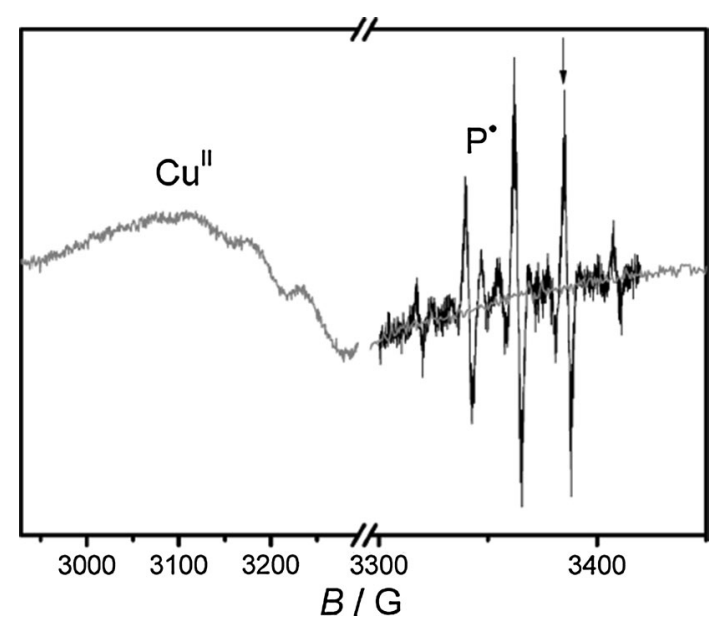

Fig. 23 EPR spectra of $\mathrm{Cu}^{\mathrm{II}}$ species (gray line) and DMA macroradicals (black line) during laser-initiated polymerization at $0{ }^{\circ} \mathrm{C}$ with $351 \mathrm{~nm}$ laser pulses being applied at a repetition rate of $20 \mathrm{~Hz}$. The arrow indicates the magnetic field position at which time-resolved experiments were carried out (EPR spectra reproduced with permission from Ref. [87])

spectroscopy in a few other catalytic reactions such as photocatalytic water splitting and related reactions in which metal initiated radical formation plays a role. EPR spectroscopic investigation in this area of research are 
dominated by EPR spectroscopic studies in isotropic solutions, including spin trapping experiments.

\subsection{Spin-Trapping Experiments and Their Relevance in EPR Studies of Photoinitiators}

Spin trapping is a technique first used in the 1960s for the detection of short lived free radicals, which combines the use of EPR spectroscopy and the chemical reactivity of specific compounds called spin traps. By reacting a spin trapping reagent with a free radical, a more stable spin adduct is formed which is persistent enough to be detected by EPR measurements. Traditionally, the most used spin trap reagents are nitrones and nitroso compounds, such as alpha-phenyl $N$-tertiary-butyl nitrone (PBN) and 5,5dimethyl-pyrroline $N$-oxide (DMPO) (Fig. 24), which upon reacting with a free radical generate rather stable (persistent or long-lived) nitroxide radicals. Analysis of the hyperfine splitting parameters of the adduct provide important information about the nature of the original radical. Spin trapping has been extensively reviewed in the past [88-91].

An interesting overview of electron spin resonance spin trapping technique (EPR-ST) has been described by Lalevée and coworkers for detecting radicals formed during the cleavage of photoinitiators [92]. The hyperfine splitting constants for the different adducts with PBN or DMPO were measured and a new set of data has been provided. Lacôte, Lalevée et al. developed a procedure for the synthesis of $\mathrm{N}$-heterocyclic carbene-boryl radicals (NHC$\mathrm{BH}_{2}$ ) upon visible light irradiation under mild conditions [93]. Three component initiating systems containing acridine orange(AO)/diphenyl sulfide/ $\mathrm{NHC}-\mathrm{BH}_{3}$ have been successfully used for the visible light photopolymerization of trimethylpropane triacrylate. EPR-spin trapping experiments have been performed to study these systems and detection of the nitroxide adduct formed by the addition of the $\mathrm{NHC}-\mathrm{BH}_{2}$ to $\mathrm{PBN}$ (hyperfine coupling constants hfc $a_{\mathrm{N}}=15.2 \mathrm{G}, a_{\mathrm{H}}=2.3 \mathrm{G}$, and $a_{\mathrm{B}}=4.3 \mathrm{G}$, Fig. 25) has been observed.

Another use of NHC-borane radicals has been reported by Curran and coworkers and involves boron-based radical hydrogen transfer [94]. Reductions and reductive cyclizations are catalyzed by thiophenol with 1,3-dimethylimidazol-2-ylidene borane $\left(\mathrm{NHC}-\mathrm{BH}_{3}\right)$ and a water-soluble triazole derivative. The PBN spin trap has been used to characterize the radical intermediates.

Other examples of photoinitiators have been presented by Lalevée et al., which are based on silyl radical chemistry [95] or copper complexes [96]. Two examples, PI-A and PI-B are presented in Fig. 26, and their ability to initiate both free radical polymerization and free radical promoted cationic polymerizations has been investigated.<smiles>CC(C)(C)[N+]([O-])=Cc1ccccc1</smiles><smiles>CC(C)(C)[N+]1=CCCC1(C)O</smiles><smiles>[R]C(c1ccccc1)N([O-])C(C)(C)C</smiles><smiles>[R]C1CCC(C)(C)N1OC</smiles>

Fig. 24 Most popular spin trapping reagents

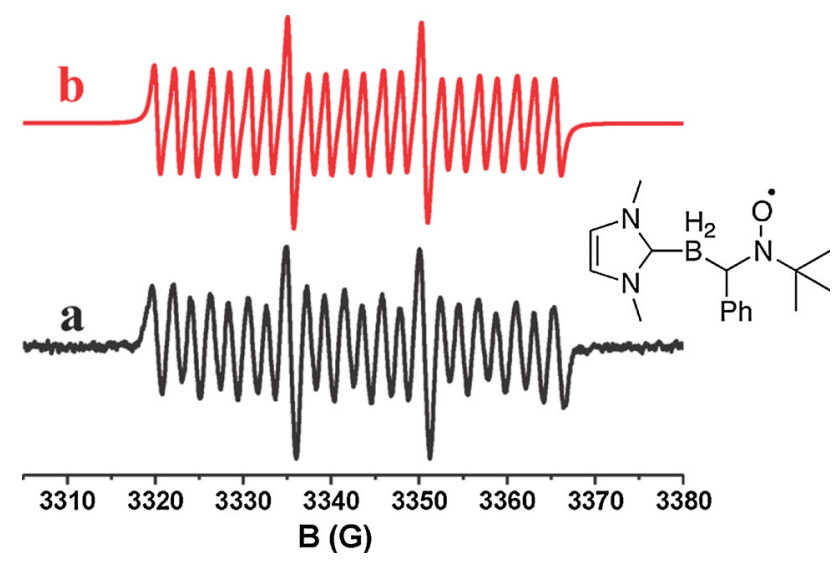

Fig. 25 EPR-ST experimental ( $a$, black) and simulated (b, red) spectra from halogen-lamp irradiation of acridine orange/ $\mathrm{PhS}-\mathrm{SPh} /$ NHC-BH 3 (PBN spin trap agent, in tert-butylbenzene) (EPR spectra reproduced with permission from Ref. [94])

Direct UV irradiation without the use of a photosensitizer involved $\mathrm{Si}-\mathrm{Si}, \mathrm{Si}-\mathrm{C}$, and $\mathrm{Si}-\mathrm{S}$ bond breaking, and trapping with PBN afforded the EPR spectrum shown in Fig. 26 (hyperfine coupling constants $a_{\mathrm{N}}=14.8 \mathrm{G}$ and $a_{\mathrm{H}}=6.1$ $\mathrm{G})$. Formation of silyl radical species was concluded based on the detection of large $a_{\mathrm{N}}$ and $a_{\mathrm{H}}$ HFI values.

\subsection{Photocatalytic Water Splitting}

Sunlight driven water splitting is an important society driven endeavor which has received a lot of attention in the past decade from the scientific community [97, 98]. Significant efforts have been undertaken to improve the activity and stability of homogeneous catalysts, as well as developing new ones [99, 100]. The overall process for water splitting can best be described as two half reactions: water reduction [101] and water oxidation [102]. EPR spectroscopy has been used as a valuable tool in detecting radical intermediates involved in these reactions, especially for $1^{\text {st }}$ row transition metal-based catalysts. For each half 


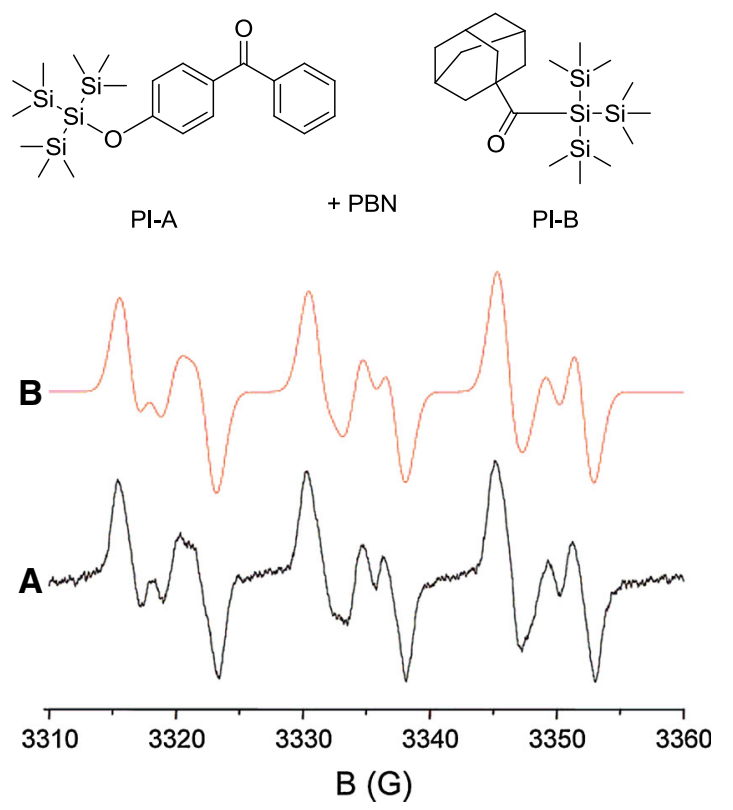

Fig. 26 Two examples of photoinitiators based on silyl radical chemistry (PI-A, PI-B) and ESR-ST experiments with PBN $(0.05 \mathrm{M})$ under the UV light irradiation of PI-A $(0.01 \mathrm{M})$ at $\lambda>310 \mathrm{~nm}$ : experimental $(A)$ and simulated $(B)$ spectra (EPR spectra reproduced with permission from Ref. [95])

reaction, one example involving the use of EPR spectroscopy is discussed in this subchapter.

An important example of water reduction in which EPR spectroscopy has been used in combination with Raman Spectroscopy and DFT studies has been published by Ludwig et al. [103]. The catalytic system consists of the iridium complex $\left[\operatorname{Ir}(\mathrm{ppy})_{2}-(\mathrm{bpy})\right] \mathrm{PF}_{6}$ (ppy $=2$-phenylpyridine, bpy $=2,2^{\prime}$-bipyridine) used as a photosensitizer (IrPS), $\left[\mathrm{Fe}_{3}(\mathrm{CO})_{12}\right]$ as the water-reduction catalyst (WRC), and triethylamine (TEA) as a sacrificial reductant. To gain insight in the catalytic cycle, the reaction was monitored by in situ EPR/Raman spectroscopy. As shown in Fig. 27a, $\left[\mathrm{Fe}_{3}(\mathrm{CO})_{12}\right]$ in THF without photosensitized irradiation is EPR silent. In contrast, in combination with the IrPS in THF/TEA/ $\mathrm{H}_{2} \mathrm{O}$ (8:2:1) even without irradiation (Fig. 27b), already three radical species appear in the EPR spectrum: $\left[\mathrm{Fe}_{3}(\mathrm{CO})_{11}\right]^{--}$at $\mathrm{g}=2.0497,\left[\mathrm{Fe}_{2}(\mathrm{CO})_{8}\right]^{--}$at $\mathrm{g}=2.0385$ and $\left[\mathrm{Fe}_{3}(\mathrm{CO})_{12}\right]^{-}$at $\mathrm{g}=2.0016$. From the spectrum a 66:32:1 ratio of the three radicals can be extracted, with a total initial spin concentration of $94 \%$ of the overall iron content. During irradiation, all three radical species disappear, but a new triplet appears (Fig. c) which is assigned to $\left[\mathrm{H}_{2} \mathrm{Fe}_{2}(\mathrm{CO})_{7}\right]^{-}(\mathrm{g}=2.0433, \mathrm{~A}(\mathrm{H})=22.3 \mathrm{G}, \Delta \mathrm{B}=$ $2.36 \mathrm{G})$. However, the major iron component in solution was determined based on Raman and IR measurements to be the diamagnetic species $\left[\mathrm{HFe}_{3}(\mathrm{CO})_{11}\right]^{-}$, as the intensity of the EPR signal represents only $3 \%$ of the total iron content. Using DFT, a detailed mechanism has been proposed in which the active species for hydrogen production

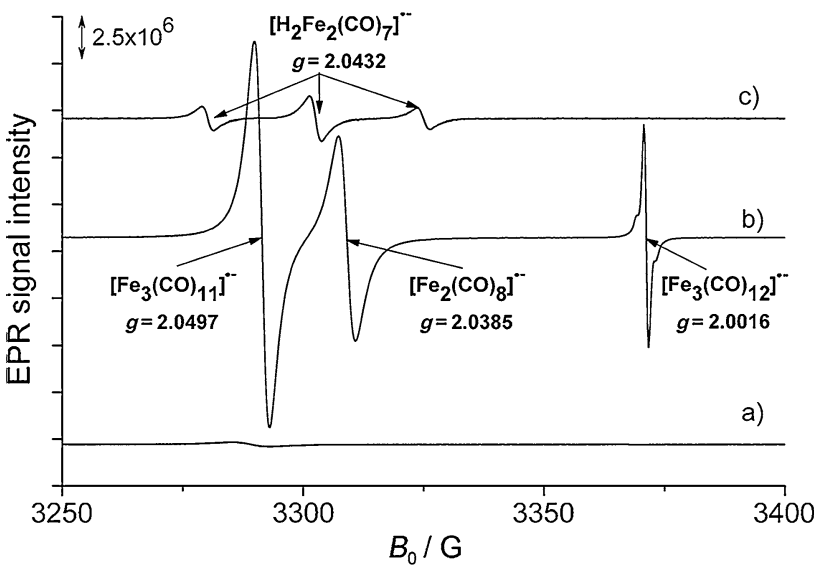

Fig. 27 EPR signals of iron-based radicals: $a\left[\mathrm{Fe}_{3}(\mathrm{CO})_{12}\right]$ in THF; $b\left[\mathrm{Fe}_{3}(\mathrm{CO})_{12}\right]$ and IrPS in THF/TEA/ $\mathrm{H}_{2} \mathrm{O}(8: 2: 1)$ without irradiation; $c\left[\mathrm{Fe}_{3}(\mathrm{CO})_{12}\right]$ and IrPS in THF/TEA/ $\mathrm{H}_{2} \mathrm{O}$ (8:2:1) after $2 \mathrm{~min}$ irradiation (EPR spectra reproduced with permission from Ref. [103])

is $\left[\mathrm{HFe}_{3}(\mathrm{CO})_{11}\right]^{-}$, obtained from $\left[\mathrm{Fe}_{3}(\mathrm{CO})_{11}\right]^{--}$by electron transfer from $\mathrm{IrPS}^{-}$and subsequent proton transfer.

EPR spectroscopy used in water oxidation has been exemplified by Wang et al. [104] who synthesized the dinuclear cobalt complex [(TPA) $\mathrm{Co}(\mu-\mathrm{OH})\left(\mu-\mathrm{O}_{2}\right)$ $\mathrm{Co}(\mathrm{TPA})]\left(\mathrm{ClO}_{4}\right)_{3} \quad(\mathrm{TPA}=$ tris$(2$-pyridylmethyl)amine $)$ (Scheme 16), which is a very good electrochemical and photochemical water oxidation catalyst. Oxygen evolution is observed under visible light irradiation at an overpotential of $540 \mathrm{mV}$ at $\mathrm{pH}=8$, in the presence of $\left[\mathrm{Ru}(\mathrm{bpy})_{3}\right]^{-}$as a photosensitizer and $\mathrm{Na}_{2} \mathrm{~S}_{2} \mathrm{O}_{8}$ as the electron acceptor. EPR spectroscopy has been performed before and after irradiation of samples containing the dinuclear cobalt catalyst, $\left[\mathrm{Ru}(\mathrm{bpy})_{3}\right]^{-}$and $\mathrm{S}_{2} \mathrm{O}_{8}{ }^{2-}$ in borate buffer. In the dark, the mixture is EPR silent, consistent with the expected $\mathrm{Co}^{\mathrm{III}} \mathrm{Co}^{\mathrm{III}}$ ground state of the catalyst. After one laser flash at $532 \mathrm{~nm}$, a signal at $\mathrm{g}=2.03$ arises, which is attributed to the mixed valent $\mathrm{Co}^{\mathrm{III}} \mathrm{Co}^{\mathrm{IV}}$ species (Fig. 28). By applying an increased number of laser flashes, the signal of the $\mathrm{Co}^{\mathrm{III}} \mathrm{Co}^{\mathrm{IV}}$ species decreases, and a broader spectrum ranging from 2500 to $2950 \mathrm{G}$ is obtained. At least two components give rise to these EPR features, with one species centered at $\mathrm{g}=2.42$ and another at $\mathrm{g}=2.33$. The last one is believed to be a form of $\mathrm{Co}^{\mathrm{IV}}$ (O) species in cobalt oxide films. The use of EPR spectroscopy proved valuable in determining the mechanism of water oxidation using the cobalt catalyst in Scheme 16.

\section{Summary, Conclusions and Outlook}

While a plethora of homogeneous catalysts today are studied relatively easily by NMR spectroscopy there is a good range of catalysts which are paramagnetic and NMR spectroscopy doesn't reveal much. This is when EPR 
Scheme 16 Formation of a dicobalt based homogeneous water oxidation catalyst
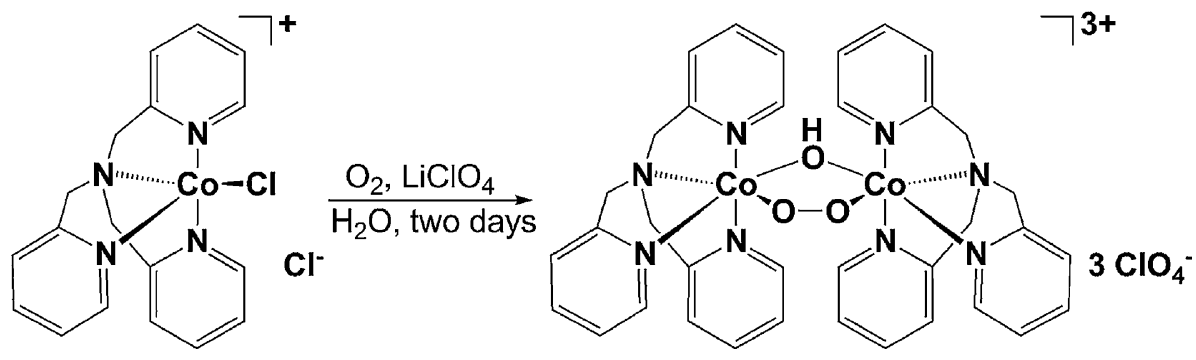

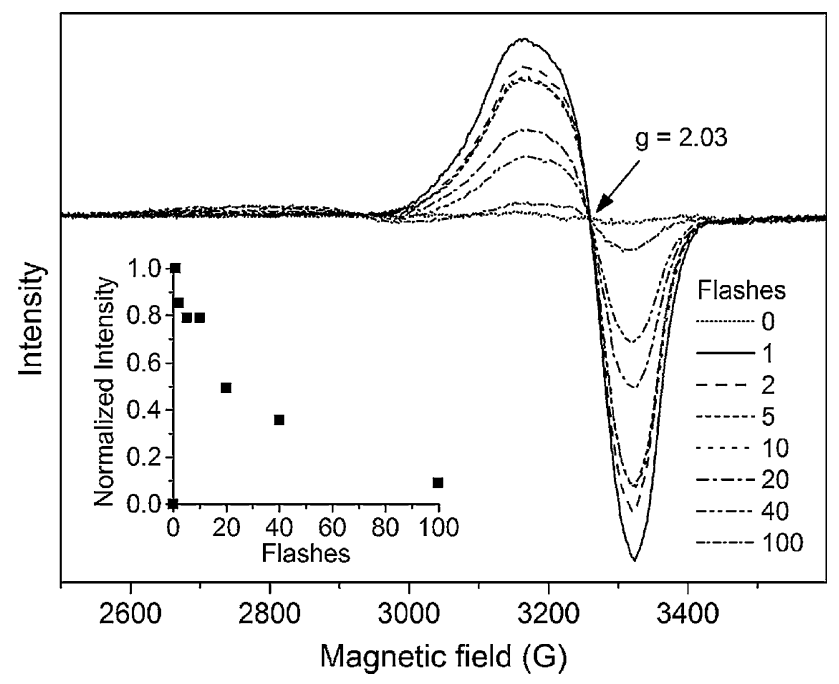

Fig. 28 EPR spectra of a mixture containing $1(52 \mathrm{~mm}),\left[\mathrm{Ru}(\mathrm{bpy})_{3}\right]^{-}$ $\left(\mathrm{ClO}_{4}\right)_{2}(0.3 \mathrm{~mm})$, and $\mathrm{Na}_{2} \mathrm{~S}_{2} \mathrm{O}_{8}(2.25 \mathrm{~mm})$ in borate buffer $(50 \mathrm{~mm}$, $\mathrm{pH} 8)$ after $0,1,2,5,10,20,40$, and 100 laser flashes $(532 \mathrm{~nm}, 6 \mathrm{~ns}$, $4 \mathrm{~W}$ ). The samples were frozen within $5 \mathrm{~s}$ after the illumination. Inset The intensity of the EPR signal centered at $\mathrm{g}=2.03$ versus the number of flashes. $\mathrm{EPR}$ parameters; $\mathrm{T}=10 \mathrm{~K}$; microwave power $=20 \mathrm{~mW}$; microwave frequency $=9.28 \mathrm{GHz}($ EPR spectra reproduced with permission from Ref. [104])

spectroscopy comes into play as it helps to probe the nature of the unpaired electron in the paramagnetic systems. EPR spectroscopy can give detailed insight in the electronic structure of an active catalysts and thus aids in understanding a catalytic process. In the first part of this review we focused on examples of catalytic reactions where the reaction pathway involved paramagnetic complexes which were studied using EPR. In most of the cases the spin density of the unpaired electron was found to be on a carbon or a nitrogen atom. It is due to EPR that the ligand/substrate non-innocence of these systems is better understood. In the other half of the review the focus was on the mechanistic studies of homogeneous catalysts involved in oligomerization and polymerization reactions. In all examples present in this review, EPR spectroscopy helped to answer questions about catalyst mode of operation leading to unusual reactivities, for example, in the cyclopropanation of the more challenging electron deficient alkenes catalyzed by Co(II)-porphyrins. Similarly, in the field of ethylene oligomerization, the final word is still to be heard about the oxidation state of $\mathrm{Cr}$ that is active in catalysis but there is no doubt that with the aid of EPR, researchers are now closer to understanding these rather elusive systems. It is also worth mentioning that EPR is now being used in conjunction with other advanced spectroscopic techniques which provide complimentary information on the system being studied. We have seen this also in the section of ATRP where the state of the art method of measuring the rate coefficients of radical polymerization, namely, PLP has been used together with EPR spectroscopy. With more and more open shell metal complexes being explored as potential catalysts, the role of EPR in the field of homogeneous catalysis is surely to be indispensable in unravelling mechanisms and characterizing intermediates.

Apart from the obvious choice to study catalytic reactions mediated by open-shell catalysts with EPR spectroscopy, the technique might have wider implications in future studies of catalytic reactions mediated by organometallic complexes. Many of these reactions start and end with diamagnetic reagents, products and complexes, but formation and catalytic involvement of paramagnetic intermediates can never be fully excluded in any catalytic reaction. Such possibilities are usually ignored, but may turn-out to be important in some of the many catalytic reactions that are currently considered to proceed via closed-shell pathways. EPR spectroscopy should thus be employed more frequently in mechanistic studies of catalytic reactions. This may well shine new light on 'established reaction mechanisms' even for reactions assumed to proceed without involvement of (metallo)radical intermediates.

Of course unraveling reaction mechanisms of catalytic reactions remains a difficult task, regardless of the (spectroscopic) method used. There is always a risk that the detected species are not the catalytically active ones, and that side-reactions or deactivation pathways are spectroscopically detected. This remains a major limitation in catalysis research in general, which also holds for EPR spectroscopic studies of catalytic reactions. In that respect, the high sensitivity of EPR spectrometers is both an 
advantage and a disadvantage. While low concentrations of active paramagnetic compounds are detectable in reactions in which catalyst activation is a limitation, such species may not represent the bulk of the (pre)catalytic material (as can be determined by spin counting) in which case it remains questionable which species truly catalyze the reaction. Future development of novel techniques that couple the formation of (diamagnetic) products formed in a catalytic reaction in a time-resolved manner to the detection of paramagnetic species would thus be helpful in that perspective (e.g. an EPR analog of KIDNP NMR experiments, but coupled to detectable EPR signals). Another major problem to solve in the future is finding ways to properly characterize catalysts and catalytic intermediates with an integer-spin electronic structure. How this should be tackled remains elusive thus far. High-field EPR helps, but (structural) information from EPR spectra of integerspin systems is limited and the signals remain difficult to detect and interpret.

Open Access This article is distributed under the terms of the Creative Commons Attribution 4.0 International License (http://crea tivecommons.org/licenses/by/4.0/), which permits unrestricted use, distribution, and reproduction in any medium, provided you give appropriate credit to the original author(s) and the source, provide a link to the Creative Commons license, and indicate if changes were made.

\section{References}

1. Van Doorslaer S, Caretti I, Fallis I, Murphy DM (2009) The power of electron paramagnetic resonance to study asymmetric homogeneous catalysts based on transition-metal complexes. Coord Chem Rev 253:2116-2130

2. Van Doorslaer S, Murphy D (2012) EPR spectroscopy in catalysis. Top Curr Chem 321:1-40

3. Mayer J (2011) Understanding hydrogen atom transfer: from bond strengths to Marcus theory. Acc Chem Res 44:36-46

4. Rebreyend C, de Bruin B (2014) Photolytic $\mathrm{N}_{2}$ splitting: a road to sustainable $\mathrm{NH}_{3}$ production? Angew Chem Int Ed Engl $54: 42-44$

5. Bokarev SI, Hollmann D, Pazidis A, Neubauer A, Radnik J, Kühn O, Lochbrunner S, Junge H, Beller M, Brückner A (2014) Spin density distribution after electron transfer from triethylamine to an $\left[\operatorname{Ir}(\mathrm{ppy})_{2}(\mathrm{bpy})\right]^{+}$photosensitizer during photocatalytic water reduction. Phys Chem Chem Phys 16:4789-4796

6. Palmer JH, Lancaster KM (2012) Molecular redox: revisiting the electronic structures of the group 9 metallocorroles. Inorg Chem 51:12473-12482

7. de Bruin B, Hetterscheid DGH, Koekkoek AJJ, Grützmacher H (2007) The organometallic chemistry of Rh-, Ir-, Pd-, and Ptbased radicals: higher valent species. Wiley, New York, pp 247-354

8. Goodman BA, Raynor JB (1970) Electron spin resonance of transition metal complexes. Adv Inorg Chem Radiochem 13:135-362

9. Krzystek J, Ozarowski A, Telser J (2006) Multi-frequency, highfield EPR as a powerful tool to accurately determine zero-field splitting in high-spin transition metal coordination complexes. Coord Chem Rev 250:2308-2324

10. Fortman GC, Kégl T, Li Q, Zhang X, Schaefer H, Xie Y, King R, Tesler J, Hoff C (2007) Spectroscopic detection and theoretical confirmation of the role of $\mathrm{Cr}_{2}(\mathrm{CO})_{5}\left(\mathrm{C}_{5} \mathrm{R}_{5}\right)_{2}$ and $\mathrm{Cr}(\mathrm{CO})_{2}$ (ketene) $\left(\mathrm{C}_{5} \mathrm{R}_{5}\right)$ as intermediates in carbonylation of $\mathrm{N}=\mathrm{N}=\mathrm{CHSiMe}_{3}$ to $\mathrm{O}=\mathrm{C}=\mathrm{CHSiMe}_{3}$ by $\mathrm{Cr}(\mathrm{CO})_{3}\left(\mathrm{C}_{5} \mathrm{R}_{5}\right) \quad(\mathrm{R}=\mathrm{H}$, $\mathrm{CH}_{3}$ ). J Am Chem Soc 129:14388-14400

11. Schweiger A, Jeschke G (2001) Principles of pulse electron paramagnetic resonance. Princ Pulse Electron Paramagn Reson ISBN 978-0-19-850634-8

12. Hoffman B (2003) Electron-nuclear double resonance spectroscopy (and electron spin-echo envelope modulation spectroscopy) in bioinorganic chemistry. Proc Nat Acad Sci 100:3575-3578

13. Schiemann O, Prisner TF (2007) Long-range distance determinations in biomacromolecules by EPR spectroscopy. Q Rev Biophys 40:1-53

14. Huyett JE, Carepo M, Pamplona A, Franco R, Moura JJG, Hoffman BM (1997) 57Fe Q-band pulsed ENDOR of the heterodinuclear site of nickel hydrogenase: comparison of the NiA, $\mathrm{NiB}$, and NiC states. J Am Chem Soc 119:9291-9292

15. Sturgeon BE, Burdi D, Chen S, Huynh B-H, Edmunson DE, Stubbe J, Hoffman BM (1996) Reconsideration of X, the diiron intermediate formed during cofactor assembly in $E$. coli ribonucleotide reductase. J Am Chem Soc 118:7551-7557

16. Lee HI, Hales BJ, Hoffman BM (1997) Metal-ion valencies of the femo cofactor in $\mathrm{CO}$-inhibited and resting state nitrogenase by 57Fe Q-band ENDOR. J Am Chem Soc 119:11395-11400

17. Lubitz W, Lendzian F, Bittl R (2002) Radicals, radical pairs and triplet states in photosynthesis. Acc Chem Res 35:313-320

18. Grützmacher H (2008) Cooperating ligands in catalysis. Angew Chem Int Ed 47:1814-1818

19. Dzik WI, van der Vlugt JI, Reek JNH, de Bruin B (2011) Ligands that store and release electrons during catalysis. Angew Chem Int Ed Engl 50:3356-3358

20. Van der Vlugt JI, Reek JNH (2009) Neutral tridentate PNP ligands and their hybrid analogues: versatile non-innocent scaffolds for homogeneous catalysis. Angew Chem Int Ed Engl 48:8832-8846

21. Meunier B, de Visser SP, Shaik S (2004) Mechanism of oxidation reactions catalyzed by cytochrome P450 enzymes. Chem Rev 104:3947-3980

22. Kaim W, Schwederski B (2010) Non-innocent ligands in bioinorganic chemistry-An overview. Coord Chem Rev 254:1580-1588

23. Lyaskovskyy V, de Bruin B (2012) Redox non-innocent ligands: versatile new tools to control catalytic reactions. ACS Catal 2:270-279

24. Dzik WI, Zhang XP, de Bruin B (2011) Redox noninnocence of carbene ligands: carbene radicals in (catalytic) C-C bond formation. Inorg Chem 50:9896-9903

25. Chirik PJ, Wieghardt K (2010) Chemistry. Radical ligands confer nobility on base-metal catalysts. Science 327:794-795

26. de Bruin B, Bill E, Bothe E, Weyhermüller T, Wieghardt $\mathrm{K}$ (2000) Molecular and electronic structures of bis(pyridine-2,6diimine)metal complexes [ML2](PF6)n ( $\mathrm{n}=0,1,2,3$; $\mathrm{M}=\mathrm{Mn}, \mathrm{Fe} \mathrm{Co}, \mathrm{Ni}, \mathrm{Cu}, \mathrm{Zn}$ ). Inorg Chem 39:2936-2947

27. Krusic PJ, Klabunde U, Casey CP, Block TF (1976) An electron spin resonance study of the radical anions derived from metal carbene complexes of chromium, molybdenum, and tungsten. J Am Chem Soc 98:2015-2018

28. Block TF, Fenske RF, Casey CP (1976) MO calculations on metal carbene complexes and metal acyl complexes. The importance of the LUMO in determining the site of nucleophilic attack. J Am Chem Soc 98:441-443 
29. Sierra MA, Gómez-Gallego M, Martínez-Álvarez R (2007) Fischer carbene complexes: beautiful playgrounds to study single electron transfer (SET) reactions. Chem A Eur J 13:736-744

30. Fuchibe K, Iwasawa N (2003) Generation of reactive species by one-electron reduction of Fischer-type carbene complexes of group 6 metals and their use for carbon-carbon bond formation. Chem A Eur J 9:905-914

31. Dzik WI, Xu X, Zhang XP, Reek JNH, de Bruin B (2010) "Carbene radicals" in Co(II)(por)-catalyzed olefin cyclopropanation. J Am Chem Soc 132:10891-10902

32. Xu X, Zhu S, Cui X, Wojtas L, Zhang XP (2013) Cobalt(II)catalyzed asymmetric olefin cyclopropanation with $\alpha$-ketodiazoacetates. Angew Chem Int Ed Engl 52:11857-11861

33. Cui X, Xu X, Wojtas L, Kim MM, Zhang XP (2012) Regioselective synthesis of multisubstituted furans via metalloradical cyclization of alkynes with $\alpha$-diazocarbonyls: construction of functionalized $\alpha$-oligofurans. J Am Chem Soc 134:19981-19984

34. Cui X, Xu X, Jin L-M, Wojtas L, Zhang XP (2015) Stereoselective radical $\mathrm{C}-\mathrm{H}$ alkylation with acceptor/acceptor-substituted diazo reagents via $\mathrm{Co}(\mathrm{ii})$-based metalloradical catalysis. Chem Sci 6:1219-1224

35. Lu H, Dzik WI, Xu X, Wojtas L, de Bruin B, Zhang XP (2011) Experimental evidence for cobalt(III)-carbene radicals: key intermediates in cobalt(II)-based metalloradical cyclopropanation. J Am Chem Soc 133:8518-8521

36. Chen Y, Fields KB, Zhang XP (2004) Bromoporphyrins as versatile synthons for modular construction of chiral porphyrins: cobalt-catalyzed highly enantioselective and diastereoselective cyclopropanation. J Am Chem Soc 126:14718-14719

37. Chen Y, Ruppel JV, Zhang XP (2007) Cobalt-catalyzed asymmetric cyclopropanation of electron-deficient olefins. J Am Chem Soc 129:12074-12075

38. Zhu S, Ruppel JV, Lu H, Wojtas L, Zhang XP (2008) Cobaltcatalyzed asymmetric cyclopropanation with diazosulfones: rigidification and polarization of ligand chiral environment via hydrogen bonding and cyclization. J Am Chem Soc 130:50425043

39. Rosati F, Roelfes G (2010) Artificial metalloenzymes. Chem Cat Chem 2:916-927

40. Otte M, Kuijpers PF, Troeppner O, Ivanović-Burmazović I, Reek JNH, de Bruin B (2013) Encapsulation of metalloporphyrins in a self-assembled cubic $\mathrm{M}_{8} \mathrm{~L}_{6}$ cage: a new molecular flask for cobalt-porphyrin-catalysed radical-type reactions. Chem A Eur J 19:10170-10178

41. Otte M, Kuijpers PF, Troeppner O, Ivanović-Burmazović I, Reek JNH, de Bruin B (2014) Encapsulated cobalt-porphyrin as a catalyst for size-selective radical-type cyclopropanation reactions. Chem A Eur J 20:4880-4884

42. Paul ND, Chirila A, Lu H, Zhang XP, de Bruin B (2013) Carbene radicals in cobalt(II)-porphyrin-catalysed carbene carbonylation reactions; A catalytic approach to ketenes. Chem A Eur J 19:12953-12958

43. Paul ND, Mandal S, Otte M, Cui X, Zhang XP, de Bruin B (2014) Metalloradical approach to $2 H$-chromenes. J Am Chem Soc 136:1090-1096

44. Zhou L, Shi Y, Xiao Q, Liu Y, Ye F, Zhang Y, Wang J (2011) $\mathrm{CuBr}$-catalyzed coupling of $\mathrm{N}$-tosylhydrazones and terminal alkynes: synthesis of benzofurans and indoles. Org Lett 13:968-971

45. Olivos Suarez AI, Lyaskovskyy V, Reek JNH, van der Vlugt JI, de Bruin B (2013) Complexes with nitrogen-centered radical ligands: classification, spectroscopic features, reactivity, and catalytic applications. Angew Chem Int Ed Engl 52:1251012529
46. Gloaguen Y, Rebreyend C, Lutz M, Kumar P, Huber M, van der Vlugt JI, Schneider S, de Bruin B (2014) An isolated nitridyl radical-bridged $\mathrm{Rh}(\mathrm{N} \cdot) \mathrm{Rh}$ complex. Angew Chem Int Ed Engl 53:6814-6818

47. Scheibel MG, Wu Y, Stückl AC, Krause L, Carl E, Stalke D, de Bruin B, Schneider S (2013) Synthesis and reactivity of a transient, terminal nitrido complex of rhodium. J Am Chem Soc 135:17719-17722

48. Zhou W, Patrick BO, Smith KM (2014) Influence of redox noninnocent phenylenediamido ligands on chromium imido hydrogen-atom abstraction reactivity. Chem Commun 50:9958-9960

49. Büttner T, Geier J, Frison G, Harmer J, Calle C, Schweiger A, Schönberg H, Grützmacher H (2005) A stable aminyl radical metal complex. Science 307(80):235-238

50. Whittaker JW (2005) The radical chemistry of galactose oxidase. Arch Biochem Biophys 433:227-239

51. Miyazato Y, Wada T, Tanaka K (2006) Redox behavior and catalytic oxidation reactions of alcohols by a new ruthenium(III)-dioxolene-amine complex of bis(2-pyridyl-methyl)-2aminoethylamine. Bull Chem Soc Jpn 79:745-747

52. Königsmann M, Donati N, Harmer J, Sreekanth A, Grützmacher $\mathrm{H}$ (2007) Metalloenzyme-inspired catalysis: selective oxidation of primary alcohols with an iridium-aminyl-radical complex. Angew Chem Int Ed Engl 46:3567-3570

53. Wiese S, Badiei YM, Gephart RT, Mossin S, Varonka MS, Melzer MM, Meyer K, Cundari TR, Warren TW (2010) Catalytic $\mathrm{C}-\mathrm{H}$ amination with unactivated amines through copper(II) amides. Angew Chem Int Ed Engl 49:8850-8855

54. Lyaskovskyy V, Suarez AIO, Lu H, Jiang H, Zhang XP, de Bruin B (2011) Mechanism of cobalt(II) porphyrin-catalyzed $\mathrm{C}-\mathrm{H}$ amination with organic azides: radical nature and $\mathrm{H}$-atom abstraction ability of the key cobalt(III)-nitrene intermediates. J Am Chem Soc 133:12264-12273

55. Olivos Suarez AI, Jiang H, Zhang P, de Bruin B (2011) The radical mechanism of cobalt(II) porphyrin-catalyzed olefin aziridination and the importance of cooperative H-bonding. Dalton Trans 40:5697-5705

56. Goswami M, Lyaskovskyy V, Domingos SR, Buma WJ, Woutersen S, Troeppner O, Ivanović-Burmazović I, Lu H, Cui X, Zhang XP, Reijerse EJ, DeBeer S, van Schooneveld MM, Pfaff FF, Ray K, de Bruin B (2015) Characterization of PorphyrinCo(III)-'Nitrene radical' species relevant in catalytic nitrene transfer reactions. J Am Chem Soc 137:5468-5479

57. Salanouve E, Bouzemame G, Blanchard S, Derat E, Desage-El Murr M, Fensterbank L (2014) Tandem C-H activation/arylation catalyzed by low-valent iron complexes with bisiminopyridine ligands. Chem Eur J 20:4754-4761

58. Broere DLJ, de Bruin B, Reek JNH, Lutz M, Dechert S, van der Vlugt JI (2014) Intramolecular redox-active ligand-to-substrate single-electron transfer: radical reactivity with a palladium(II) complex. J Am Chem Soc 1:8-11

59. Broere DLJ, Metz LL, de Bruin B, Reek JNH, Siegler MA, van der Vlugt JI (2015) Redox-active ligand-induced homolytic bond activation. Angew Chem Int Ed Engl 54:1516-1520

60. Sledź P, Mauduit M, Grela K (2008) Olefin metathesis in ionic liquids. Chem Soc Rev 37:2433-2442

61. Kucherov AV, Vasnev AV, Greish AA, Kustov LM (2005) Catalytically active species in new metathesis systems [Wn $+($ Mon+)-ionic liquid-olefin]: a quantitative ESR study. J Mol Catal A: Chem 237:165-171

62. Forestière A, Olivier-Bourbigou H, Saussine L (2009) Oligomerization of monoolefins by homogeneous catalysts. Oil Gas Sci Technol Rev l'IFP 64:649-667

63. Skupinska J (1991) Oligomerization of a-olefins to higher oligomers. Chem Rev 91:613-648 
64. Mcguinness DS (2011) Olefin oligomerization via metallacycles : dimerization, trimerization, tetramerization, and beyond. Chem Rev 111:2321-2341

65. Dixon JT, Green MJ, Hess FM, Morgan DH (2004) Advances in selective ethylene trimerisation-a critical overview. J Organomet Chem 689:3641-3668

66. Bollmann A, Blann K, Dixon JT, Hess FM, Killian E, Maumela H, McGuinness DS, Morgan DH, Neveling A, Otto S, Overet M, Slawin AMZ, Wasserscheid P, Kuhlmann S (2004) Ethylene tetramerization: a new route to produce 1-octene in exceptionally high selectivities. J Am Chem Soc 126:14712-14713

67. Bryliakov KP, Talsi EP (2012) Frontiers of mechanistic studies of coordination polymerization and oligomerization of $\alpha$-olefins. Coord Chem Rev 256:2994-3007

68. Briggs JR (1989) The selective trimerization of ethylene. Chem Commun 11:674-675

69. Emrich R, Heinemann O, Jolly PW, Krüger C, Verhovnik GPJ (1997) The role of metallacycles in the chromium-catalyzed trimerization of ethylene. Organometallics 16:1511-1513

70. Jabri A, Mason CB, Sim Y, Gambarotta S, Burchell TJ, Duchateau R (2008) Isolation of single-component trimerization and polymerization chromium catalysts: the role of the metal oxidation state. Angew Chem Int Ed Engl 47:9717-9721

71. Vidyaratne I, Nikiforov GB, Gorelsky SI, Gambarotta S, Duchateau R, Korobkov I (2009) Isolation of a self-activating ethylene trimerization catalyst. Angew Chem Int Ed Engl 48:6552-6556

72. Overett MJ, Blann K, Bollmann A, Dixon JT, Haasbroek D, Killian E, Maumela H, McGuinness DS, Morgan DH (2005) Mechanistic investigations of the ethylene tetramerisation reaction. J Am Chem Soc 127:10723-10730

73. Brückner A, Jabor JK, Mcconnell AEC, Webb PB (2008) Monitoring structure and valence state of chromium sites during catalyst formation and ethylene oligomerization by in situ EPR spectroscopy. Organometallics 27:3849-3856

74. Skobelev IY, Panchenko VN, Lyakin OY, Byliakov KP, Zakharov VA, Talsi EP (2010) In situ EPR monitoring of chromium species formed during $\mathrm{Cr}-$ pyrrolyl ethylene trimerization catalyst formation. Organometallics 29:2943-2950

75. McDyre LE, Hamilton T, Murphy DM, Cavell KJ, Gabrielli WF, Hanton MJ, Smith DM (2010) A cw EPR and ENDOR investigation on a series of $\mathrm{Cr}(\mathrm{I})$ carbonyl complexes with relevance to alkene oligomerization catalysis: $\left[\mathrm{Cr}(\mathrm{CO})_{4} \mathrm{~L}\right]+\left(\mathrm{L}=\mathrm{Ph}_{2} \mathrm{PN}(\mathrm{R})\right.$ $\left.\mathrm{PPh}_{2}, \mathrm{Ph}_{2} \mathrm{P}(\mathrm{R}) \mathrm{PPh}_{2}\right)$. Dalton Trans 39:7792-7799

76. Moulin JO, Evans J, McGuinness DS, Reid G, Rucklidge AJ, Tooze RP, Tromp M (2008) Probing the effects of ligand structure on activity and selectivity of $\mathrm{Cr}$ (III) complexes for ethylene oligomerisation and polymerisation. Dalton Trans 3:1177-1185

77. Rabeah J, Bauer M, Baumann W, McConnell AEC, Gabrielli WF, Webb PB, Selent D, Brückner A (2013) Formation, operation and deactivation of $\mathrm{Cr}$ catalysts in ethylene tetramerization directly assessed by Operando EPR and XAS. ACS Catal 3:95-102

78. Monillas WH, Young JF, Yap GP, Theopold KH (2013) A welldefined model system for the chromium-catalyzed selective oligomerization of ethylene. Dalton Trans 42:9198-9210

79. Matyjaszewski K, Kajiwara A (1998) EPR study of atom transfer radical polymerization (ATRP) of styrene. Macromolecules 31:548-550

80. Kajiwara A, Matyjaszewski K (1998) Simultaneous EPR and kinetic study of styrene atom transfer radical polymerization. Macromolecules 31:5695-5701

81. Kajiwara A, Matyjaszewski K (1998) EPR study of the atom transfer radical polymerization (ATRP) of (met h)acrylates. Macromol Rapid Commun 19:319-321
82. Kajiwara A, Matyjaszewski K (1999) EPR and kinetic studies of atom transfer radical polymerization of (meth)acrylates. Polym $\mathbf{J}$ 31:70-75

83. Yu Q, Zeng F, Zhu S (2001) Atom transfer radical polymerization of poly(ethylene glycol) dimethacrylate. Macromolecules 34:1612-1618

84. Knuehl B, Pintauer T, Kajiwara A, Fischer H, Matyjaszewski K (2003) Characterization of $\mathrm{Cu}$ (II) bipyridine complexes in halogen atom transfer reactions by electron spin resonance. Macromolecules 36:8291-8296

85. Kajiwara A, Nanda AK, Matyjaszewski K (2004) Electron spin resonance study of monomeric, dimeric, and polymeric acrylate radicals prepared using the atom transfer radical polymerization technique. Direct detection of penultimate-unit effects. Macromolecules 37:1378-1385

86. Kajiwara A, Maeda K, Kubo N, Kamachi M (2003) Origin of 16-line spectra observed in ESR study of radical polymerization of tert-butyl methacrylate: clear evidence for ESR detection of polymeric propagating radicals. Macromolecules 36:526-528

87. Soerensen N, Barth J, Buback M, Morick J, Schroeder H, Matyjaszewski K (2012) SP-PLP-EPR measurement of ATRP deactivation rate. Macromolecules 45:3797-3801

88. Beckert D, Burkitt M, Canters G, Groenen E, Collison D, McInnes E, Eaton GR, Eaton SS, Giamello E, Huttermann J, Kappl R, Kay C, Weber S, Lurie D, Smirnov A, Smith G, Riedi P, Gilbert BC, Davies MJ, Murphy DM (2002) Electron Paramagn Reson 18:47-73

89. Buettner GR (1987) Spin trapping: eSR parameters of spin adducts. Free Radic Biol Med 3:259-303

90. Pou S, Halpern HJ, Tsai P, Rosen GM (1999) Issues pertinent to the in vivo in situ spin trapping of free radicals. Acc Chem Res 32:155-161

91. Berliner LJ, Khramtsov V, Fujii H, Clanton TL (2001) Unique in vivo applications of spin traps. Free Radic Biol Med 30:489-499

92. Criqui A, Lalevée J, Allonas X, Fouassier JP (2008) Electron spin resonance spin trapping technique: application to the cleavage process of photoinitiators. Macromol Chem Phys 209:2223-2231

93. Telitel S, Schweizer S, Morlet-Savary F, Graff B, Tschamber T, Blanchard N, Fouassier JP, Lelli M, Lacôte E, Lalevée J (2013) Soft photopolymerizations initiated by dye-sensitized formation of NHC-boryl radicals under visible light. Macromolecules 46:43-48

94. Pan X, Lacôte E, Lalevée J, Curran DP (2012) Polarity reversal catalysis in radical reductions of halides by $\mathrm{N}$-heterocyclic carbene boranes. J Am Chem Soc 134:5669-5674

95. Lalevée J, Blanchard N, El-Roz M, Graff B, Allonas X, Fouassier JP (2008) New photoinitiators based on the silyl radical chemistry: polymerization ability, ESR spin trapping, and laser flash photolysis investigation. Macromolecules 41:4180-4186

96. Xiao P, Dumur F, Zhang J, Fouassier JP, Gigmes D, Lalevée J (2014) Copper complexes in radical photoinitiating systems: applications to free radical and cationic polymerization upon visible LEDs. Macromolecules 47:3837-3844

97. Schiermeier Q, Tollefson J, Scully T, Witze A, Morton O (2008) Energy alternatives: electricity without carbon. Nature 454:816-823

98. Kudo A, Miseki Y (2009) Heterogeneous photocatalyst materials for water splitting. Chem Soc Rev 38:253-278

99. Yamazaki H, Shouji A, Kajita M, Yagi M (2010) Electrocatalytic and photocatalytic water oxidation to dioxygen based on metal complexes. Coord Chem Rev 254:2483-2491

100. Sartorel A, Bonchio M, Campagna S, Scandola F (2013) Tetrametallic molecular catalysts for photochemical water oxidation. Chem Soc Rev 42:2262-2280 
101. McCormick TM, Calitree BD, Orchard A, Kraut ND, Bright FV, Detty MR, Eisenberg R (2010) Reductive side of water splitting in artificial photosynthesis: new homogeneous photosystems of great activity and mechanistic insight. J Am Chem Soc 132:15480-15483

102. Chen Z, Concepcion JJ, Luo H, Hull JF, Paul A, Meyer TJ (2010) Nonaqueous catalytic water oxidation. J Am Chem Soc 132:17670-17673
103. Hollmann D, Gärtner F, Ludwig R, Barsch E, Junge H, Blug M, Hoch S, Beller M, Brückner A (2011) Insights into the mechanism of photocatalytic water reduction by DFT-supported in situ EPR/Raman spectroscopy. Angew Chem Int Ed Engl 50:10246-10250

104. Wang H-Y, Mijangos E, Ott S, Thapper A (2014) Water oxidation catalyzed by a dinuclear cobalt-polypyridine complex. Angew Chem Int Ed 53:14499-14502 